AROUEOLOGÍA Y SOCIEDAD

№ $27,2014: 255^{-296}$

ISSN: $0254-8062$

\title{
SACRIFICIOS DE NIÑOS, ADOLESCENTESY CAMÉLIDOS JÓVENES DURANTE EL INTERMEDIO TARDÍO EN LA PERIFERIA DE CHAN CHAN, VALLE DE MOCHE, COSTA NORTE DEL PERÚ
}

\author{
GABRIEL PRIETO \\ Ph. D Candidate, Departamento de Antropología, Yale University \\ oscar.prieto@yale.edu \\ NicolÁs GOEPFERT \\ CENTRO NACIONAL DE INVESTIGACIÓn CiEntífiCA DE FRAnCIA (CNRS) \\ nicolasgoepfert@yahoo.fr \\ KATIA VALLADARES \\ BioArqueóloga, EOUipo PERUANo de ANTROPOlogía Forense (EPAF) \\ katyavalladares_2005@yahoo.es \\ JUAN VILELA \\ DiRECCIÓn DESCONCENTRADA DE CULTURA DE LA LIBERTAD \\ jvvilela@hotmail.com
}

\section{RESUMEN}

Se presentan datos preliminares del contexto sacrificial masivo del periodo Intermedio Tardío hallado en el sitio de Huanchaquito-Las Llamas, zona norte del valle de Moche. Estos datos se refieren a estudios preliminares de antropología física así como estudios preliminares en los restos de camélidos hallados en las excavaciones. En el texto se reflexiona acerca de la naturaleza del sacrificio humano en la sociedad Chimu, los posibles patrones existentes en base a un análisis de los datos disponibles de otros sitios excavados en el valle y se plantea una hipótesis de trabajo para la interpretación de este contexto. Del mismo modo se reflexiona acerca de las implicancias sociales, políticas e ideológicas que significó realizar un evento de esta naturaleza durante el desarrollo de Chan Chan, el centro urbano más complejo de la costa norte del Perú previo a la conquista Inca.

Palabras Clave: Sacrificios humanos y de animales masivos; Intermedio Tardío; Chimu.

\begin{abstract}
This article presents the preliminary results of recent excavation of a massive sacrificial context at the site of Huanchaquito-Las Llamas, in the northern end of the Moche valley. Results of preliminary field and laboratory analysis of the human and camelid remains are presented, along with a description of their archaeological context. One of the major concerns of this paper is to discuss the nature of the Chimu sacrificial practices, based on the available data for other sites within the Moche valley and in other valleys of the north coast region. From this comparative analysis we develop a working hypothesis for interpreting this sacrifical context. The potential social, political and ideological impact of this kind of sacrificial event is evaluated in the context of the emergence of Chan Chan, the largest urban settlement along the Peruvian north coast prior to the Inca invasion.
\end{abstract}

KEYwords: Massive human and animal sacrifice; Late Intermediate Period; Chimu. 
El valle de Moche es una de las regiones del Perú en las que se ha estudiado ampliamente las prácticas sacrificiales humanas y de animales del periodo Intermedio Temprano (Bourget 1997a; Sutter y Verano 2007; Donnan y Foote 1978; Goepfert 2008, 2012). Si bien es cierto se sabe que durante el periodo Inicial, Horizonte Temprano, Horizonte Medio e Intermedio Tardío también se realizaron sacrificios humanos y de animales, estos han sido menos investigados. Esto último se debe, en esencia, a la falta de excavaciones extensas en sitios de estos periodos. Para el caso del Horizonte Medio, sabemos que se realizaron sacrificios humanos asociados al «Templo Nuevo» ubicado junto a Huaca de la Luna (Tufinio et al. 2011; John Verano, comunicación personal julio del 2012), mientras que los trabajos realizados por el Proyecto Chan Chan valle de Moche en la década de 1970 revelaron la presencia de posibles sacrificios humanos del periodo Intermedio Tardío asociados a las plataformas funerarias de los palacios de Chan Chan (Conrad 1980; Pozorski 1980). Como parte del mismo proyecto, en Huanchaco se registró un conjunto de niños y camélidos jóvenes enterrados cerca de la iglesia colonial de dicho pueblo que fueron posiblemente el resultado de prácticas sacrificiales Chimu durante el Intermedio Tardío (Donnan y Foote 1978).

En este artículo presentamos los resultados preliminares de un contexto sacrificial masivo que incluía niños, adolescentes y camélidos jóvenes enterrados en las afueras de Chan Chan, el centro urbano de carácter político y económico más importante de la sociedad Chimu entre los siglos X y XV de nuestra era (Moseley 2001). Adicionalmente exploraremos las características de este contexto para entender las posibles causas del sacrificio, así como los elementos que utilizó el estado Chimu para su ejecución. Más importante aún, estudiaremos las posibles circunstancias ambientales, sociales y políticas que pudieron haber condicionado la realización de este evento.

\section{UBICACIÓN Y DeSCRIPCIÓN DEL SITIO ARQUEOLÓGICO}

El sitio arqueológico se encuentra ubicado en el poblado menor de Huanchaquito, distrito de Huanchaco, provincia de Trujillo en la región La Libertad. Sus coordenadas UTM son 17L E 70888.20 - S 9103922.37 y está ubicado a escasos 350 metros de la orilla del mar y a una altura de 11 metros sobre el nivel del mar (Fig. 1). Se trata de una duna de arena de mar depositada sobre la falda de la terraza marina que limita la playa de Huanchaquito en su flanco NE. Esta terraza marina se inicia $4 \mathrm{~km}$ al sur de este punto y sobre ella también se encuentra el sitio Preceramico de «Padre Abán» $(1,2 \mathrm{~km}$ al sur) y el Complejo Arqueológico de Chan Chan (2,3 km al sur), mientras que a 370 metros al norte y siempre sobre la misma terraza marina se encuentra el sitio del Periodo Inicial de Pampas Gramalote (Fig. 1). A pesar que el sitio en cuestión ha sido inventariado con el nombre de «Gramalote A» ${ }^{1}$, los pobladores locales han bautizado esta zona como «Las Llamas» debido a la gran cantidad de camélidos de esta especie hallados en las excavaciones. Por esta razón, de aquí en adelante se le denominará «Huanchaquito-Las Llamas».

En la actualidad, este sitio tiene una extensión de 1980 m² $^{2} 91$ m eje SE-NW y 22 m en su eje SW$\mathrm{NE}$ ). Sin embargo, su área original debe haber sido (tomando en cuenta su eje SE-NW, $216 \mathrm{~m}$ de longitud y aproximadamente $25 \mathrm{~m}$ de ancho en su eje E-W) un aproximado de $5400 \mathrm{~m}^{2}$. Lamentablemente el sector sur ha sido destruido por construcciones modernas, mientras que el lado norte ha sido utilizado por los pobladores de la zona como basurero y para la construcción de silos. Por otro lado, entre 1995 y 1998, el sitio fue destruido en su sector oeste por una Caterpillar que en su intento de ensanchar la trocha de la avenida Aviación de Huanchaquito, afectó parte de los contextos funerarios allí depositados (Fig. 2).

En la zona que no fue afectada se abrió un área de 17 x 6 m (102 m²) para rescatar los restos arqueológicos expuestos por alteraciones de carácter cultural y natural durante los meses de agosto a noviembre

1 Entre el 2000 y 2007, el sitio fue identificado por el Proyecto Arqueológico Qapac Ňam con el nombre de «Gramalote A» por su cercanía al sitio del Periodo Inicial Pampas Gramalote. 


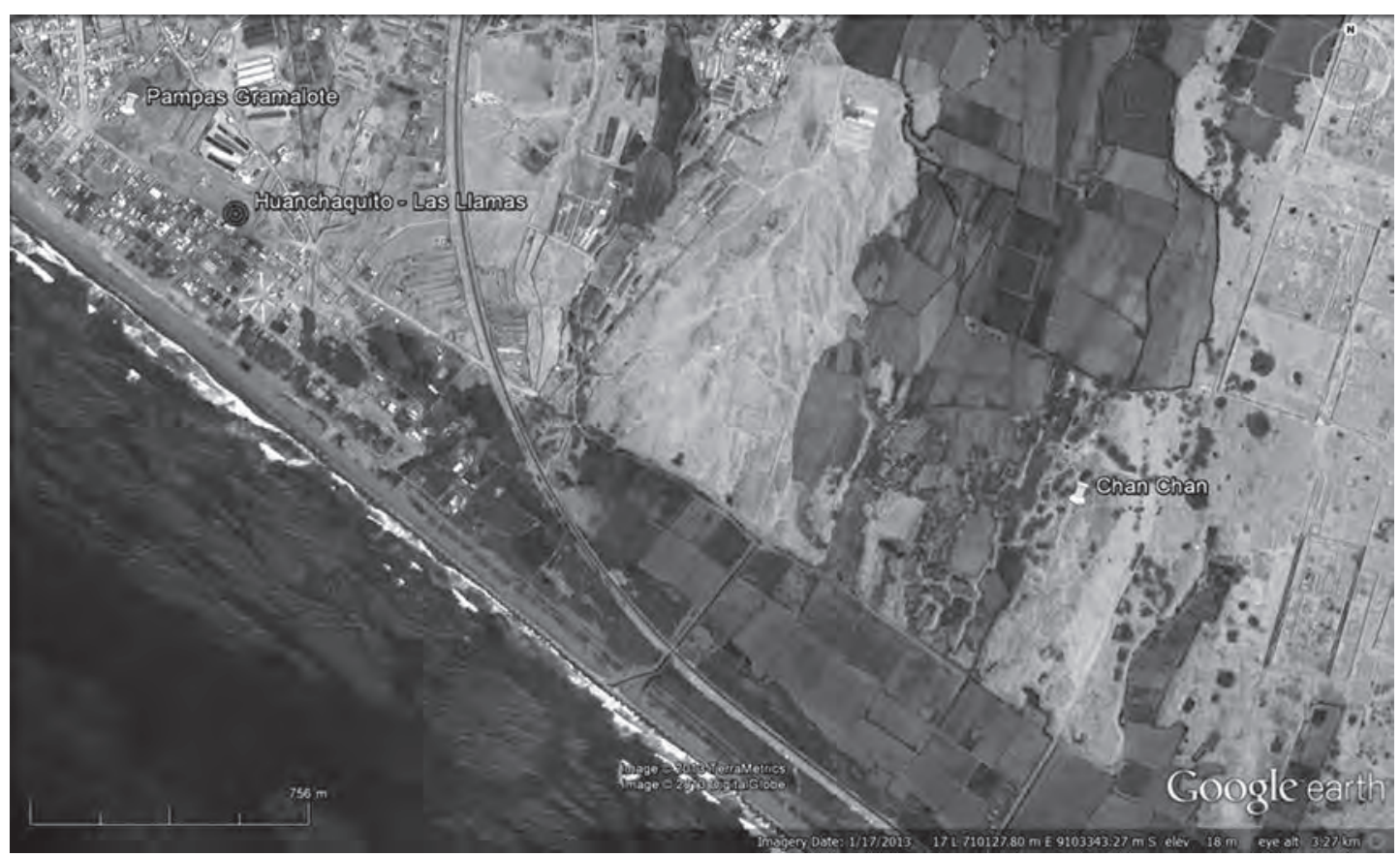

Figura 1. Vista satelital de la ubicacion del sitio Huanchaquito - Las Llamas en relacion con Chan Chan y el mar.

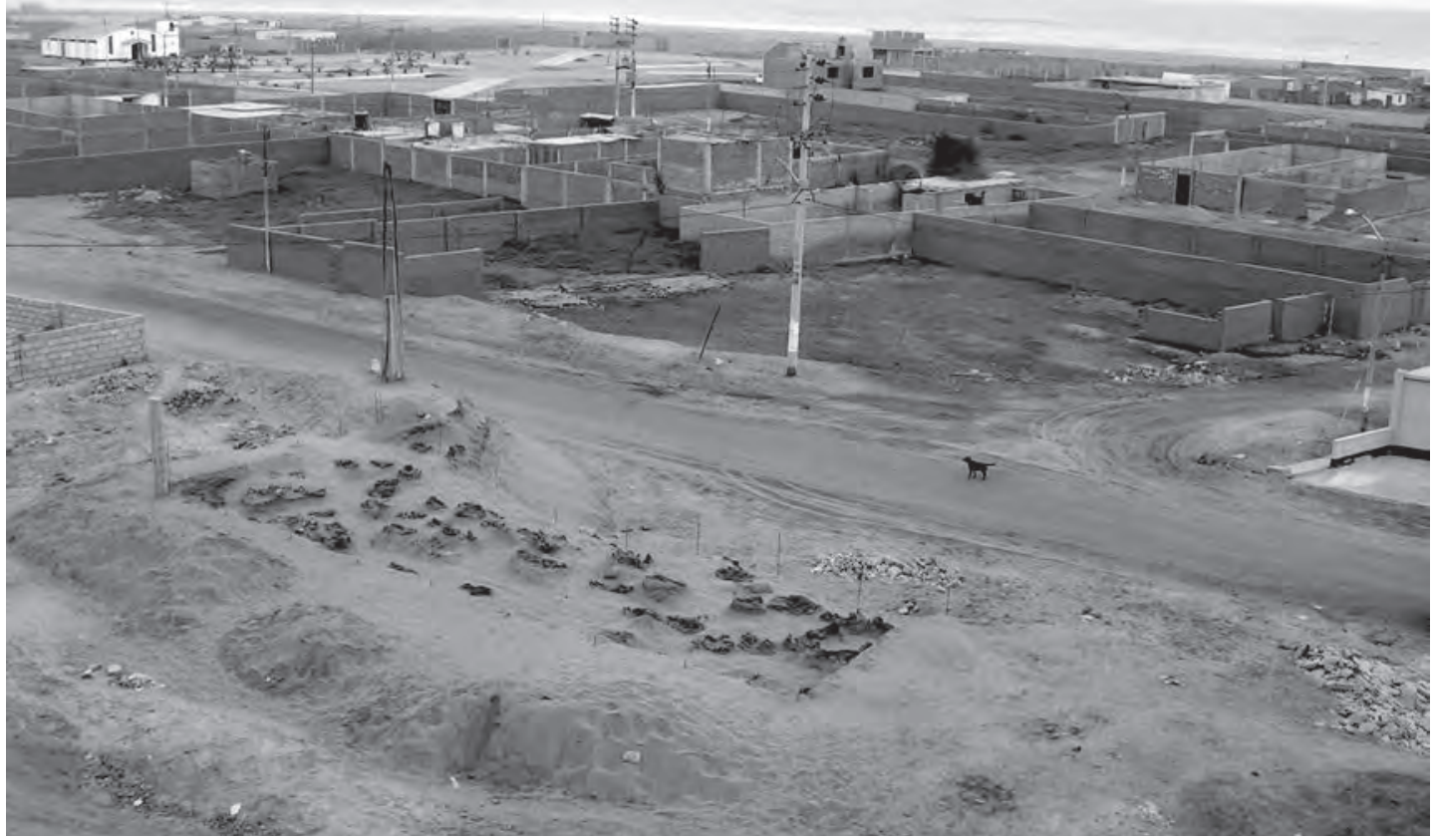

Figura 2. Vista general de norte a sur del entorno actual que rodea el sitio. 
del 2011 (Fig. 3). Cabe recalcar que en esta zona de excavación no se ha registrado restos de elementos arquitectónicos, ni evidencia de estratigrafía ocupacional. Es decir, los restos arqueológicos presentes se limitan a contextos funerarios de humanos y camélidos dentro de fosas cuyas bocas rompen un grueso sedimento de arcilla natural depositado sobre la arena. En otros casos, hemos hallado camélidos directamente sobre dicha capa de barro, los que fueron posteriormente cubiertos por la arena.

\section{Descubrimiento y tRabajos en el Sitio aRQueológico de HuANChaquito-Las Llamas}

La mañana del 13 de Agosto del 2011 el equipo de investigación del Proyecto Arqueológico Pampas Gramalote 2011, venía realizando excavaciones en el sitio del mismo nombre cuando el director del proyecto fue abordado por un ciudadano italiano que reside frente al sitio de Huanchaquito-Las Llamas. Este poblador indicó que días atrás los fuertes vientos del invierno habían expuesto huesos humanos en la superficie y que sus hijos habían llevado a casa osamentas y restos parecidos a pieles. Debido a esas circunstancias, nos sugería aproximarnos a la zona para evaluar dichos restos. Su insistencia sobre nuestra urgente intervención, motivó a que uno de los autores de este artículo se dirija a la zona con dos estudiantes de arqueología de la Universidad Nacional de Trujillo.

Al aproximarnos lo primero que saltó a la vista era una inusitada cantidad de restos óseos de camélidos jóvenes y pelaje de los mismos, junto con varios restos humanos desparramados en la suave pendiente de la duna de arena. Al inspeccionar la parte alta de la duna, se pudieron apreciar casi en superficie cráneos humanos no disturbados con textiles a manera de mortajas. La cantidad de los restos observados, especialmente los cuerpos humanos no disturbados en superficie, motivó a entablar contacto con las autoridades competentes de la Dirección Regional de Cultura de La Libertad para emprender acciones inmediatas. Se corría el riesgo que los contextos arqueológicos se sigan disturbando, perdiéndose valiosa información para la ciencia. Gracias a la efectiva y rápida gestión del entonces director de la Dirección Regional de Cultura de La Libertad, Sr. Enrique Sánchez-Maura y de los arqueólogos de la misma institución Juan Vilela, Cesar Gálvez, Susan Bringas, Arturo Paredes y Víctor Piminchumo, se pudo gestionar y aprobar un Proyecto de Emergencia para excavar el sitio. Por otro lado, el Ing. Fernando Bazán Pinillos, alcalde de la Municipalidad Distrital de Huanchaco inmediatamente dispuso de fondos económicos para contratar el personal necesario para realizar la excavación de emergencia, gastos de logística, así como los análisis preliminares de los restos.

Es importante señalar que esta es una investigación en proceso y que se tiene planeado ir publicando más resultados conforme obtengamos los datos de dichos estudios. Esta es una primera entrega escrita dado que resultados preliminares de esta investigación fueron presentados en enero del 2012 en la Primera Conferencia Intercontinental de la Sociedad de Arqueología Americana (SAA) en la Ciudad de Panamá (Prieto et al. 2012) y recientemente en la 111 Conferencia Anual de la American Anthropological Association (AAA) como parte del Simposio «Recent Anthropological Perspectives on Past and Present Andean Pastoralism» (Goepfert y Prieto 2012).

Actualmente venimos trabajando con el Dr. Jeffrey Quilter y el Dr. Steven LeBlanc del Peabody Museum de la Universidad de Harvard quienes están llevando a cabo estudios de isotopos estables y ADN para poder caracterizar a la población humana enterrada en el sitio de Huanchaquito-Las Llamas. Del mismo modo, el Dr. Nicolás Goepfert del Centro Nacional de Investigación Científica de Francia (CNRS) va a iniciar una investigación de isotopos estables en los camélidos para determinar su dieta y procedencia, mientras que la Dra. Veronique Wright del Instituto Francés de Estudios Andinos, viene estudiando los pigmentos aplicados en la cara de los niños y adolescentes. Estos resultados esperan tenerse en un mediano plazo y una vez procesados serán debidamente publicados.

Por tal motivo, los resultados presentados en este artículo son preliminares y tienen por objetivo dar una perspectiva general sobre este descomunal contexto sacrificial del periodo Intermedio Tardío en el valle de Moche. 


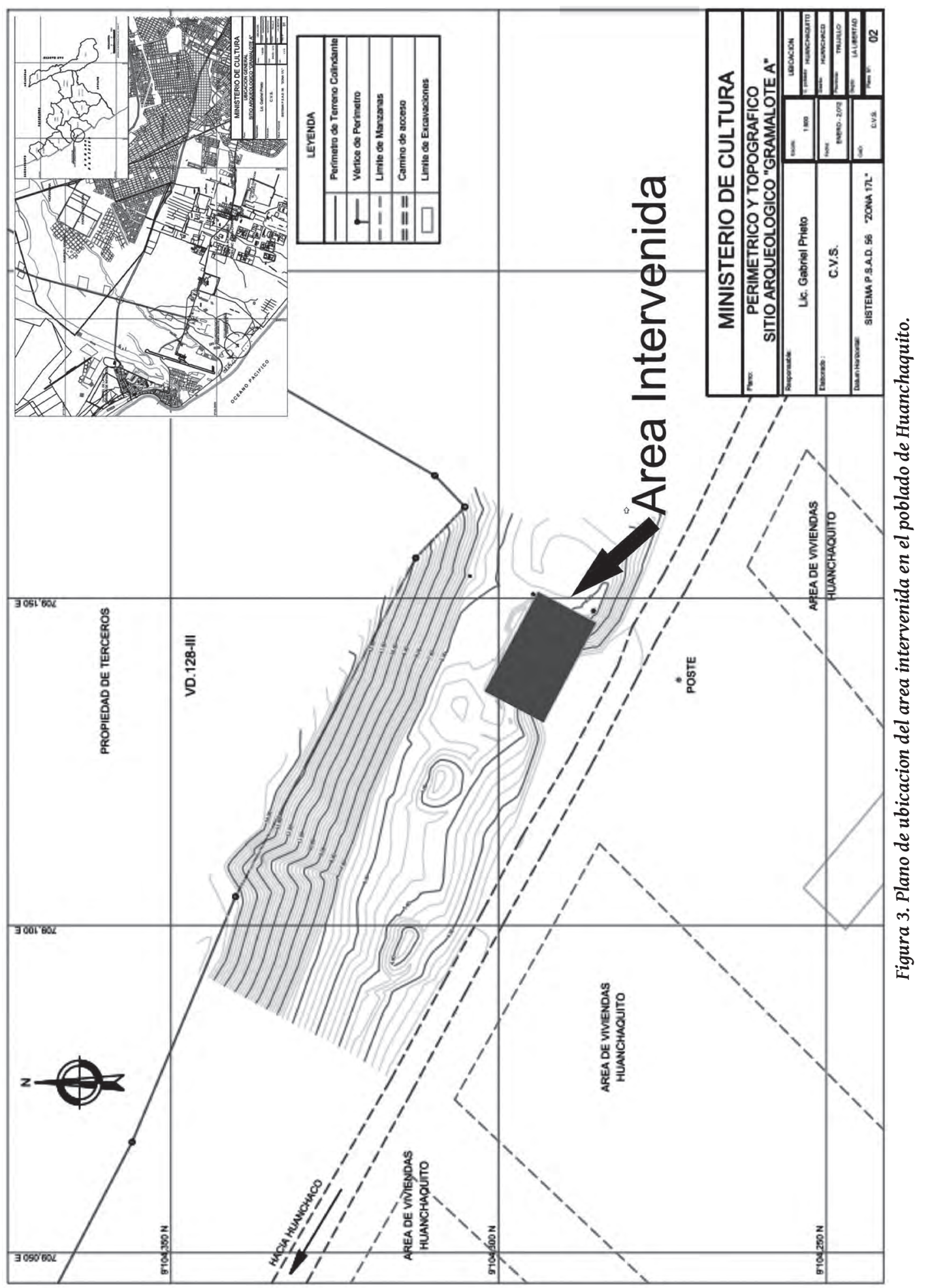




\section{El Intermedio Tardío en el Valle de Moche: La Sociedad Chimu}

La sociedad Chimu se desarrolló entre los siglos X a XV de nuestra era en la costa norte del Perú. Su área de influencia llegó al sur de la actual ciudad de Lima y por el Norte cerca de la frontera del Perú con el Ecuador (Moore y Mackey 2008). Su centro político, económico y religioso más importante fue la ciudad de Chan Chan, ubicada en el valle de Moche, cerca de la actual ciudad de Trujillo.

Tras el colapso político de la sociedad Mochica, el valle de Moche experimentó un rápido cambio en su estructura política, social, económica e ideológica (Bawden 1996; Uceda 2010). Este periodo de transición que actualmente se conoce como «Post-Moche» viene siendo recientemente investigado gracias a los contextos del Horizonte Medio Tardío e Intermedio Tardío Temprano hallados en el complejo arqueológico Huacas de Moche (Orbegoso et al. 2012; Santiago Uceda, comunicación personal mayo del 2012). Esta re-configuración en la estructura política, social, económica e ideológica marcó algunos cambios como la preferencia por construir amplias cercaduras con plataformas bajas en vez del uso de grandes pirámides escalonadas como las utilizadas durante el periodo Intermedio Temprano. Del mismo modo se puede advertir un desarrollo más complejo y sofisticado en torno al culto a los ancestros, lo cual parecería ser el centro de los rituales Chimu (Moore 1992; Uceda 1997). La evidencia arqueológica sugiere que los Chimu se expandieron hacia la zona del valle medio y alto de Moche, teniendo aparentemente interés en los fértiles campos de maíz, ají y sobretodo coca de esa región (Billman 1996; Alicia Boswell, comunicación personal enero del 2012). Por otro lado, la iconografía Chimu acusa una preferencia marcada por temas marinos y la fauna del mar, lo cual se convirtió en el elemento central en la ideología de esta nueva reconfiguración política del valle (Ravines 1980; Mackey 2001; Campana 2008). Un cambio radical fue el emplazamiento en el que se decidió construir Chan Chan, alejado completamente del «corazón» del valle y de la zona donde tradicionalmente se ubicaron los centros ceremoniales al menos desde el periodo Inicial (Moseley y Mackey 1973; Moseley y Day 1982; Conklin 1990; Billman 1996).

En el valle de Moche la ocupación Chimu está presente en todas partes, sugiriendo un incremento poblacional durante este periodo (Billman 1996). Esta alta densidad poblacional motivó no solo la re-ocupación de sitios de periodos previos, sino la construcción de estructuras administrativas en pampas eriazas no habitadas, el desarrollo de pueblos donde nunca antes hubo ocupación humana como el mismo Chan Chan ${ }^{2}$ o el centro poblado de Cerro de La Virgen al norte de Huanchaco, así como la inclusión de grandes extensiones de terrenos para la producción agrícola expansiva (Moseley y Day 1982; Ravines 1980; Keatinge 1975; Kus 1972, 1980).

\section{El centro urbano de Chan Chan y su entorno inmediato}

En su época de mayor apogeo, Chan Chan tuvo un área de aproximadamente $20 \mathrm{~km}^{2}$ y fue probablemente uno de los asentamientos urbanos más complejos de los Andes Centrales (Moseley y Mackey 1973; Moore y Mackey 2008). Esta ciudad tuvo un crecimiento paulatino, lo cual incluyó la sucesiva construcción de palacios exquisitamente decorados con altorrelieves que enfatizan principalmente temas marinos (Moseley y Day 1982; Kolata 1978, 1990; Pillsbury y Leonard 2004). Al mismo tiempo la ciudad contaba con residencias de elite para la clase gobernante y grandes barrios populares donde habitó el grueso de la población (Klymyshyn 1982; Topic 1982, 1990). Estudios recientes han comprobado que la ciudad de Chan Chan tenia avenidas y calles que organizaban y articulaban su «centro monumental» con el resto de los complejos residenciales, barrios-talleres artesanales, campos de cultivo, cementerios y templos (Campana 2006). La ciudad de Chan Chan se abastecía de agua con pozos artesianos y tenía áreas de cementerios, así como zonas administrativas en la periferia de la urbe las cuales controlaban un eficiente y bien diseñado sistema hidráulico que irrigaba campos de cultivo en

2 Si bien es cierto se han identificado algunas ocupaciones del Horizonte Medio en la zona oeste de Chan Chan así como una ocupación muy pequeña del Preceramico Tardío (Moseley 1975), estas son muy reducidas. Obviamente, más excavaciones son necesarias para determinar la presencia de ocupaciones previas en la zona. 
pampas eriazas (Topic y Lange-Topic 1980; Ortloff 1981; Mackey y Klymyshing 1990). Ciertos edificios, como las plataformas funerarias en las que enterraron a sus gobernantes, parecen estar alineados con los cerros circundantes del valle, formando una geografía sagrada o «sacred landscape» que articuló todo el complejo a su entorno paisajístico (Sakai 1998).

A pesar que Chan Chan se encuentra frente al mar, el área no es propicia para un puerto de embarque, ni siquiera la playa es utilizada hoy en día por los pescadores tradicionales de la zona para navegar con sus balsas de totora debido a las fuertes rompientes en la orilla. Si bien es cierto los Chimu desarrollaron un sofisticado comercio basado en un posible monopolio de la concha Spondylus y la producción de objetos de metal, textil y cerámica, la ubicación de Chan Chan no parece obedecer a criterios comerciales o control de dichos productos. Tampoco está ubicada en el cuello del valle o en algún paso que permita controlar el ingreso y salida a dicho complejo o al valle de Moche. No obstante, existen grandes murallas de varios kilómetros de largo que parecen proteger a la ciudad por su límite norte (Piminchumo y Galvez 2003). Al parecer la ubicación de Chan Chan, relativamente apartada de las mejores tierras cultivables del valle y en el extremo norte del valle de Moche, obedece más al aprovechamiento estratégico de las amplias terrazas marinas eriazas donde hasta el momento no se habían desarrollado ocupaciones prehispánicas de envergadura. Posiblemente el uso planificado de dichas pampas con fines urbanos y de expansión agrícola fue un proyecto que los Chimu desarrollaron paulatinamente a lo largo de casi 4 siglos y que no llegaron a completar debido a la invasión Inca hacia 1470 (Rowe 1948).

Por otro lado, la ubicación de la ciudad de Chan Chan prácticamente de cara al mar, puede estar asociada a criterios ideológicos, relacionados a los mitos de origen y a los mecanismos de legitimación del estado Chimu (Rowe 1948; Donnan 1990; Roscoe 2008). Al respecto cabe indicar dos aspectos fundamentales. Por un lado se ha argumentado que los accesos principales y la organización de los palacios de Chan Chan están orientados al norte y por lo tanto miran hacia las montañas ubicadas al noreste. Esto es cierto, pero todas las plataformas, plazas y elementos arquitectónicos están diseñados para la que la gente congregada en dichos espacios dirija su atención hacia el suroeste, es decir, hacia el mar. Así, la presencia de plataformas o banquetas en las que se ubicaban los sacerdotes y gobernantes Chimu estuvieron diseñadas para que estos personajes salieran y ejecutaran sus actos como si estuvieran viniendo o saliendo del mar (Fig. 4). Este aspecto se enfatiza por

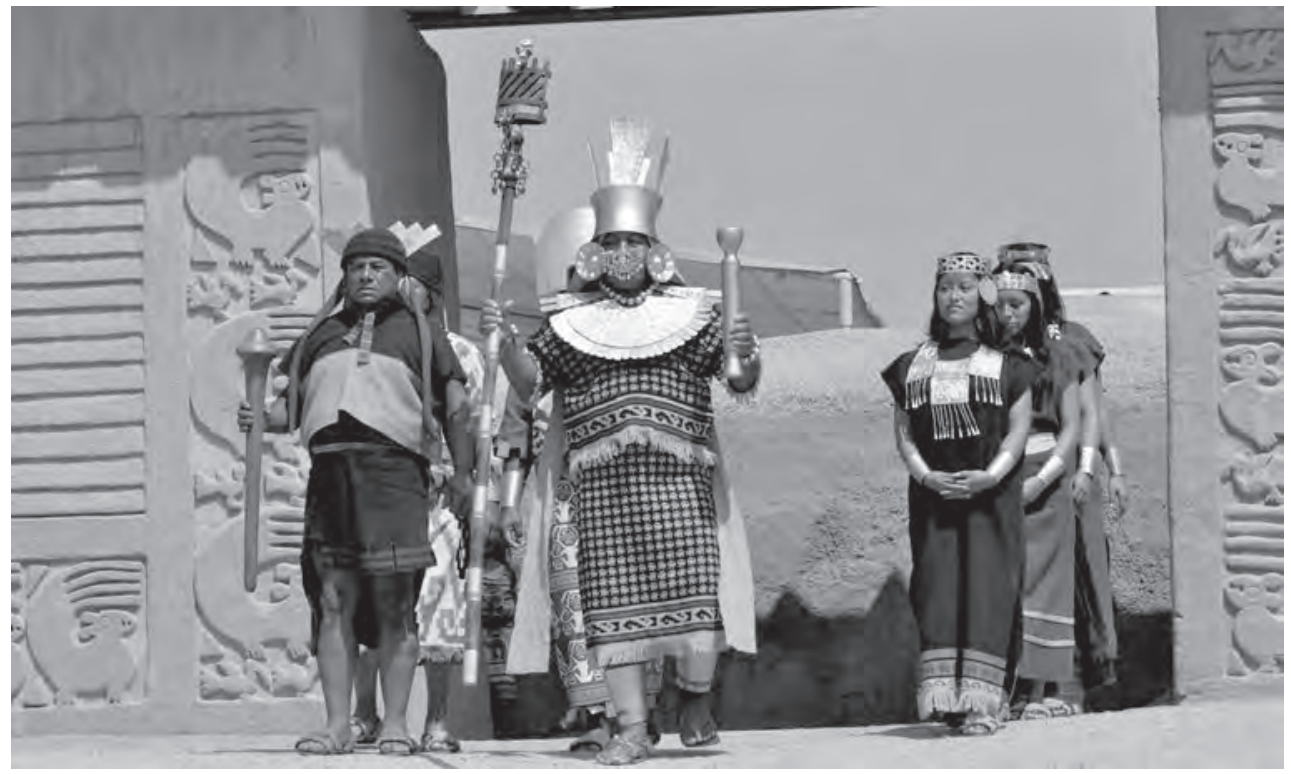

Figura 4. Recreacion artistica en la que se aprecia una corte Chimu saliendo del único acceso orientado al mar, palacio Tschudi, Chan Chan. 
el hecho que prácticamente todos los palacios Chimu de Chan Chan están decorados con elementos marinos dando la impresión que dichos complejos quisieran representar el ambiente marino (Pillsbury 1996; Campana 2008). Por otro lado, es importante recordar que de acuerdo a los mitos de origen Chimu, su fundador Taycanamo vino del mar en balsas por lo que tiene sentido usar al mar como «pacarina» o lugar de origen y por ende como una entidad sagrada (Donnan 1990). Cabe agregar que las recientes investigaciones en el sitio Pampas Gramalote del Periodo Inicial, ubicado muy cerca a Chan Chan, indican un temprano culto al mar en el valle de Moche el cual también se observa posteriormente en la iconografía de la sociedad Mochica durante el Intermedio Temprano (Donnan y McClelland 1999; Prieto 2010a).

\section{Chimu en el contexto de la Costa norte}

La sociedad Chimu desarrolló un sofisticado sistema político que expandió en todos los valles de la costa desde el norte de Lima hasta la región de Tumbes (Moore 2008). Una red de centros administrativos provinciales y centros administrativo-rurales fueron construidos para controlar la producción agrícola de dichos valles y posiblemente también para garantizar el desarrollo de las prácticas religiosas del estado Chimu (Mackey 1987; Swenson 2004). Al parecer el poder de esta sociedad se basó en un creciente desarrollo de la actividad artesanal que implicaba, entre otros productos el comercio de las conchas de Spondylus y sus productos derivados. Del mismo modo el desarrollo en la producción artesanal de artefactos de aleaciones de cobre para uso suntuario pero sobre todo de uso diario como herramientas agrícolas o de pesca, no tiene precedente en los Andes Centrales.

Esta explosión en la producción artesanal se vio acompañada de un desarrollo y expansión agrícola en el valle de Moche. Al parecer, estos esfuerzos en materia agrícola, estuvieron orientados a garantizar el aprovisionamiento de recursos estratégicos para el propio estado como maíz para elaborar chicha y el algodón para la manufactura de textiles. Muestras de polen tomadas de campos de cultivo estatales Chimu en el valle de Jequetepeque indican que las especies cultivadas en dichos campos fueron maíz y algodón, lo cual confirmaría nuestra propuesta anterior (Glendon y Eling 1989) ${ }^{3}$. Chicha y textiles pudieron ser utilizados por el estado Chimu en el contexto de rituales y festines orientados a establecer alianzas políticas con señores locales de los valles conquistados (Prieto 2011).

El estudio de la ocupación Chimu es prácticamente desconocida al sur del valle de Moche con la excepción de algunos datos en el valle de Viru (Strong y Evans 1956) y la descripción de sitios del Intermedio Tardío en el valle de Santa (Wilson 1988). Por otro lado se tiene buena información gracias a los trabajos realizados en el valle de Casma por Carol Mackey y recientemente el extenso trabajo que viene realizando Melissa Vogel sobre el Intermedio Tardío en esta región (Mackey y Klymyshing 1990; Vogel 2011, 2012). A excepción del valle de Chicama, en la región al norte del valle de Moche se cuenta con abundantes datos sobre Chimu especialmente en el valle de Jequetepeque y el complejo de valles de Lambayeque (Mackey 2004, 2005, 2011; Zori y Johnson 2011; Cutright 2010, 2011; Wester 2010).

La complejidad de la sociedad Chimu no puede ser explicada por si sola o como el desarrollo aislado de una elite sofisticada en el valle de Moche, sino como el producto de una sociedad que exportó su sistema político, económico y religioso a otros valles tanto al sur como al norte de su foco de origen. En dichos valles aplicó estrategias de control social, político y económico que se adaptaron a las circunstancias locales de cada realidad (Prieto 2008, 2010b, 2011), prevaleciendo el sistema de

3 Actualmente Lorenzo Risco de la Universidad Nacional de Trujillo viene realizando, como parte de su tesis de licenciatura, análisis de sedimentos tomados de campos de cultivo Chimu de las Pampas de Huanchaco. Sus resultados podrán resolver dos preguntas clave: si realmente se llegaron a usar y si fue el caso, que especies se cultivaron en ellos. Cabe indicar que los campos eriazos (hacia donde los Chimu enfocaron su ingeniería hidráulica con el fin de cultivarlos) son óptimos para el cultivo de maíz y algodón, mas no para otros productos alimenticios comunes. 
instaurar centros administrativos que arquitectónicamente imitaban los palacios de Chan Chan (Mackey y Klymyshing 1990; Moore 1992; Mackey 2004; Moore y Mackey 2008). Del mismo modo, dicha apertura a otras realidades sociales, políticas y económicas le permitió a la elite Chimu incorporar lo mejor de dichas regiones, generando quizá un ambiente más cosmopolita del que actualmente pensamos. Esta interacción entre Chan Chan, centro del poder político, económico y religioso de la costa norte durante los siglos X a XV y sus «provincias» motivó posiblemente a que las elites y pobladores comunes de varias regiones interactuaran más fluidamente que en periodos anteriores. Este flujo de nuevas experiencias, interacción social y de tradiciones así como creencias religiosas, tendencias ideológicas, tecnologías, tradiciones culinarias y prácticas diversas, debió motivar una reconfiguración social como nunca antes en el valle de Moche, dado que posiblemente hacia Chan Chan llegaba todo este flujo innovador. En este contexto y en referencia a las prácticas de sacrificios humanos y de animales, es posible que no solo hayan estado orientadas a cumplir con los protocolos del estado Chimu, sino que posiblemente hayan tomado en consideración incluir a una amplia diversidad de técnicas sacrificiales, significados y visiones de grupos conquistados y/o asimilados no-Chimu que eran parte o conformaban «lo Chimu» en ese momento.

\section{LOS SACRIFICIOS HUMANOS Y DE ANIMALES EN EL VALLE DE MOCHE PREVIOS A CHIMU}

\section{SACRIFICIO DE ANIMALES}

Recientemente Prieto ha identificado en el sitio del periodo Inicial Pampas Gramalote, ofrendas de pescados, aves y mamíferos marinos (estos últimos solo en partes) en contexto doméstico (Prieto 2010a). De este conjunto, es posible que solo las aves hayan sido sometidas a sacrificio en ofrenda, ya que presentan huellas de corte en sus vertebras superiores.

Muy temprano, las poblaciones andinas depositaron animales al lado de los difuntos. En el valle de Moche, se nota un incremento de la utilización de los animales en las prácticas rituales a partir del Periodo Intermedio Temprano. Es particularmente relevante en la cultura Mochica donde se identificó doce especies dentro de los contextos funerarios y ceremoniales (Goepfert 2008, 2011, 2012). En las tumbas del sitio de Huacas de Moche, los animales domésticos dominan el espectro faunístico con una mayoría de camélidos, llamas (Lama glama) y alpacas (Vicugna pacos) pero también perros (Canis familiaris) y cuyes (Cavia porcellus). Las especies silvestres son escasas en las sepulturas, sin embargo se encontró murciélago (Desmodus rotundus), huerequeque (Burhinus superciliaris) y anfibios (Amphisbaena occidentalis). Los Mochicas depositaron principalmente cráneos y extremidades de patas de camélidos, y partes del cuerpo del animal. En otros sitios y valles, como Sipán por ejemplo, se registró cuerpos enteros de camélidos dispuestos al lado del muerto, pero también otros taxones como loros y serpientes (Alva 1999). Los diferentes tipos de ofrendas parecen ser ligados al estatus social del difunto. Aquí, los animales parecen jugar varios papeles simbólicos. Son a la vez ofrendas alimentarias, procurando comida al muerto para su viaje hacia el inframundo y psicopompas, es decir que fueron enterrados para guiarlo.

Pero los animales fueron también utilizados en contextos ceremoniales. En la Plataforma Uhle, al pie de la fachada oeste de la Huaca de la Luna, se estudió varios miles de restes óseos dentro de los cuales abundaron los camélidos y peces. Parece que este gran depósito es el resultado de actividades de festines que recuerdan el Repositorio de Ofrendas I de Sipán (Goepfert 2010). A parte de las actividades de banquete, los camélidos fueron también utilizados en grandes contextos sacrificiales. Otro ejemplo podría ser el hallado en San José de Moro, donde se encontró un mínimo 88 camélidos dentro de un depósito ceremoniales donde se enterró solamente cráneos y extremidades (Goepfert 2011). 


\section{SACRIFICIOS HUMANOS}

Si bien es cierto se asume que existió la costumbre de hacer sacrificios humanos durante el Periodo Inicial y Horizonte Temprano, hasta el momento no se han hallado restos humanos de estos periodos que indiquen este tipo de prácticas en el valle de Moche. Sin embargo la iconografía del estilo Cupisnique es muy gráfica al respecto y muy posiblemente las prácticas sacrificales humanas ocurrieron en contextos ceremoniales (Cordy-Collins 1992, 2001).

Las excavaciones que se vienen realizando en el complejo arqueológico Huacas de Moche y específicamente en la Huaca de la Luna nos permiten conocer en detalle los sacrificios humanos durante el Intermedio Temprano en el valle de Moche. Hasta el momento se han identificado dos tipos de sacrificios humanos asociados posiblemente a dos ceremonias religiosas de la sociedad Moche. La primera está relacionada a ritos de fertilidad que se iniciaban con combates rituales. Los perdedores en el combate eran trasladados al templo y tras ser preparados por los ayudantes de los sacerdotes, eran degollados y su sangre utilizada en la ceremonial del sacrificio, conocida también como el tema de la presentación. El segundo tipo de sacrificio implicaba muerte por golpes en la cabeza. Sus cuerpos eran luego descarnados y utilizados como esqueletos-marionetas en rituales de culto a los muertos (Verano 2001; Bourget 2001; Uceda y Tufinio 2003). En ambos casos, los sacrificados fueron adolescentes y jóvenes adultos masculinos posiblemente guerreros locales Moche, pero también se han hallado pobladores de otros valles y regiones ajenas al valle en cuestión (Sutter y Cortez 2005; Sutter y Verano 2007).

\section{EL CONTEXTO SACRIFICIAL DE HUMANOS Y CAMÉLIDOS DE HuANCHAQUito-Las Llamas}

Este contexto estuvo conformado por 43 humanos y 74 camélidos jóvenes excavados arqueológicamente. Aproximadamente 15 cráneos y otros huesos humanos fueron hallados en superficie junto a aproximadamente 30 cráneos y numerosos huesos de camélidos disturbados, regados por toda la zona antes de nuestra intervención. A ello debe sumarse que no hemos terminado de excavar el área y se han identificado por lo menos 5 cuerpos humanos y un similar número de camélidos en los perfiles del área excavada. Es decir que estamos ante un evento de sacrificio masivo sin precedentes en el valle de Moche y el área Andina en general, aunque el de Punta Lobos comprometió un mayor número de víctimas (Verano y Toyne 2012) (Fig. 5).

La primera pregunta que nos hicimos al estar frente a tantos restos humanos y de camélidos fue ¿es este un cementerio? ¿O acaso estamos ante un evento masivo de sacrificio humano y animal? La primera posibilidad fue descartada debido a que los cementerios Chimu son bastante variados en el rango de edades (Donnan y Mackey 1978). En el caso de Huanchaquito-Las Llamas prevalecen niños y adolescentes. ¿Podría tratarse entonces de un cementerio especial para enterrar niños y adolescentes? Hasta la fecha no se ha registrado un cementerio Chimu dedicado exclusivamente a individuos con rango de edades específicos, lo cual tampoco descarta que existan, pero esto último es menos probable. No obstante, en el valle de Moche se han registrado sitios Chimu con grandes concentraciones de osamentas de niños y adolescentes. Por ejemplo en la cima del Cerro Blanco (montaña en cuya falda fue construida la Huaca de la Luna), Uhle halló a principios del siglo XX un templo con murales policromos asociados a gran cantidad de objetos suntuarios Chimu. Posteriormente, Steve Bourget re-excavó el sitio pero este había sido objeto de saqueos por casi 90 años. Sin embargo, Bourget señala que en los escombros se registraron varias centenas de huesos de niños y adolescentes, los cuales debieron ser enterrados allí, proponiendo que se pudo haber tratado de un cementerio especializado, aunque posteriormente arguye que podría tratarse de sacrificios humanos con ese rango de edades hechos por el estado Chimu (Bourget 1997b). Sorprendentemente, en un sector se registraron densos depósitos de huesos de camélidos menores a un año, los cuales aparentemente fueron abandonados en la superficie y después estuvieron asociados a un fuerte evento de lluvia, quizá un Fenomeno ENSO 


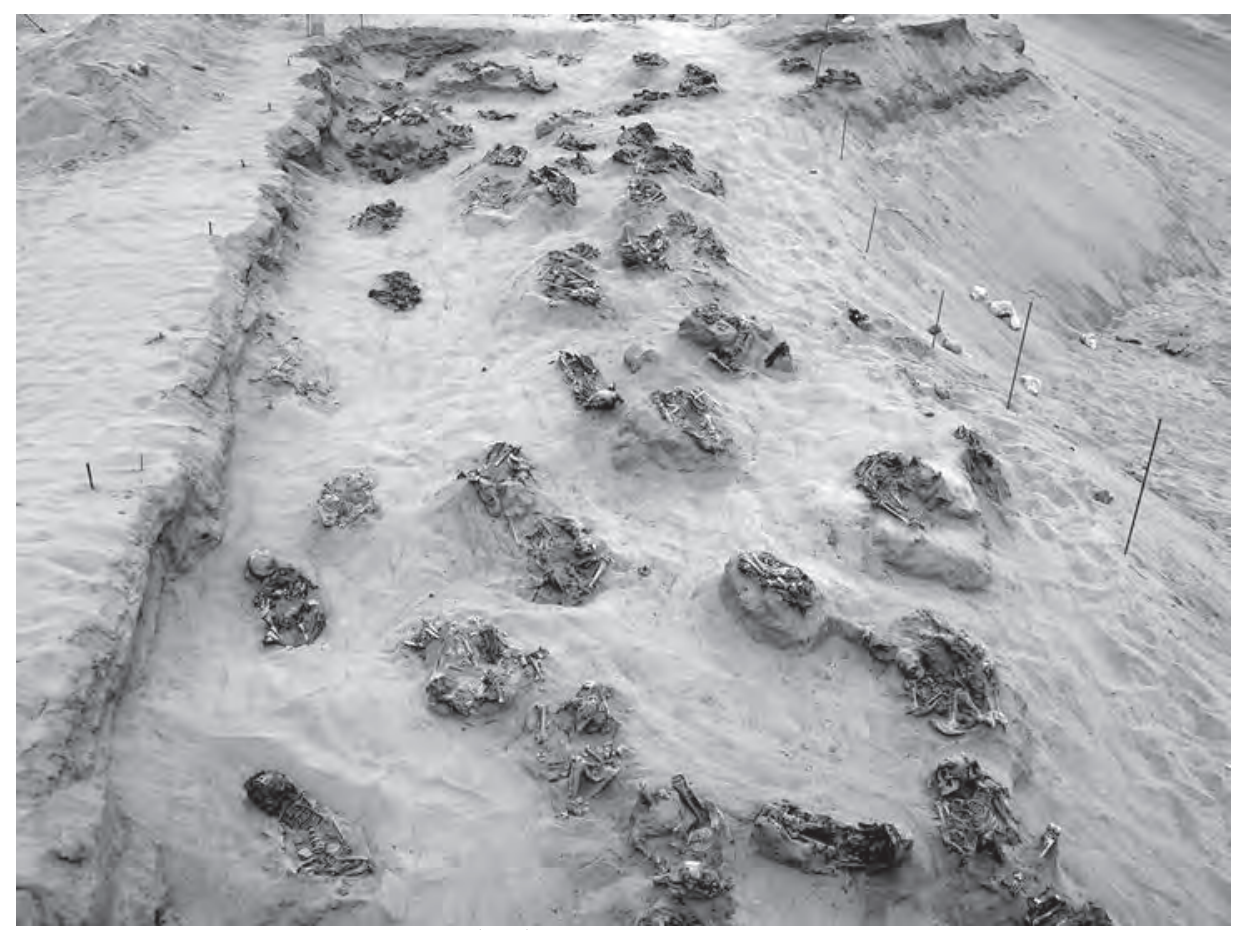

Figura 5. Vista general (N-S) del contexto de Huanchaquito-Las Llamas.

(Bourget 1997b: 113). Del mismo modo, los trabajos efectuados por Hans Horkheimer en la década de 1940 en las afueras del grupo denominado «Calvario de los Incas», «El Castillo» o «Grupo Hrdlicka» (Chan Chan) arrojaron un número incierto de varios restos de individuos jóvenes sin ofrendas funerarias (Horkheimer 1944: 70). Así mismo, resulta interesante que Bourget notó la presencia de restos de camélidos y abundantes restos de concha de spondylus y conus fergusoni en este sitio durante una visita de campo (Bourget 1997b).

Los contextos humanos y animales descritos por estos investigadores, asociados a estructuras arquitectónicas que pueden haber sido templos o santuarios, parecen ser el resultado de ofrendas y sacrificios humanos y de animales. Curiosamente, estos contextos están por lo general (aunque no exclusivamente) asociados a semillas de ishpingo (Nectandra sp.), tallas miniaturas de madera, textiles finos, conchas de spondylus y otros artefactos suntuarios y/o exóticos (Horkheimer 1944; Bourget 1997b; Montoya 2004). En resumen, se podría argumentar que estas concentraciones de niños y adolescentes no son el producto de cementerios especializados, sino la acumulación de una intensa actividad ritual alrededor de estructuras ceremoniales.

Un aspecto diferente del contexto de Huanchaquito-Las Llamas fueron las posiciones de los cuerpos de los individuos humanos: se observaron cuatro posiciones corporales: extendido dorsal con extremidades inferiores flexionadas; flexionado lateral; cuerpo fuertemente flexionado y echado sobre su espalda y extendido de cubito dorsal (Fig. 6). Ninguna de estas coincide con la clásica posición flexionadasentada observada en las prácticas funerarias Chimu. Esto último se puede observar en los cementerios de Banderas (sur del Rio Moche) y Huaca del Sol excavados por el Proyecto Chan Chan valle de Moche en la década de 1970. Asimismo el reciente hallazgo de 88 tumbas en la Plaza 1 de Huaca de la Luna, confirma que el patrón de enterramiento Chimu en el valle de Moche fue la posición flexionada-sentada (Donnan y Mackey 1978; Orbegoso et al. 2012) (Fig. 7). En ambos cementerios prevalece dicha posición y los individuos enterrados, dependiendo de su status, tienen mayor o menor cantidad de ofrendas así como 


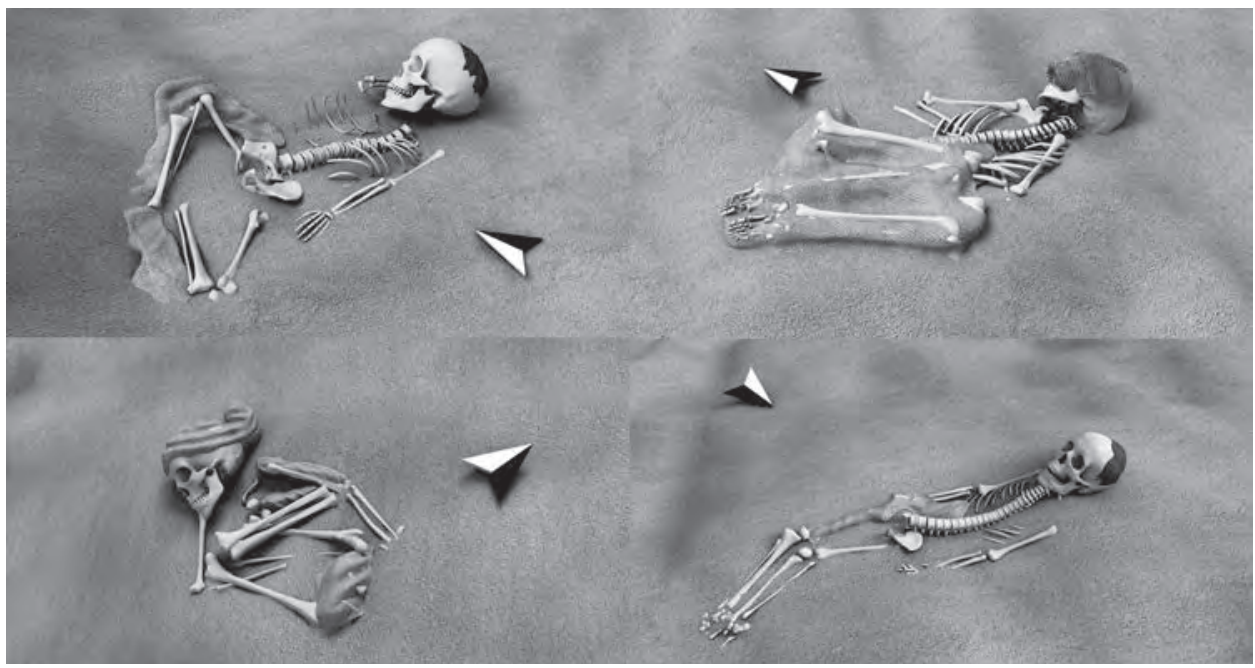

Figura 6. Composicion 3D de las 4 posturas halladas en los individuos de Huanchaquito-Las Llamas.

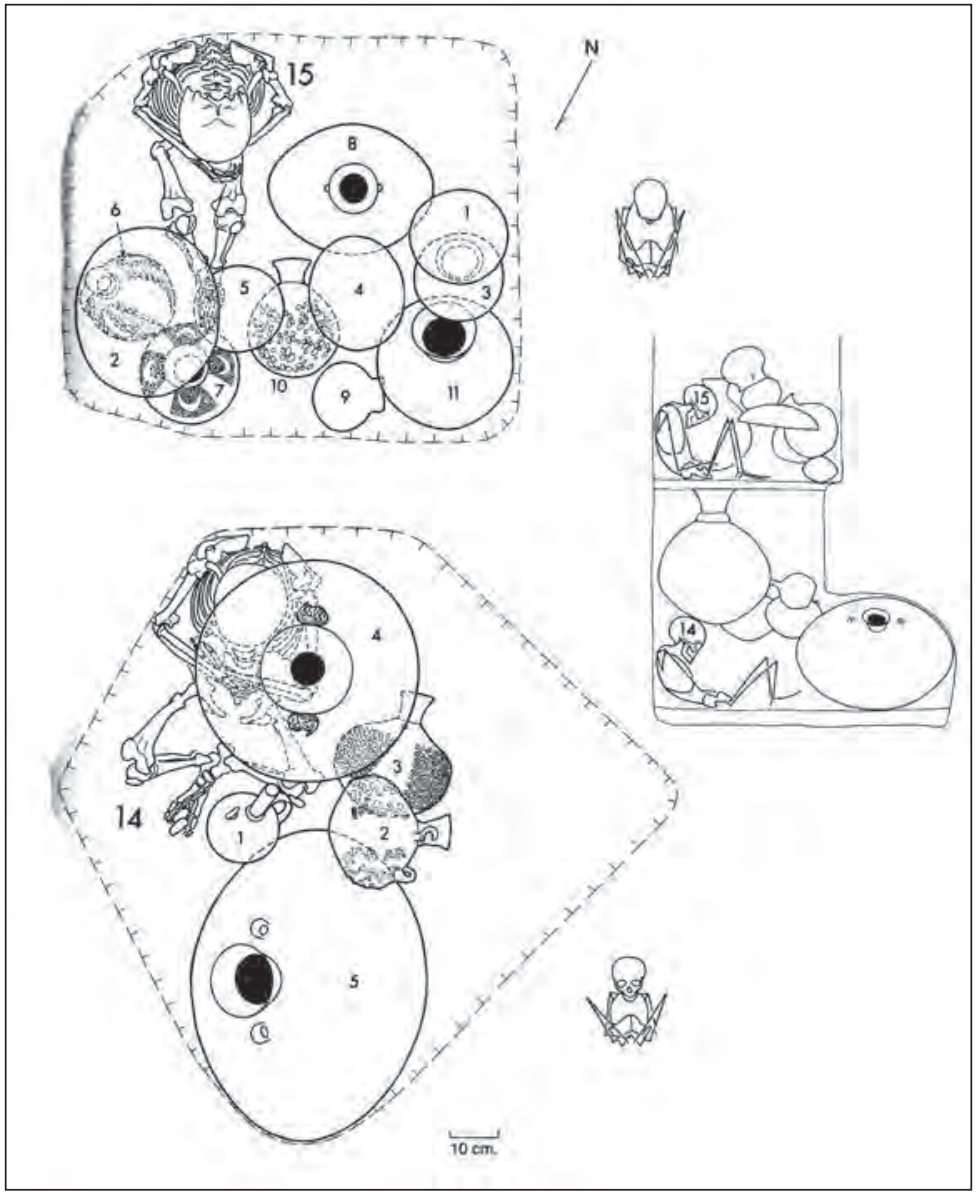

Figura 7. Típico entierro Chimu en el valle de Moche. Tumba MC 14. (Tomado de Donnan y Mackey 1978). 
variación en la calidad de las mismas (Donnan y Mackey 1978; Ravines 1980). Esto último es interesante ya que hasta las tumbas más modestas Chimu presentan ofrendas funerarias como vasijas domésticas de cerámica u objetos de metal o concha (Ibid.). En el caso de Huanchaquito-Las Llamas ninguno de los individuos presentaron este tipo de ofrendas funerarias.

Finalmente queda el factor de los camélidos, los cuales podrían considerarse como las «ofrendas» de estos individuos. Sin embargo, el patrón de distribución indica que fueron junto con los individuos humanos parte de una ofrenda conjunta. La concentración masiva de humanos y animales en contexto sacrificial ya había sido identificado previamente en un contexto local contemporáneo muy similar en las inmediaciones de Huanchaco (Donnan y Foote 1978) así como en los sitios de Chotuna, Cerro Cerrillos y Túcume en la región de Lambayeque (Wester 2010; Klaus et al. 2010; Toyne 2011) (Fig. 8).

Tomando en consideración todos los elementos anteriores, el contexto de Huanchaquito-Las Llamas es claramente un evento sacrificial masivo de humanos y animales de una escala sin precedentes hallado hasta el momento en la costa norte del Perú.

De los 43 individuos humanos registrados, 33 estuvieron asociados directamente a uno o varios camélidos, 6 no presentaron camélidos y en 4 casos no pudo ser definido debido a alteraciones post deposicionales previas a nuestra intervención o debido a que el individuo humano no se excavó com-

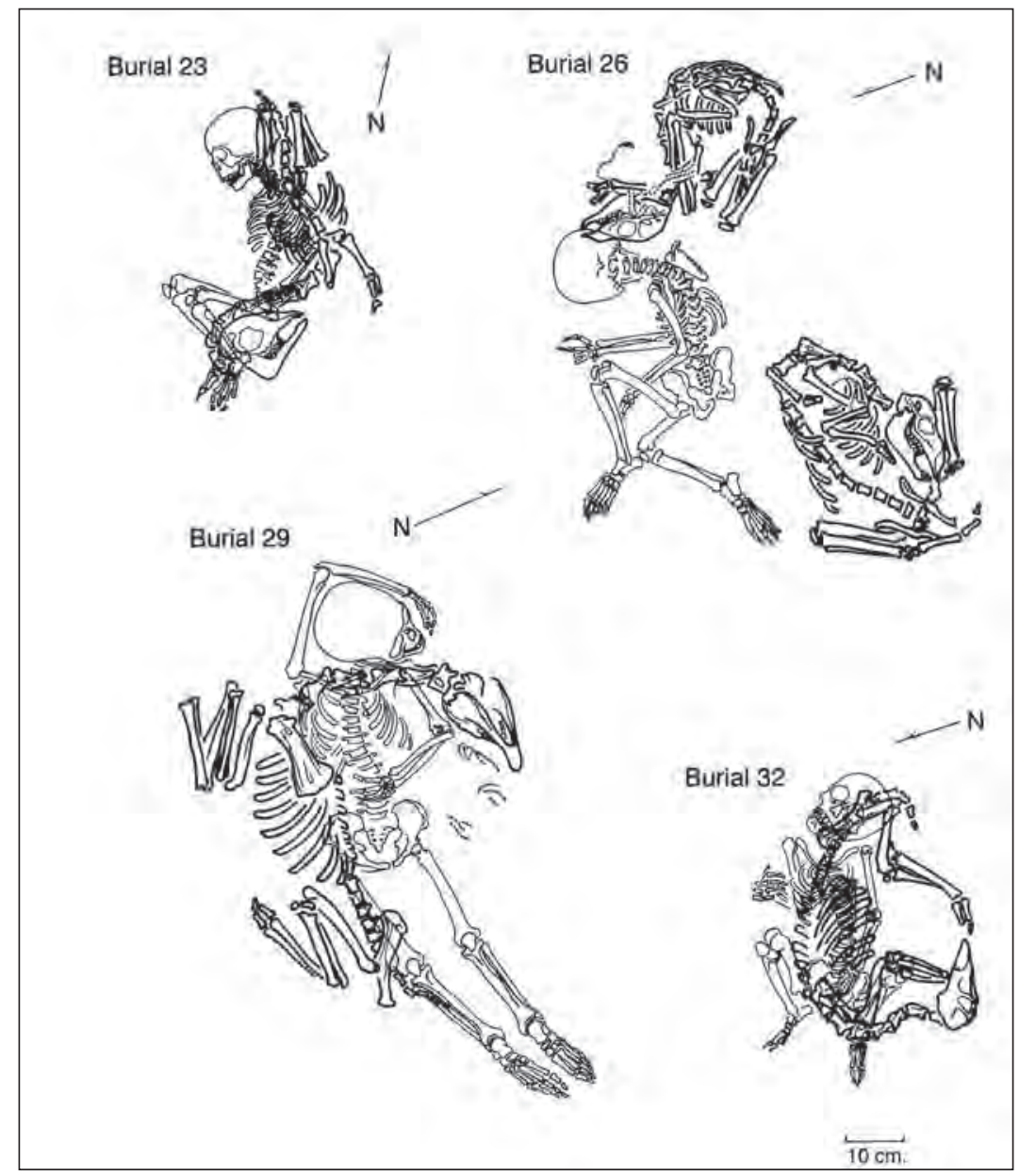

Figura 8. Contexto de niños y camelidos registrado por Donnan en Huanchaco. (Tomado de Donnan y Foote 1978). 
pletamente (Tabla 1). Así, 42 camélidos estuvieron asociados directamente a individuos humanos mientras que 32 estuvieron enterrados solos o en grupos, pero sin estar asociados directamente a humanos. Es decir, el patrón de enterramiento en Huanchaquito-Las Llamas incluye niños o adolescentes asociados a uno o varios camélidos. Por lo general se trató de un camélido joven sobre el cuerpo del individuo humano (Fig. 9).

Todo en conjunto, sumado al factor que 29 de los 43 cuerpos humanos ${ }^{4}$ presentaron alteración in situ o manipulación de las primeras costillas (primera a cuarta) especialmente las del lado izquierdo, sugieren alguna acción peri mortem en los niños y adolescentes hallados en las excavaciones. Esta práctica no es extraña en la costa norte para periodos tardíos y ha sido identificada en los sitios de Pacatnamu, Cerro Cerrillos y Túcume (Verano 1986; Klaus et al. 2010; Toyne 2011). Por otro lado, llama mucho la atención que de la reducida muestra en la que se ha podido analizar los restos óseos humanos, 10 de ellos muestran un patrón de corte oblicuo u horizontal en el esternón. Este patrón no es muy común en la costa norte, dado que hasta el momento se habían hallado cortes verticales o transversales sobre el esternón, pero no horizontales como los del caso de Huanchaquito-Las Llamas. Del mismo modo, nuestros estudios preliminares sugieren que muchos de los camélidos hallados en Las Llamas presentan huellas de cortes a la altura de la tercera y cuarta costilla (derechas e izquierdas) así como en la segunda y tercera esternebra, sugiriendo que la muerte de estos animales se pudo dar de una manera similar a la de los humanos, es decir afectando el área del tórax (Goepfert y Prieto 2012).

Todo parece indicar que se trató de un solo episodio o evento sacrificial ya que casi todos los contextos están enterrados al mismo nivel estratigráfico. Tres fechados AMS realizados en los huesos de tres individuos humanos (E27, E29 y E31) ubicados en diferentes sectores del contexto arrojaron fechas consistentes entre 1400 y 1450 d.C. ${ }^{5}$ (Tabla 2). En algunos casos se excavó una fosa en el barro arcilloso depositado posiblemente por un evento de lluvia fuerte previo al entierro, mientras que en otros casos (especialmente los camélidos no asociados a los individuos) fueron abandonados sobre la capa de barro arcillosa (Fig. 10). En Huanchaquito-Las Llamas se han hallado tres formas de ente-

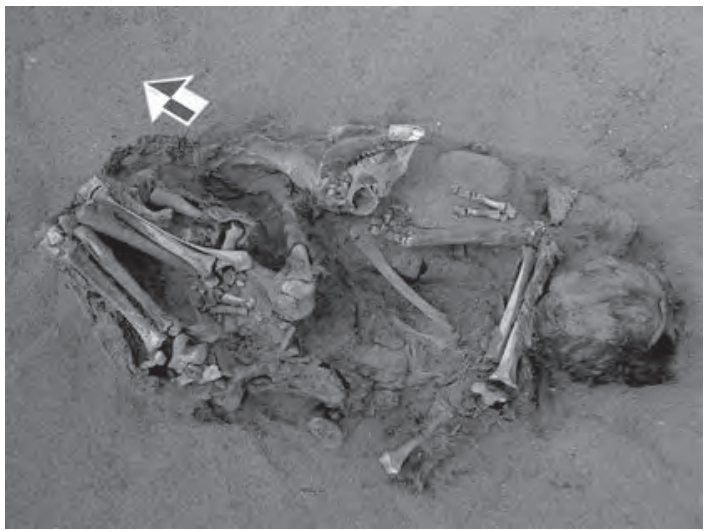

Figura 9. Contexto tipico de Huanchaquito Las Llamas, un camelido sobre un individuo humano.

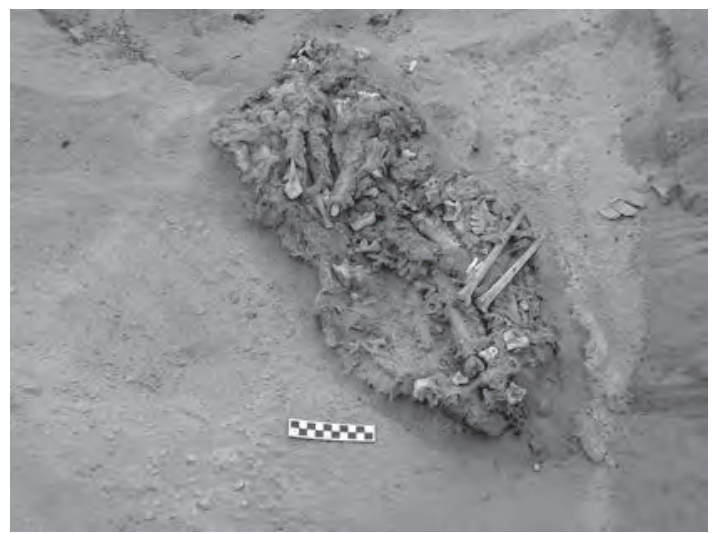

Figura 10. Camelido directamente sobre capa de barro con evidencia de pisos de agua por lluvias

4 Cabe indicar que hasta el momento solo se ha podido estudiar 20 cuerpos humanos del total de 43 . De esta muestra 10 tienen cortes que segmentan en dos el primer o segundo cuerpo esternal, mientras que los restantes presentaron alteraciones probablemente peri-mortem en la posición de las costillas (primera a cuarta), indicando una posible remoción o manipulación de algún musculo, arteria u órgano en ese sector. Es necesario continuar con los estudios de antropología física en laboratorio para identificar lesiones en los restantes cuerpos excavados.

5 Los tres fechados AMS se han realizado gracias a la generosa contribución de los Drs. Jeffrey Quilter y Steven LeBlanc del Peabody Museum de la Universidad de Harvard, Estados Unidos. Tómese en cuenta el «efecto reservorio» para una calibración más precisa. 
G. Prieto, N. Goepfert y K. Valladares / Sacrificios de niños, adolescentes y camélidos jóvenes durante...

\begin{tabular}{|c|c|c|c|c|c|c|c|c|c|c|c|c|c|c|}
\hline 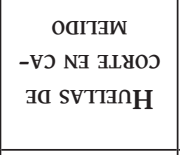 & 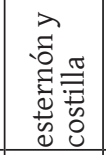 & 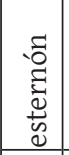 & \& & & & 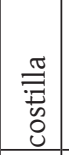 & 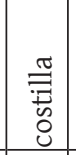 & 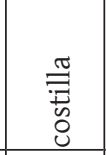 & & 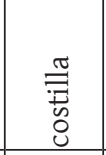 & 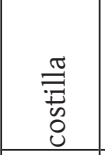 & \& & & \& \\
\hline 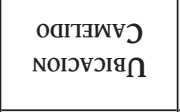 & 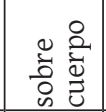 & $\begin{array}{ll} & 0 \\
0 & 0 \\
0 & 0 \\
0 & 0 \\
0 & 0 \\
0\end{array}$ & 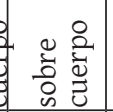 & & & $\begin{array}{l} \\
0 \\
0 \\
0 \\
0 \\
0 \\
0\end{array}$ & 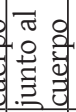 & 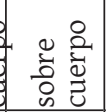 & & 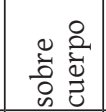 & 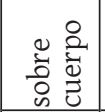 & 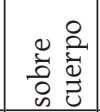 & & 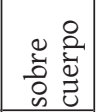 \\
\hline 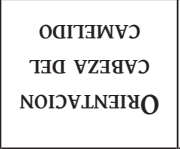 & 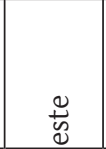 & 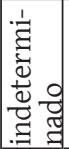 & 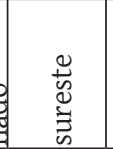 & & & 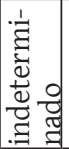 & $\begin{array}{l}0 \\
\tilde{U} \\
0 \\
0 \\
0 \\
0\end{array}$ & 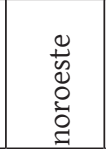 & & 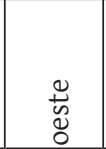 & 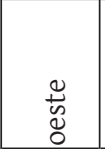 & $\frac{\ddot{d}}{\tilde{d}}$ & & 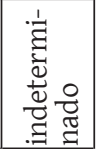 \\
\hline 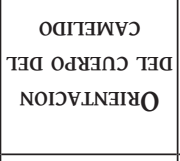 & 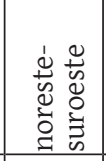 & 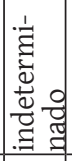 & 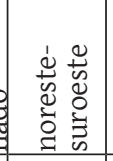 & & & 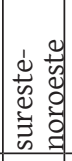 & 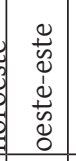 & 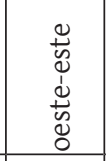 & & 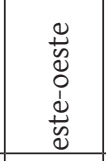 & $\begin{array}{l}0 \\
\stackrel{0}{0} \\
0 \\
0 \\
\vdots \\
\tilde{0} \\
0 \\
0\end{array}$ & 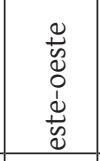 & & 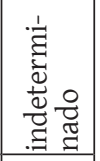 \\
\hline \begin{tabular}{|c|} 
оагт \\
-зพУว уотоว
\end{tabular} & 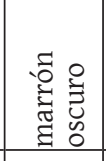 & 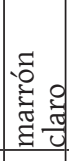 & 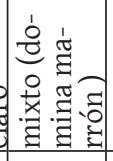 & & & 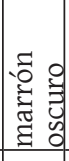 & 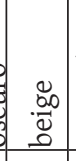 & 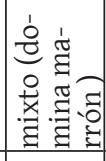 & & 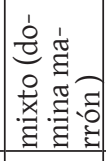 & $\begin{array}{l}0 \\
0 \\
0 \\
0\end{array}$ & 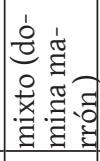 & & 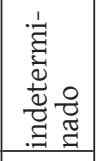 \\
\hline 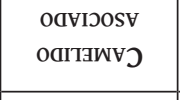 & in & $N$ & in & \& & \& & 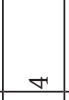 & 0 & $\infty$ & ‡ & $F$ & 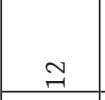 & $\stackrel{m}{-}$ & $\vec{z}$ & $\hat{m}$ \\
\hline $\begin{array}{c}\text { OnaINIGNI Na } \\
\text { ofoy OLNGWפI }\end{array}$ & ‡ & $\bar{w}$ & 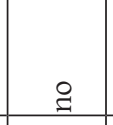 & 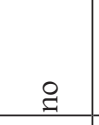 & is & ‡ & ‡ & ‡ & ‡ & $\bar{w}$ & $\bar{s}$ & ๕ & $\bar{z}$ & $\bar{\omega}$ \\
\hline 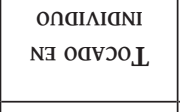 & \& & \& & $\vec{\omega}$ & $\vec{w}$ & is & \& & \& & is & \& & \& & \& & \& & $\bar{z}$ & is \\
\hline 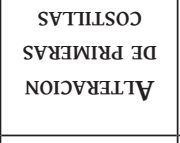 & $\ddot{\omega}$ & $\vec{\omega}$ & $\vec{\omega}$ & $\vec{\omega}$ & $\ddot{\omega}$ & $\vec{\omega}$ & $\ddot{\omega}$ & ๕ & $\vec{\omega}$ & $\dot{\omega}$ & $\vec{\omega}$ & $\vec{\omega}$ & $\bar{z}$ & $\vec{\omega}$ \\
\hline 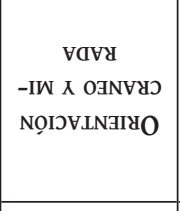 & 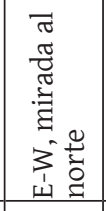 & 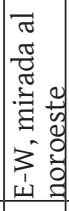 & 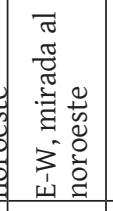 & 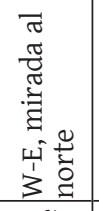 & 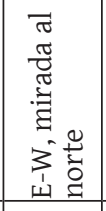 & 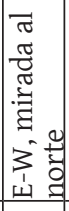 & 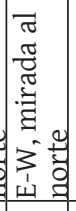 & 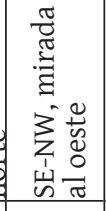 & 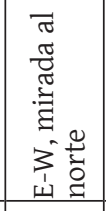 & 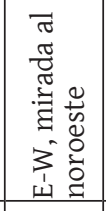 & 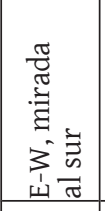 & 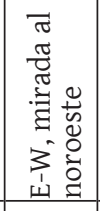 & $\bar{z}$ & 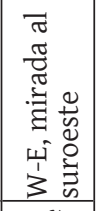 \\
\hline NọISOSO $_{d}$ & 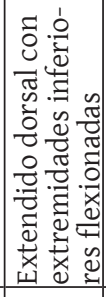 & 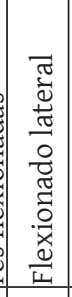 & 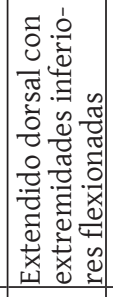 & 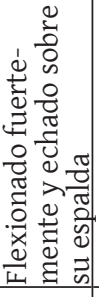 & 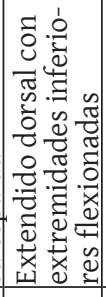 & 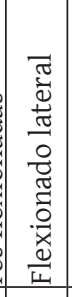 & 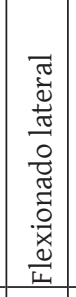 & 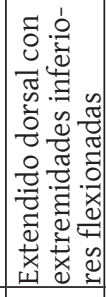 & 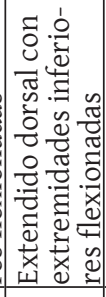 & 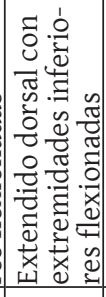 & 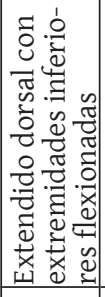 & 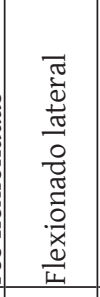 & $\bar{z}$ & 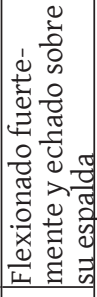 \\
\hline vavwiısa ava & 况 & 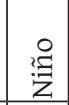 & 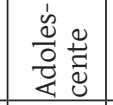 & 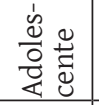 & 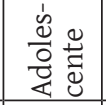 & 绍 & 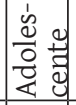 & 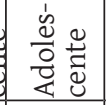 & : & 导 & 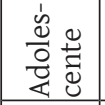 & 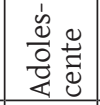 & $\bar{z}$ & 导 \\
\hline •oyn onainianI & 年 & 先 & 壵 & 岁 & 占 & $\begin{array}{r}0 \\
\dot{1} \\
\end{array}$ & 告 & 虫 & 虫 & 站 & 孚 & 帛 & $\begin{array}{c}m \\
\vec{\omega} \\
\dot{\omega}\end{array}$ & $\begin{array}{l}\stackrel{n}{7} \\
\stackrel{1}{\omega}\end{array}$ \\
\hline
\end{tabular}




\begin{tabular}{|c|c|c|c|c|c|c|c|c|c|c|c|c|c|c|}
\hline 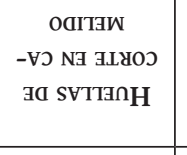 & \& & & & & & 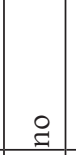 & 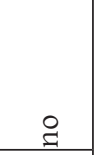 & \& & 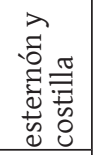 & \& & \& & \& & \& & 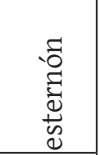 \\
\hline 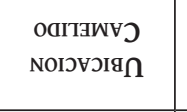 & 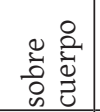 & & & & & 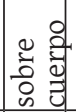 & 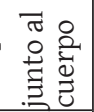 & $\begin{array}{l} \\
0 \\
0 \\
0 \\
0 \\
0 \\
\text { in }\end{array}$ & 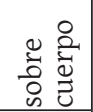 & 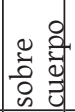 & 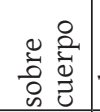 & 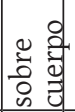 & 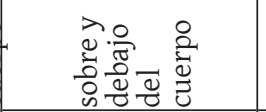 & 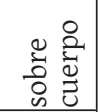 \\
\hline 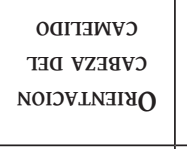 & 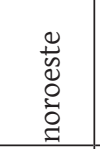 & & & & & 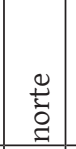 & 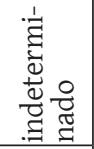 & 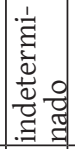 & 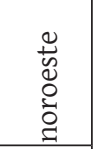 & 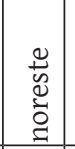 & 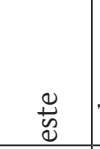 & 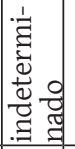 & 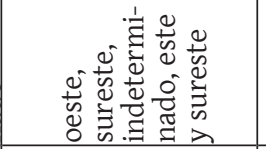 & $\stackrel{\vec{\Delta}}{\tilde{D}}$ \\
\hline 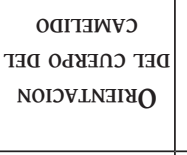 & 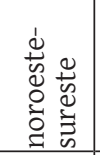 & & & & & 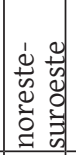 & 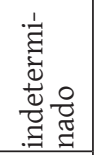 & 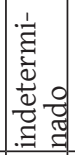 & 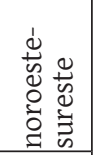 & 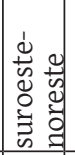 & 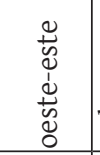 & 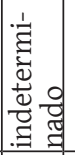 & 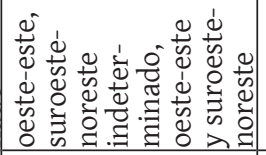 & 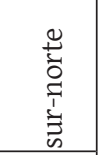 \\
\hline $\begin{array}{c}\text { оагт } \\
\text {-зพษว уотоว }\end{array}$ & 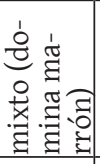 & & & & & 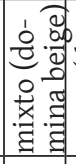 & 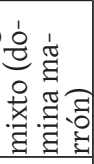 & 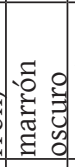 & 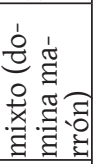 & 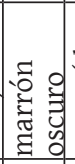 & 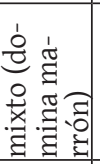 & $\begin{array}{r}0 \\
.0 \\
0 \\
\end{array}$ & 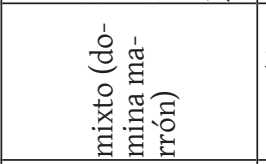 & 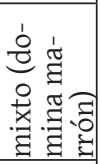 \\
\hline $\begin{array}{l}\text { oaviost } \\
\text { oaiาawyว }\end{array}$ & $\vec{N}$ & \& & \& & 요 & $\bar{\Sigma}$ & $\stackrel{\leftrightarrow}{q}$ & g & i & i & ㄱ & ก & $\stackrel{2}{7}$ & 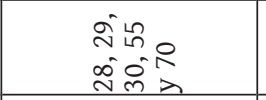 & $\stackrel{0}{-1}$ \\
\hline 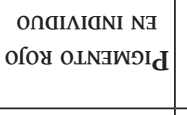 & $\vec{n}$ & \& & $\stackrel{8}{2}$ & I & $\bar{z}$ & \& & \& & $\nsubseteq$ & \& & \& & $\bar{z}$ & $\bar{z}$ & $\bar{\omega}$ & $\bar{\omega}$ \\
\hline 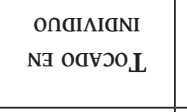 & \& & 요 & \& & \& & $\bar{z}$ & \& & \& & \& & $\bar{\omega}$ & \& & $\bar{z}$ & $\bar{z}$ & \& & £ \\
\hline 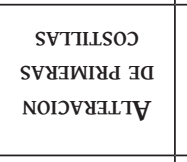 & $\ddot{\omega}$ & 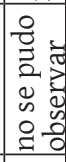 & 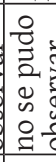 & c) $\bar{s}$ & $\bar{\omega}$ & $\vec{\omega}$ & $\bar{\Sigma}$ & $\bar{s}$ & $\stackrel{2}{\circledR}$ & $\bar{s}$ & $\bar{z}$ & $\bar{z}$ & $\bar{s}$ & $\bar{\omega}$ \\
\hline 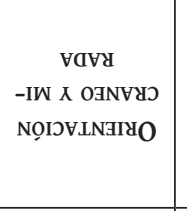 & 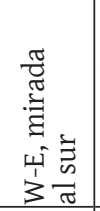 & 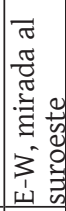 & 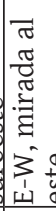 & 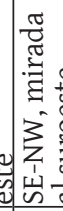 & 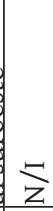 & 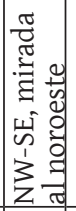 & $\Sigma$ & 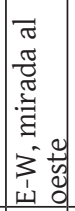 & 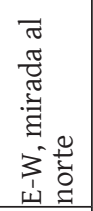 & 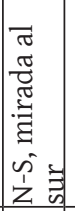 & $\bar{z}$ & $\bar{z}$ & 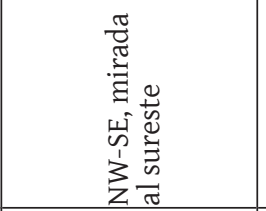 & 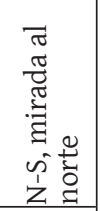 \\
\hline NoIIISO & 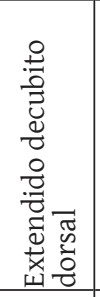 & 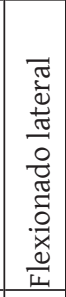 & 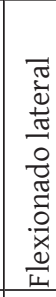 & 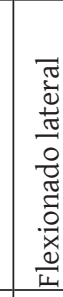 & $\bar{z}$ & 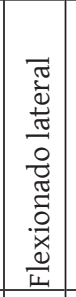 & $\bar{z}$ & 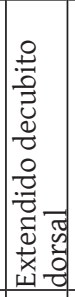 & 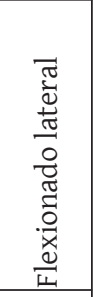 & 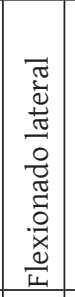 & $\bar{z}$ & $\bar{z}$ & 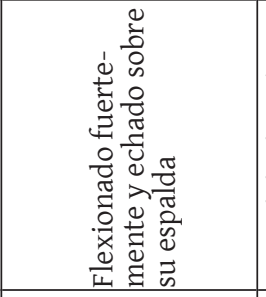 & 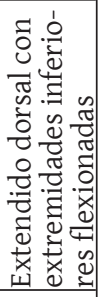 \\
\hline vavWILSI ava马 & 㣽 & 容 & 劲 & 高 & $\bar{z}$ & 高 & $\bar{z}$ & 高 & 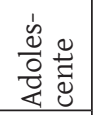 & 高 & $\bar{z}$ & 结 & 吕 & : \\
\hline - oצn OnAIAIGNI & $\begin{array}{l}0 \\
\stackrel{1}{\omega} \\
\end{array}$ & 吉 & $\begin{array}{l}\infty \\
\stackrel{1}{w} \\
\vec{w}\end{array}$ & $\begin{array}{c}2 \\
\overrightarrow{1} \\
\vec{\omega}\end{array}$ & 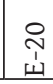 & $\underset{⿱}{\vec{H}}$ & $\underset{N}{\mathbb{N}}$ & 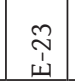 & $\underset{\sim}{\stackrel{H}{\omega}}$ & $\begin{array}{c}\stackrel{\sim}{N} \\
\stackrel{\omega}{\omega}\end{array}$ & $\begin{array}{l}\text { i } \\
\text { H) } \\
\end{array}$ & $\begin{array}{c}\hat{N} \\
\omega \\
\omega\end{array}$ & \begin{tabular}{c}
$\infty$ \\
\multirow{1}{\omega}{} \\
\end{tabular} & సે \\
\hline
\end{tabular}




\begin{tabular}{|c|c|c|c|c|c|c|c|c|c|c|c|c|c|}
\hline \& & 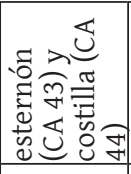 & 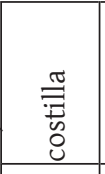 & \& & ‡ & & \& & 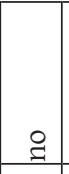 & 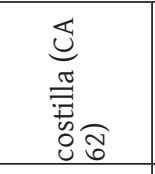 & & 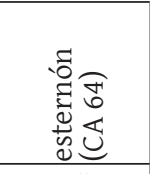 & 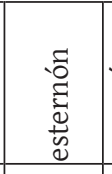 & 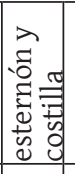 & \& \\
\hline 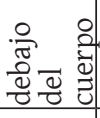 & 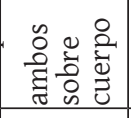 & 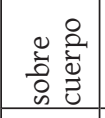 & 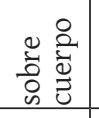 & 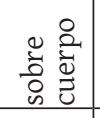 & & 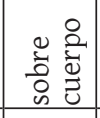 & $\begin{array}{l} \\
0 \\
0 \\
0 \\
0 \\
0 \\
\infty\end{array}$ & 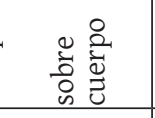 & & 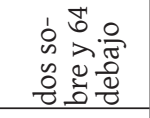 & 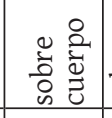 & . & 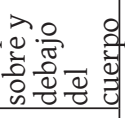 \\
\hline 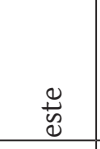 & 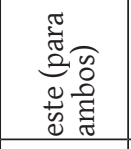 & 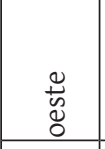 & 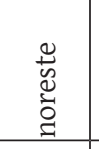 & 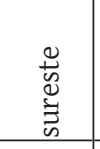 & & 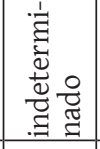 & 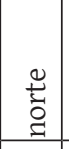 & 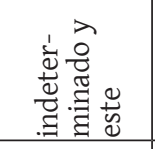 & & 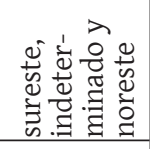 & 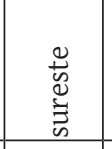 & 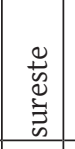 & 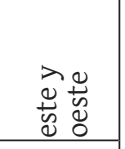 \\
\hline 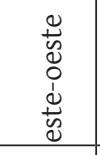 & 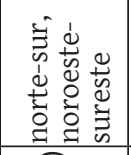 & 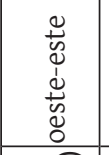 & 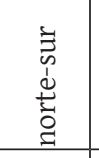 & 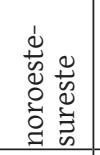 & & 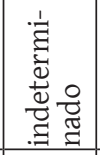 & 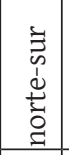 & 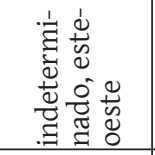 & & 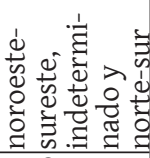 & 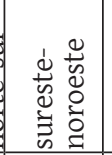 & 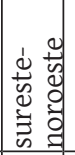 & 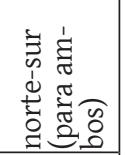 \\
\hline 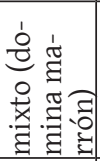 & 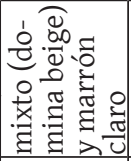 & 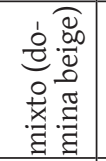 & 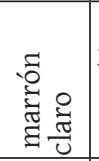 & 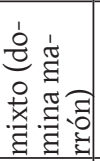 & & 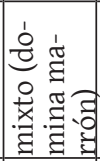 & 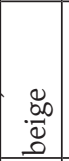 & 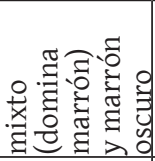 & & 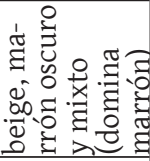 & 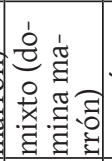 & 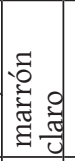 & 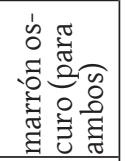 \\
\hline శ్ర & 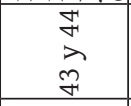 & $\stackrel{n}{m}$ & m & $m$ & $\bar{z}$ & 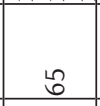 & 8 & $\begin{array}{l}\text { तु } \\
\text { ᄀ } \\
\text { ก }\end{array}$ & $\bar{z}$ & $\begin{array}{l}\overrightarrow{0} \\
\stackrel{\circ}{n} \\
\sigma^{\prime}\end{array}$ & ה & 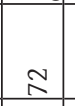 & 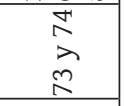 \\
\hline$\nsubseteq$ & $\overline{\text { es }}$ & ๕ & $\vec{e}$ & $\vec{w}$ & $\bar{z}$ & $\vec{w}$ & 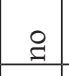 & is & $\bar{z}$ & in & $\vec{n}$ & $\bar{\omega}$ & $\vec{n}$ \\
\hline \& & \& & \& & $\vec{\omega}$ & ‡ & $\bar{z}$ & g & \& & $\stackrel{9}{ }$ & $\bar{z}$ & ¿ & $\bar{n}$ & \& & ‡ \\
\hline 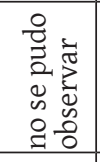 & $\ddot{\omega}$ & ๕ & $\vec{w}$ & $\vec{w}$ & $\bar{z}$ & 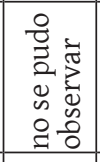 & $\vec{w}$ & $\vec{\omega}$ & $\Sigma$ & $\vec{w}$ & $\stackrel{\text { I }}{ }$ & $\vec{\omega}$ & $\overrightarrow{e n}$ \\
\hline 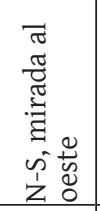 & 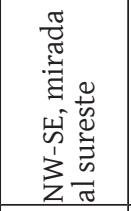 & 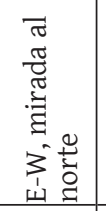 & 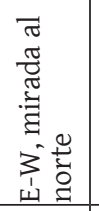 & 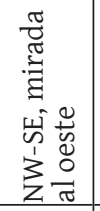 & $\vec{z}$ & 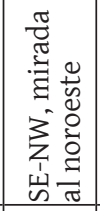 & 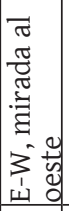 & 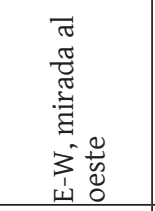 & $\bar{z}$ & 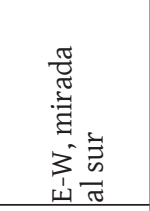 & 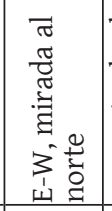 & 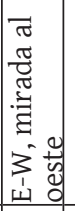 & 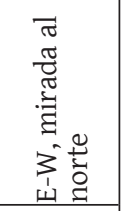 \\
\hline 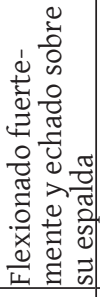 & 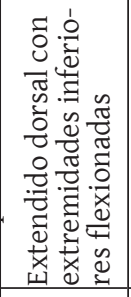 & 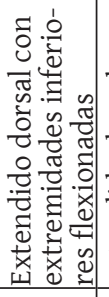 & 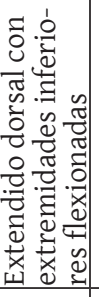 & 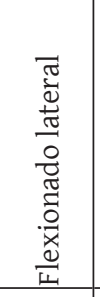 & $\Sigma$ & 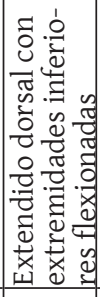 & 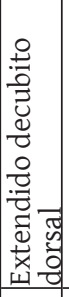 & 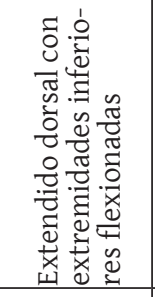 & $\bar{z}$ & 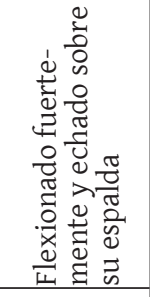 & 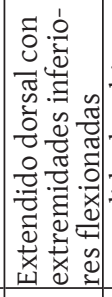 & 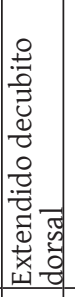 & 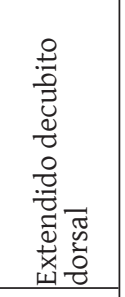 \\
\hline 呑 & 肎 & 急 & 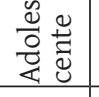 & 急 & $\bar{z}$ & 急 & 名 & ફ્ & $\bar{z}$ & 名 & 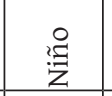 & 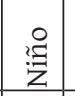 & ફ્ \\
\hline 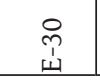 & $\vec{⿱}$ & $\underset{\sim}{\sim}$ & $\underset{\tilde{\omega}}{m}$ & 岕 & $\begin{array}{c}n \\
m \\
\omega \\
\omega\end{array}$ & 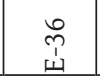 & $\begin{array}{c}\hat{a} \\
\tilde{w} \\
\end{array}$ & 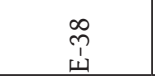 & $\begin{array}{c}\hat{\tilde{m}} \\
\dot{\omega}\end{array}$ & 古 & 劣 & $\underset{\text { I }}{\stackrel{7}{\Psi}}$ & $\begin{array}{l}\text { F } \\
\text { 虫 }\end{array}$ \\
\hline
\end{tabular}


Tabla 2: Fechados AMS

\begin{tabular}{|c|c|l|c|c|}
\hline $\begin{array}{c}\text { UCIAMS } \\
\#\end{array}$ & $\begin{array}{c}\text { Sample } \\
\text { ID }\end{array}$ & \multicolumn{1}{|c|}{ Other ID } & Material & $\begin{array}{c}\text { fraction } \\
\text { modern }\end{array}$ \\
\hline 120948 & S27 & Huanchaquito - Las Llamas, Individuo E27 & $>30 \mathrm{kDa}$ Gelatin & 0.9246 \\
\hline 120949 & S29 & Huanchaquito - Las Llamas, Individuo E29 & $>30 \mathrm{kDa}$ Gelatin & 0.9425 \\
\hline 120950 & S31 & Huanchaquito - Las Llamas, Individuo E31 & >30kDa Gelatin & 0.9370 \\
\hline
\end{tabular}

\begin{tabular}{|c|c|c|c|c|c|c|}
\hline \pm & $\begin{array}{l}\mathrm{D}^{14} \mathrm{C} \\
(\% \mathrm{o})\end{array}$ & \pm & $\begin{array}{c}{ }^{14} \mathrm{C} \text { age } \\
\text { (BP) }\end{array}$ & \pm & $\begin{array}{c}1 \text { Sigma } \\
\text { AD }\end{array}$ & $\begin{array}{c}2 \text { Sigma } \\
\text { AD }\end{array}$ \\
\hline 0.0015 & -75.4 & 1.5 & 630 & 15 & $1325-1368$ & $1319-1404$ \\
\hline 0.0016 & -57.5 & 1.6 & 475 & 15 & $1445-1455$ & $1438-1464$ \\
\hline 0.0015 & -63.0 & 1.5 & 525 & 15 & $1425-1442$ & $1416-1448$ \\
\hline
\end{tabular}

rramiento: humanos solos, humanos con uno o varios camélidos y camélidos solos (Figs. 11, 12 y 13). Todo este conjunto de sacrificados parece haber sido cuidadosamente dispuesto en el lugar donde se enterraron. La distribución espacial de estos elementos sugiere que tantos humanos (E) y camélidos (CA) fueron ordenados en dos grupos: norte y sur.

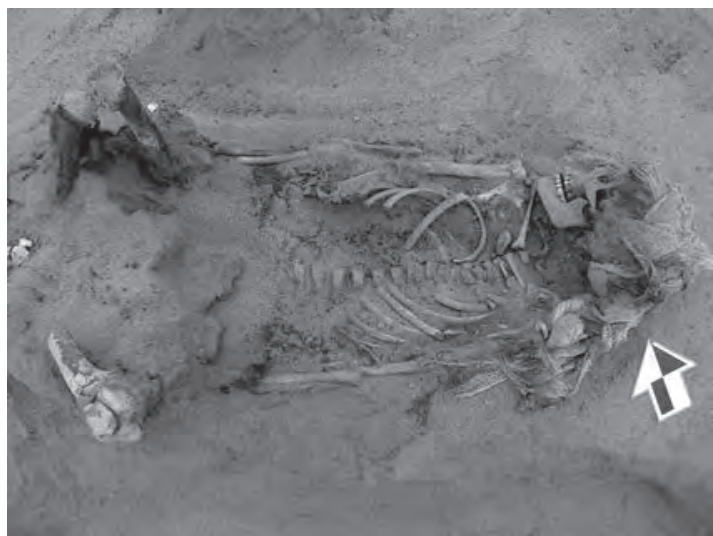

Figura 11. Humano (E-5) sin asociacion de camelido.

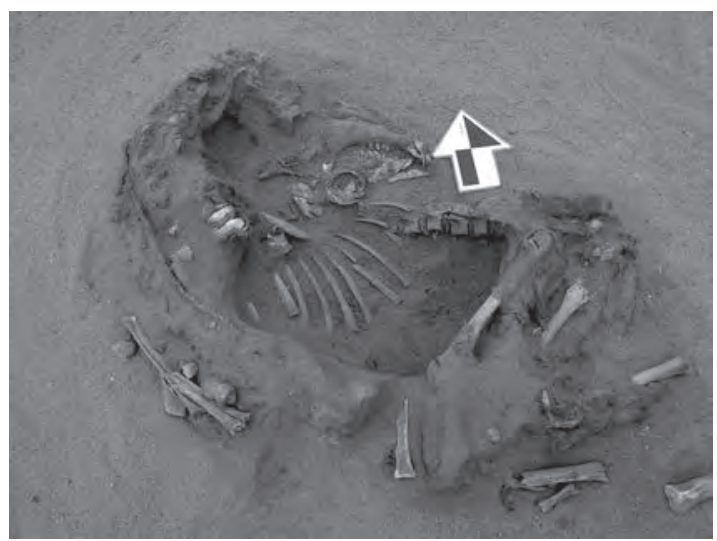

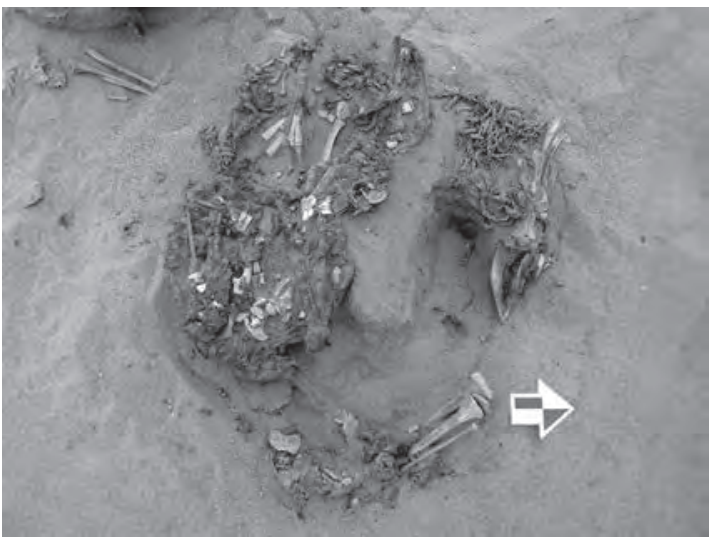

Figura 12. Individuo 31 (abajo) asociado a camelidos 43 y 44 .

\section{GRUPO NORTE}

Ubicado en el extremo norte de la excavación, debe tratarse de una parte de un grupo más grande aun no excavado pero observado en los perfiles de la excavación. En este grupo hemos hallado un total de 21 humanos y 31 camélidos (Figs. 14 y 15).

Al parecer los humanos fueron colocados en fosas continuas ordenadas una delante de la otra de sureste a noroeste en un patrón lineal ligeramente curvo formando hasta dos alineamientos

Figura 13. Ejemplo de llama que fue enterrada sola (CA 47). 


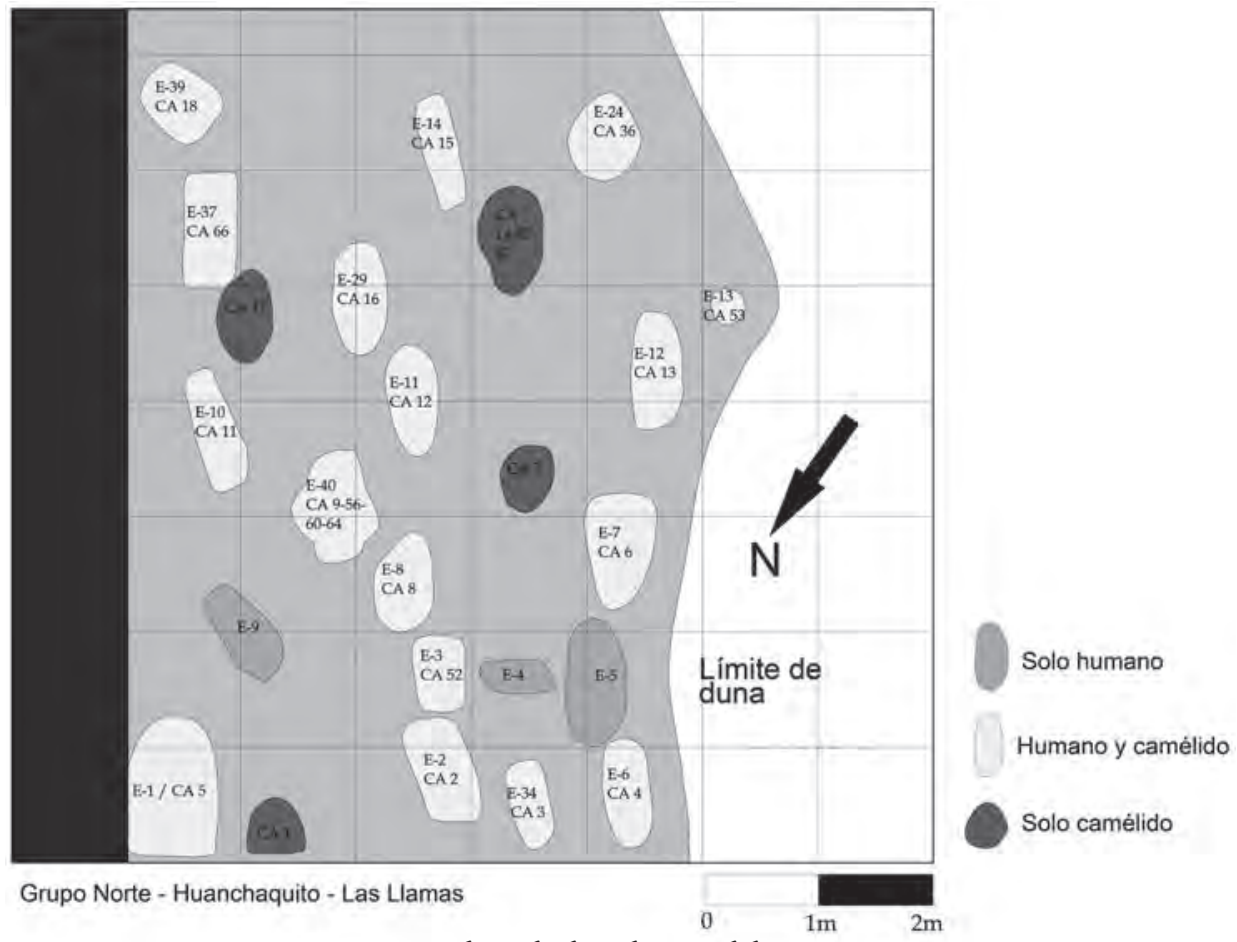

Figura 14. Plano de distribucion del Grupo Norte.

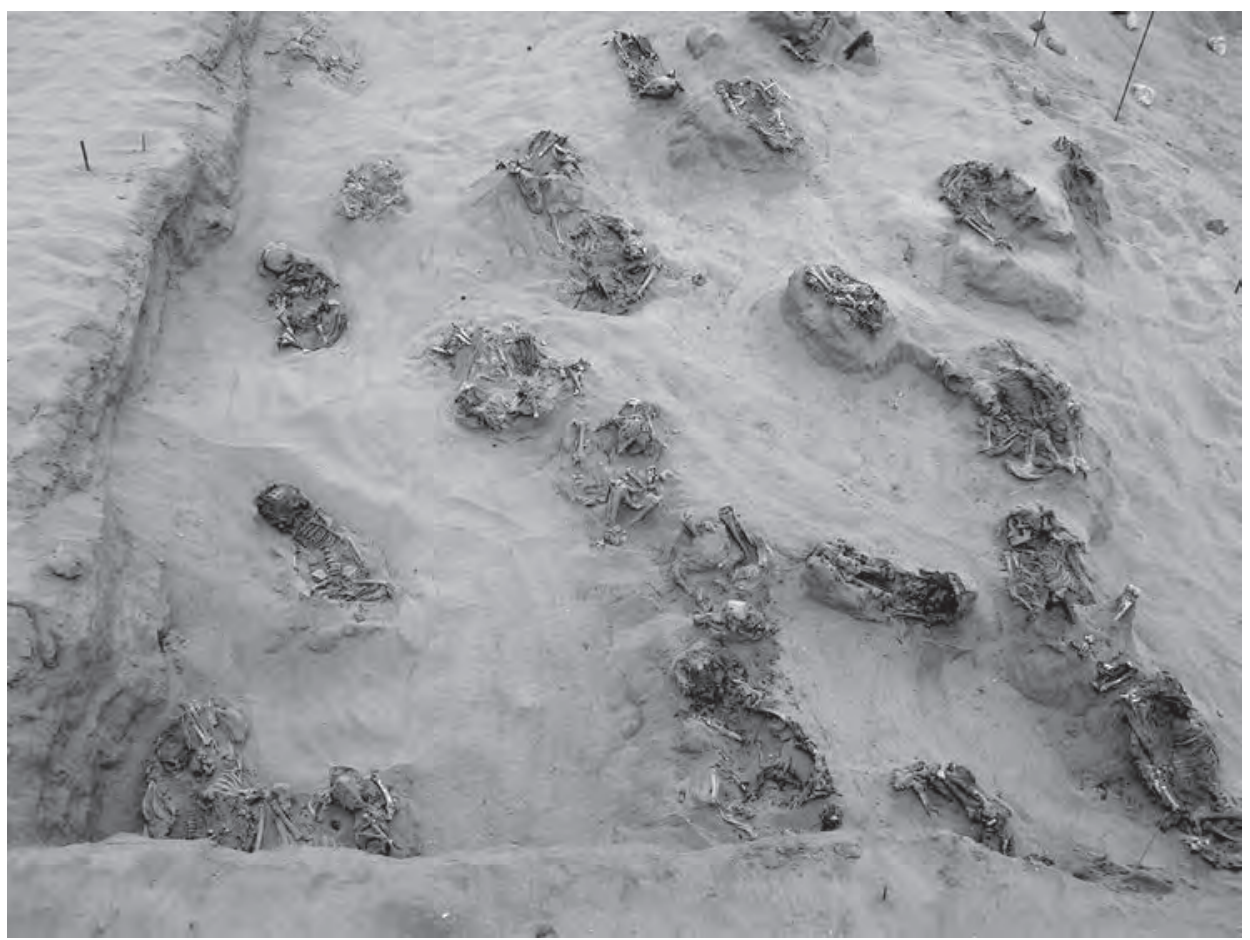

Figura 15. Vista general N-S del Grupo Norte. 
paralelos. Los camélidos solos fueron dispuestos en 4 grupos ubicados entre los alineamientos de humanos, también uno delante del otro. Al parecer la intención fue que estos camélidos enterrados solos estuvieran rodeados de humanos (Fig. 14).

Se hallaron un total de 21 humanos en este grupo. Quince humanos estuvieron asociados con camélidos, mientras que tres humanos estuvieron sin ellos (E4, E5 y E9) y en los tres casos restantes (E13, E35 y E39) no se pudo determinar porque estuvieron alterados o no llegaron a excavarse completamente. Por otro lado en este sector se hallaron 26 camélidos en muy buen estado de conservación. Veinte camélidos estuvieron asociados directamente a humanos, predominando 1 camélido por individuo humano. El único caso en el que hemos hallado más de un camélido asociado a un humano es el E40 sobre el cual se depositó al CA64 y encima de este los CA 60, 56 y 9, es decir 4 camélidos. Por otro lado se hallaron 6 camélidos (CA1, 7, 14, 17, 57 y 67) que fueron enterrados juntos en una fosa y no se hallaron asociados a humanos o cerca de ellos.

En cuanto a las posiciones en las que fueron colocados los humanos, predominó en este grupo la extendida dorsal con las extremidades inferiores flexionadas, seguida de la posición flexionada lateral. En cuanto a la orientación de los individuos humanos predominó el cráneo al sur (12 casos) y el cuerpo orientado ligeramente hacia el noroeste.

\section{GRUPO SUR}

Este grupo también es parte de un conjunto más grande que no fue excavado en su totalidad. Nuestras excavaciones revelaron la presencia de 22 humanos y 48 camélidos. En este sector son los camélidos los que rodean a los humanos, siendo exactamente opuesto a lo observado en el sector norte (Fig. 16 y 17). Así, se observan semi círculos de camélidos que rodean cuerpos humanos alineados uno al costado del otro, generalmente con la misma orientación y posición. Se han determinado 4 grupos de humanos rodeados de camélidos (Fig. 16). El primer grupo de humanos estuvo debajo de una concentración de piedras pequeñas y medianas que formaban un círculo. Alrededor de las piedras se colocaron camélidos cuidadosamente seleccionados en base al color de su pelaje, alternando colores claros y oscuros (beige y marrón) (Fig. 18). Debajo de las piedras y hacia el centro se halló un individuo (E42) en posición extendida con el rostro pintado de rojo. Delante de él (es decir hacia el norte), se hallaron tres individuos, uno al lado del otro con la misma orientación y posición corporal, todos con pigmento rojo en la cara y uno de ellos (E33) presentaba un tocado hecho con textiles de algodón a manera de turbante en la cabeza. Llamó la atención que este individuo fue el único que presentó decoración facial con pintura roja de líneas paralelas (Fig. 19).

De los 22 humanos, 19 estuvieron asociados a uno o más camélidos, mientras que los tres restantes estuvieron solos. En el caso de los camélidos, 27 estuvieron asociados a humanos y 21 fueron enterrados solos o en grupos. Por otro lado registramos un único caso de sobre-posición de humanos. En el extremo norte del Grupo Sur, se registró al E30 sobre el cual se depositó al CA 63 y sobre ambos se colocó al E27 con el CA 19. Otro caso que llamó la atención es el del E28 el cual tuvo asociados cinco camélidos (CA 28, 29, 30, 55 y 70). Un aspecto interesante es que cada camélido depositado en este contexto tuvo un color diferente: marrón oscuro, marrón claro, beige, beige dominante mezclado con marrón y marrón dominante mezclado con beige (Fig. 20). En dos casos hallamos dos individuos humanos asociados a dos camélidos cada uno (E42 y E43). También en otros dos casos, hallamos más de un camélido no asociados a humanos. Entre dos agrupaciones de humanos se hallaron juntos los camélidos CA 24, 58, 61 y 69. Al igual que el caso anterior, cada camélido tuvo un color de pelaje diferente. También se hallaron dos camélidos juntos que no estuvieron asociados a humanos: CA 32 y 68 siendo uno marrón oscuro (CA 32) y el de abajo marrón claro (CA 68).

La distribución de las posiciones corporales en las que se colocó a los individuos humanos enterrados en el Grupo Sur fue más uniforme que en el Grupo Norte. Así, tanto la posición extendida 


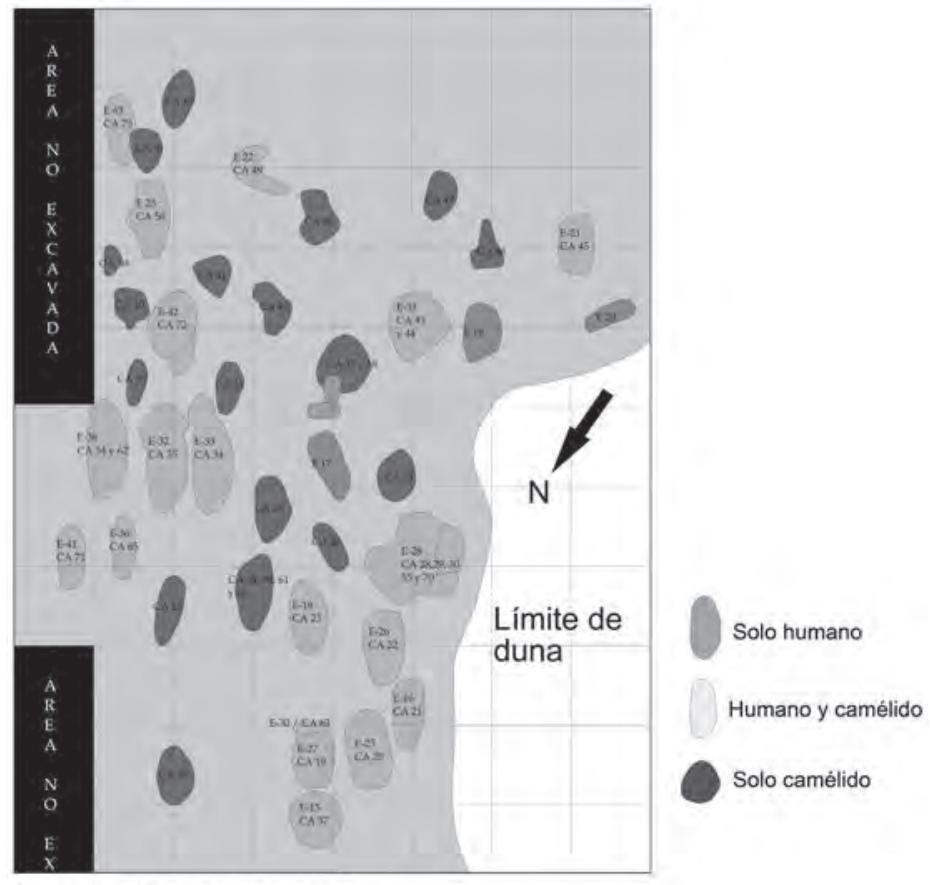

Grupo Sur - Huanchaquito - Las Llamas

Figura 16. Plano de distribucion del Grupo Sur.

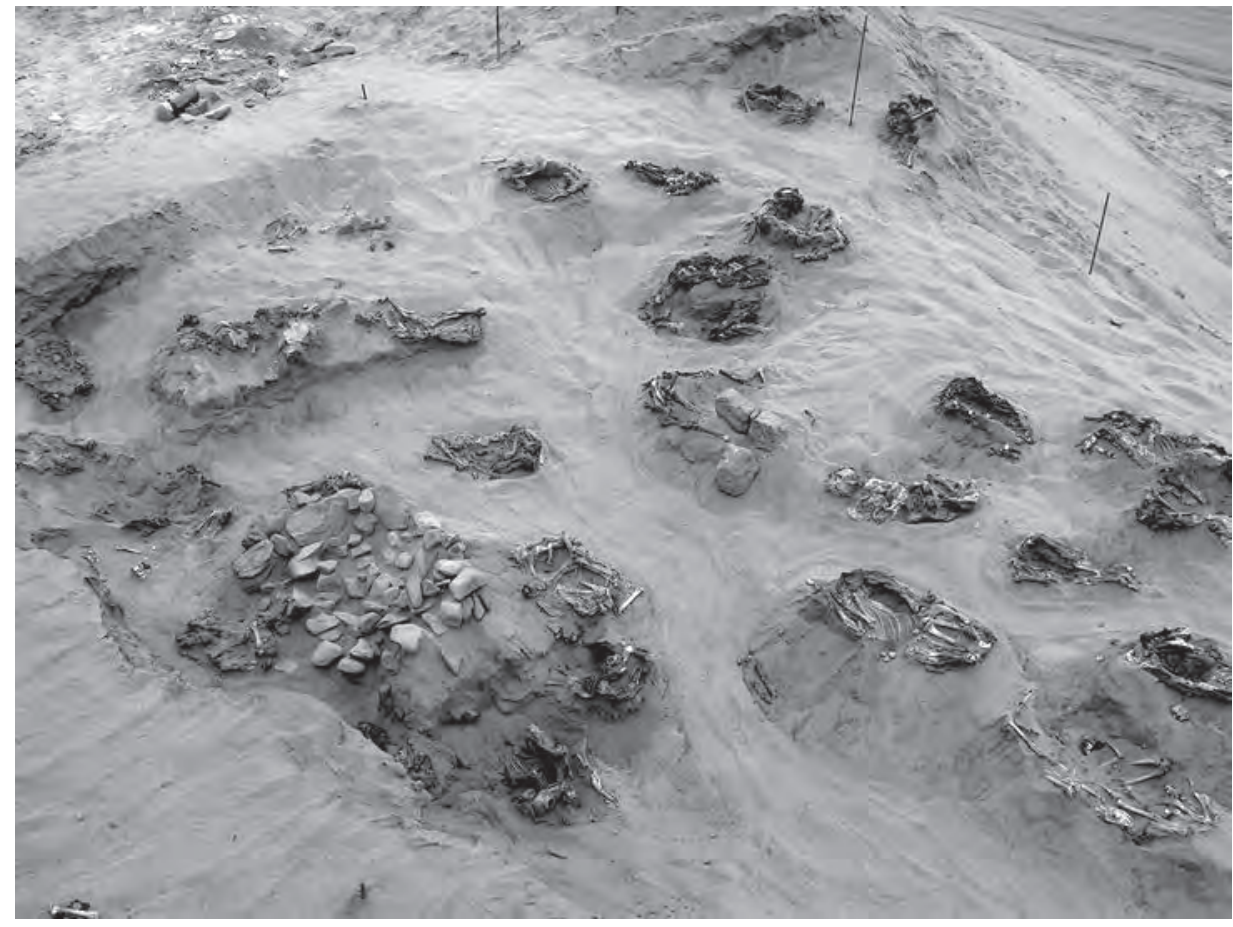

Figura 17. Vista general S-N de Grupo Sur. 


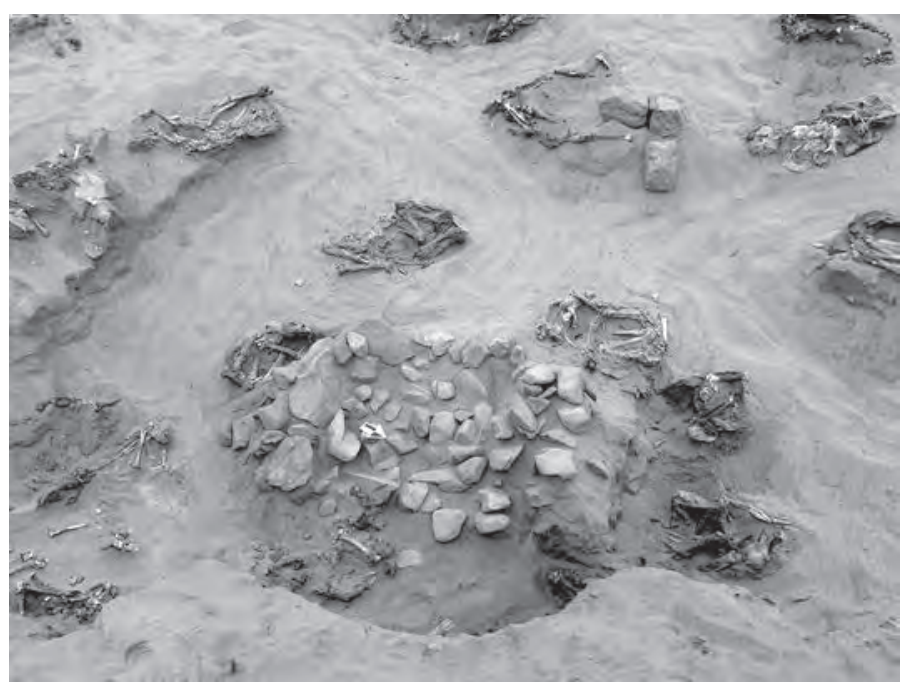

Figura 18. Conjunto de camelidos y humanos alrededor y debajo de concentracion de piedras.

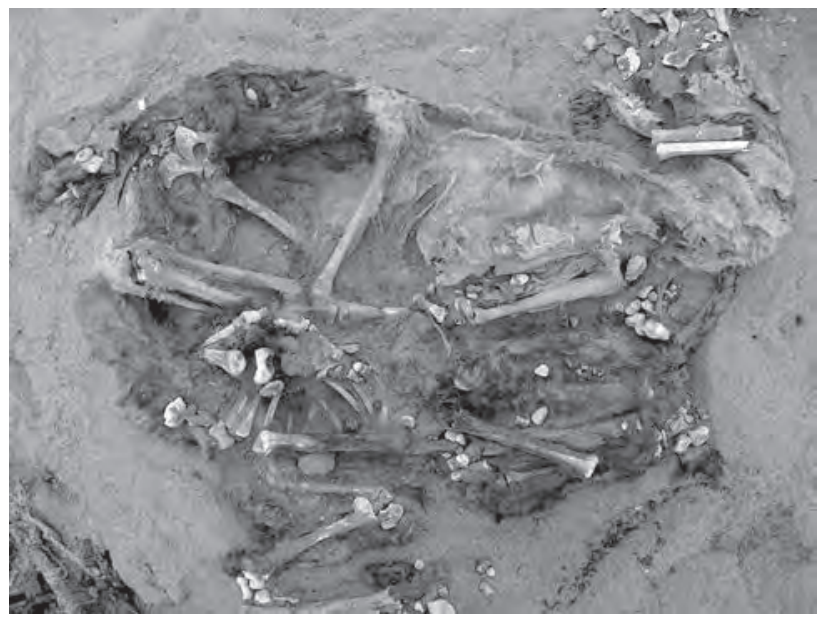

Figura 20. CA 9 y CA 56 sobre E 40. Adiverta el contraste de los dos colores y posiciones opuestas.

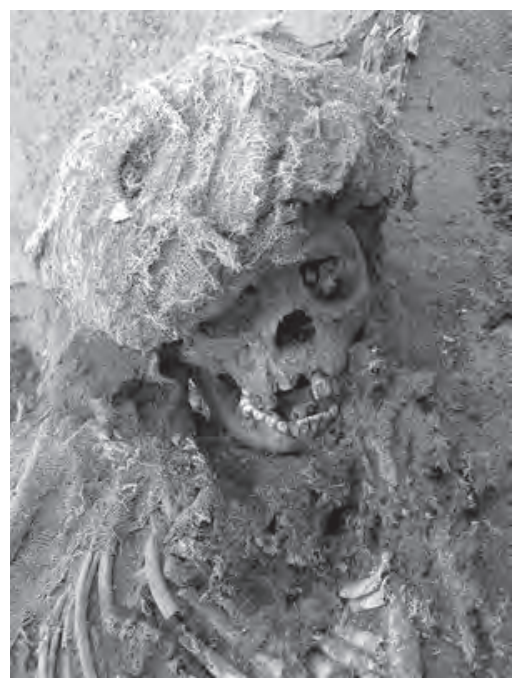

Figura 19. Individuo 33 con tocado en la cabeza. Adviértase las lineas de pigmento rojo en el textil.

dorsal con extremidades inferiores flexionadas y la posición flexionada lateral se observó en 6 casos cada una. En el caso de la posición flexionado fuertemente echado sobre su espalda y la posición extendida dorsal, presentó cinco y cuatro casos respectivamente. Es decir que no se observa una tendencia o preferencia en el uso de una de estas posiciones como si se ha visto en el Grupo Norte (Tabla 3). En cuanto a las orientaciones de los cuerpos, destaca en este grupo los cráneos hacia el sur y el cuerpo hacia el norte (nueve casos). La segunda orientación más común fue la del cráneo hacia el norte y el cuerpo al sur (seis casos) (Tabla 1).

\section{EL SACRIFICIO DE LOS NIÑOS Y ADOLESCENTES}

De los 43 individuos identificados, 27 fueron niños (rango entre 6 y 8 años), diez adolescentes (rango entre 11 y 15 años) y seis no pudieron determinarse debido a que los cuerpos estuvieron incompletos y/o disturbados. La posición predominante fue la extendida dorsal con extremidades inferiores flexionadas, seguida de la posición flexionada lateral. El 51\% de los individuos tuvieron el cráneo orientado al sureste (es decir con el cuerpo hacia el noroeste), mientras que la mirada fue direccionada en un 37\% hacia el oeste, noroeste o suroeste, es decir hacia el mar. Todos los individuos estuvieron envueltos en mortajas de textiles llanos de algodón que los cubrieron completamente (Fig. 21). En 9 casos, los cuerpos humanos presentaron tocados en la cabeza como turbantes, pañuelos y el «tocado del pescador» (turbante con abultamiento cilíndrico sobresaliendo de la base), típico en Chimu (Fig. 22). Resulta interesante mencionar que de los nueve individuos portando tocado, seis fueron adoles- 


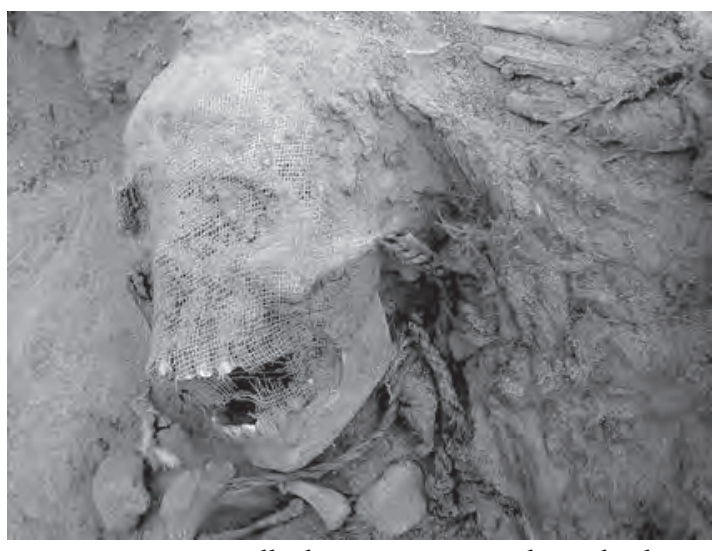

Figura 21. Detalle de una mortaja cubriendo el rostro de Individuo E-7

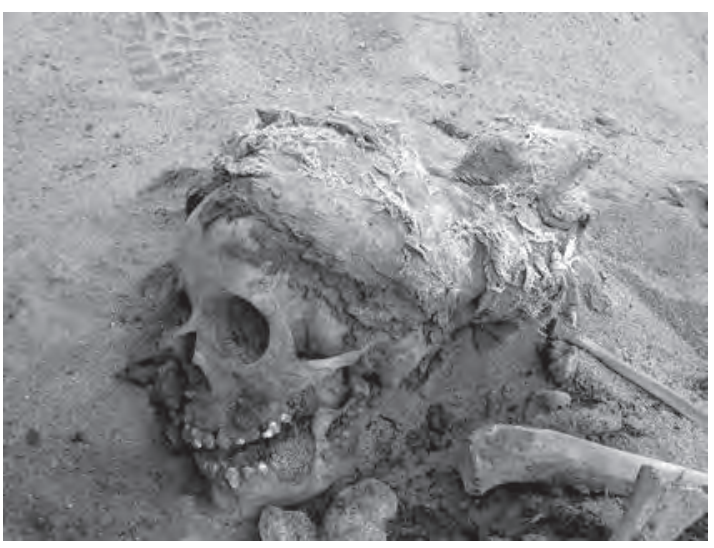

Figura 22. Tipico tocado de pescador en Chimu. Individuo $\mathrm{E}-15$

centes indicando una preferencia y selectividad por utilizar este tipo de elementos en ese rango de edad. Varios individuos también presentaron taparrabos. No se observó calzado ni elementos que decoren los cuerpos fuera de pintura facial de color rojo en 17 individuos (Tabla 1).

Es muy difícil poder determinar el sexo de esqueletos de niños y adolescentes (ya que las diferencias sexuales básicas no han aparecido aún (Byers 2002). Por ello, se han tomado muestras de todos los individuos para hacer análisis de ADN y así determinar el sexo. Estos resultados están actualmente procesándose y esperamos en un futuro cercano tener los datos correspondientes. Sin embargo, es muy posible que se tratara en su mayoría de varones. Esto se debe específicamente a dos líneas de evidencia. La primera es que debido a la buena conservación de los restos se ha preservado en el 90\% de los casos las cabelleras de los individuos. Casi todas muestran un patrón de pelo corto, típico en los niños varones del periodo Chimu. En segundo lugar, varios de los individuos vestían taparrabos sencillos, una prenda típicamente masculina en la costa norte del Perú (Verano 2007: 113) (Fig. 23).

Cabe indicar que a la fecha, solo se han realizado estudios muy preliminares de antropología física en 20 individuos. El rasgo más significativo hallado hasta el momento es la recurrencia de una lesión peri-mortem ubicada en el esternón en $50 \%$ de la muestra analizada. Se trata de un tajo de bordes netos que divide uno de los cuerpos del esternón en dos partes (Fig. 24). Este tajo es perpendicular u

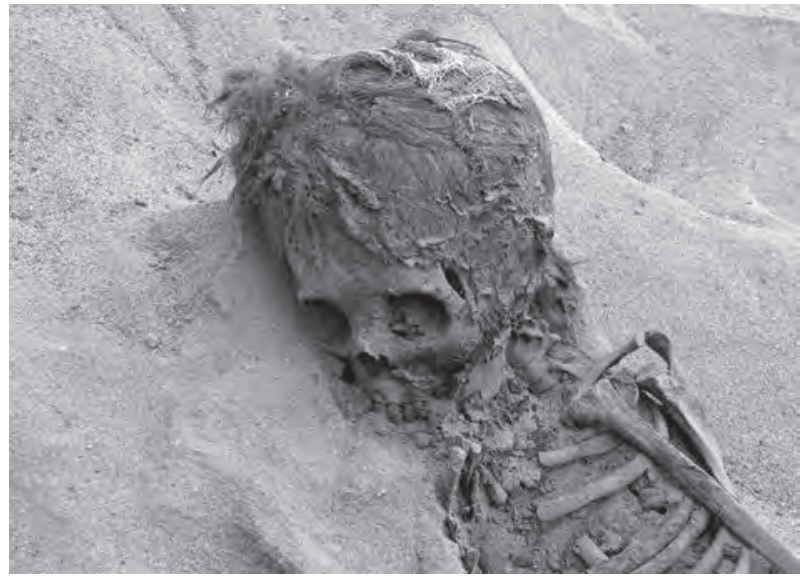

Figura 23. Cabello corto, muy posiblemente un niño varon. Individuo E-9.

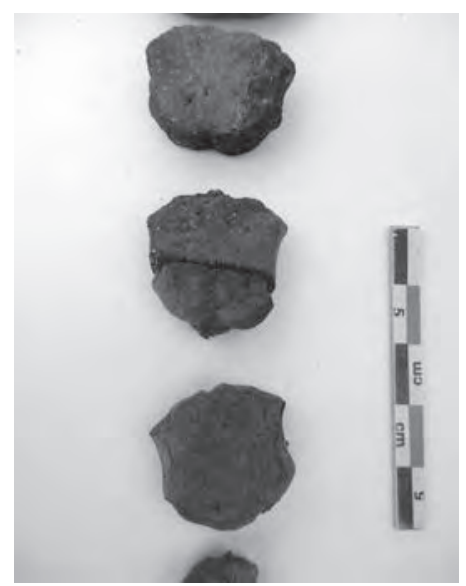

Figura 24. Detalle de corte horizontal en uno de los cuerpos del esternon. 
oblicuo al eje del esternón. Todavía no se han hecho estudios detallados en las costillas o los patrones de ruptura de las mismas, pero durante el trabajo de campo, se advirtió que 30 cuerpos presentaron in situ, una manipulación y remoción intencionada en la parte superior izquierda de la caja torácica (Fig. 25). De este modo, no se puede excluir la posibilidad de remoción de algún órgano interno (Prieto et al. 2012). La práctica de aplicar cortes posiblemente mortales en la caja torácica ha sido reportada por otros investigadores en contextos más o menos contemporáneos de la costa norte del Perú (Verano 1986; Klaus et al. 2010; Toyne 2011).

El sacrificio de estos individuos, muy probablemente varones es muy sugestivo. Por un lado marca una continuidad con la tradición previa de los Moche quienes sacrificaron individuos masculinos aunque de mayor edad, los cuales eran guerreros locales y de otras regiones durante alteraciones climáticas severas que incluyeron lluvias torrenciales (Bourget 2001). Sin embargo no hay evidencia que los niños y adolescentes varones de Huanchaquito-Las Llamas hayan sido guerreros o aprendices para tal oficio. Entonces, ¿se trató de niños y adolescentes comunes o de la elite? ¿Eran ciudadanos de Chan Chan o de otras regiones del estado Chimu? La presencia de dos tocados tipo «pescador» en dos individuos indica que algunos de los sacrificados pudieron pertenecer a grupos de pescadores de las inmediaciones, posiblemente de Huanchaco o pescadores viviendo en la misma ciudad de Chan Chan. Como habíamos indicado arriba, al ser Chan Chan una ciudad cosmopolita, es muy posible que personas de otras regiones incorporadas al sistema estatal Chimu hayan residido en ella, tal como sabemos ocurrió poco después en el Cuzco con los Incas (Rowe 1946). Hasta tener más evidencia, la procedencia o «ciudadanía» de los niños y adolescentes de Huanchaquito-Las Llamas es un misterio.

\section{¿TRES PATRONES SACRIFICIALES EN CHAN CHAN Y EL VALLE DE MOCHE DURANTE EL INTERMEDIO TARDÍO?}

Para el caso del valle de Moche se ha podido determinar que los chimu sacrificaron exclusivamente mujeres adolescentes y jóvenes que acompañaron a los reyes de Chan Chan en sus tumbas (Conrad 1980; Pozorski 1980) ${ }^{6}$. Cabe anotar, no obstante, que recientemente el Dr. Andrew Nelson y su equipo de trabajo a re-estudiado la muestra procedente de la plataforma funeraria de las Avispas, determinando una mayor variedad en la edad y sexo de los individuos de lo que previamente se pensó (Andrew Nelson comunicacion personal, mayo del 2013) A pesar del intenso saqueo que han sufrido las plataformas funerarias de Chan Chan desde el virreinato (Delibes 2012), las excavaciones en estas estructuras han arrojado gran cantidad de huesos disturbados de mujeres jóvenes. Esta práctica ya se había observado en Lambayeque, coincidentemente en las tumbas de los gobernantes (Shimada et al. 2004). Por otro lado, hicimos mención anteriormente a los múltiples hallazgos de niños y adolescentes (aparentemente de ambos sexos) enterrados a manera de ofrendas en los santuarios y huacas alrededor de Chan Chan, e incluso en plataformas asociadas a las grandes lagunas artificiales dentro de los palacios de la ciudad (Montoya 2004). Tomando esto último en consideración, estaríamos ante un triple patrón de género sacrificial muy marcado para la sociedad Chimu de Chan Chan: a) sacrificio de mujeres jóvenes para acompañar a los grandes señores en sus mausoleos b) sacrificios periódicos y constantes de niños y adolescentes (posiblemente de ambos sexos) a los santuarios y «huacas» importantes al interior y que rodeaban la ciudad de Chan Chan (como Arco Iris, Tacaynamo, Cerro Blanco, re-utilización de Huaca de la Luna) y c) en sacrificio extraordinario y masivo de niños y adolescentes varones para otras causas, posiblemente relacionadas con fines estrictamente políticos y asociados a legitimar el poder de la elite Chimu en situaciones extraordinarias de inestabilidad política, social y económica. Esta última categoría implicó (probablemente entre otras prácticas sacrificiales) abrir

6 Cabe indicar que un patrón muy similar ha sido hallado por Izumi Shimada en las tumbas de personajes importantes del sitio de Batan Grande en la región de Lambayeque (Shimada et al. 2004). 
las cajas torácicas de las víctimas, algo que hasta el Intermedio Tardío parece haber sido desconocido en el valle de Moche (Verano 2007). Por tal motivo esta práctica debió ser foránea e introducida de alguna otra región, quizá de una de las conquistadas por los Chimu. Para los dos primeros casos (mujeres jóvenes y niños y adolescentes ofrendados periódicamente), no se ha hecho hasta el momento estudios exhaustivos de antropología física, pero resultados preliminares no indican la presencia de violencia sobre estos cuerpos. María Montoya ha propuesto, en base a experimentos de reacción química en algunas muestras de posibles sacrificios de niños Chimu en Huaca de la Luna, que estos pudieron morir en base a envenenamiento con frutos exóticos como el ishpingo (Nectandra sp.) los cuales coincidentemente fueron hallados siempre asociados a este tipo de contextos (Montoya 2004).

Por otro lado, algo que ha llamado la atención, es que ninguna de las posiciones corporales en Huanchaquito-Las Llamas de ambos grupos (norte y sur) incluye las posiciones de cubito ventral o posiciones que reflejen un escaso tratamiento de los cuerpos como si hubieran sido maltratados o abandonados. Varios contextos del Intermedio Temprano e incluso del Intermedio Tardío muestran este tipo de posiciones, producto de la muerte violenta a la cual fueron sometidos (Verano 1986; 2001 2007; Bourget 2001). Por ejemplo, en el sector noreste del palacio Velarde en Chan Chan, se halló una fosa cuadrangular con 7 cuerpos de adultos los cuales presentaron posiciones y posturas muy atípicas, sugiriendo que fueron arrojados una vez muertos o en proceso de morir a la fosa para ser luego abandonados por un tiempo sin enterrar. Las posiciones indican que fueron enterrados tal como cayeron al hoyo o sin una intención de acomodar el cuerpo (Donnan y Mackey 1978: 363).

Las posiciones de cúbito ventral parecen estar asociadas en el caso Chimu a eventos de ajusticiamiento o muertes súbitas producto de conflictos sociales o posibles revueltas contra el estado (Verano 1986, 2007, 2008). Esta posición y sus variantes han sido ampliamente documentadas en los contextos de Punta Lobos en el valle de Huarmey y en la fosa común de Pacatnamu en el valle de Jequetepeque; siendo ambos contextos relativamente contemporáneos al de Huanchaquito-Las Llamas. Del mismo modo, el patrón de sacrificar mujeres jóvenes en los mausoleos reales de Chan Chan así como los entierros de niños y adolescentes en los santuarios Chimu del valle parecen ser contemporáneos a todas las prácticas sacrificiales mencionadas, indicando un alto índice -sin precedentes en la costa norte- de sacrificios humanos durante el Intermedio Tardío.

\section{EL SACRIFICIO DE LOS CAMÉLIDOS}

En Huanchaquito-Las Llamas, registramos un mínimo de 74 camélidos en muy buen estado de conservación. Fueron depositados en sepulturas individuales, dobles o múltiples, y con individuos humanos (al costado, por debajo, encima). Los encontramos depositados en cuatro posiciones: echado del lado derecho o izquierdo (74.3\%) posición fetal, ventral o dorsal. Muchos presentaban una torsión del cuello que dejó la cabeza de este último en una posición invertida, probablemente para poder depositar el cuerpo dentro de la fosa (Fig. 26, 27 y 28). No hubo una orientación preferencial pero notamos que la mayoría de los camélidos miraban hacia el norte-noreste. Esto último es significativo pues la mayoría de los individuos humanos miraban hacia el norte-noroeste. Podría establecerse que mientras camélidos estuvieron mirando hacia las montañas, los humanos orientaban su mirada hacia el mar.

Para entender los criterios de selección de los animales para el sacrificio, es ideal conocer la edad, el sexo y el color del pelaje de los especímenes. En nuestro caso, el dimorfismo sexual no puede ser identificado a partir del estudio osteológico. La estimación de la edad fue propuesta a partir de la ob-

7 Un fechado no calibrado de la Tumba 7, de filiación Chimu en Huaca de la Luna, podría darnos una fecha tentativa para todo el conjunto de ofrendas Chimu halladas hasta el momento en este sitio tras su abandono a finales del Intermedio Temprano. Esta fecha arrojó un rango de 1440-1665 d.C. (Montoya 2004). Coincidentemente, uno de los extremos de la fecha coincide con las fechas disponibles para el contexto de Huanchaquito - Las Llamas, indicando cierta contemporaneidad o que ocurrieron en un rango muy cercano de tiempo. 


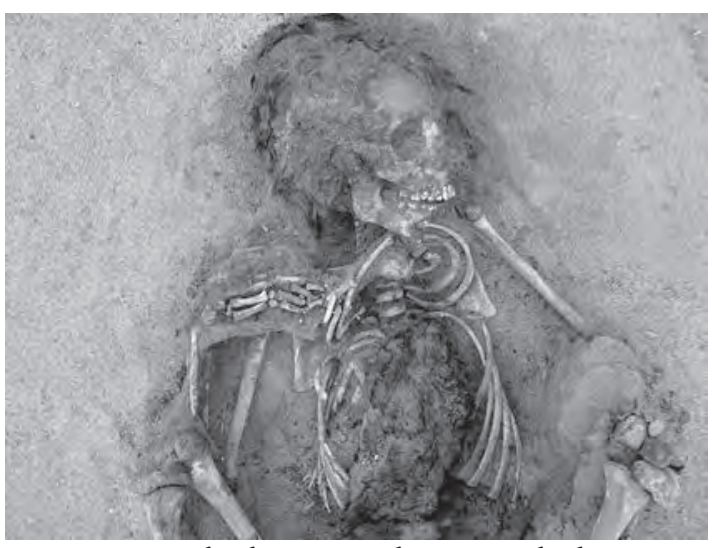

Figura 25. Individuo E-40 en el que se puede observar claramente la manipulacion perimortem de la caja torácica.

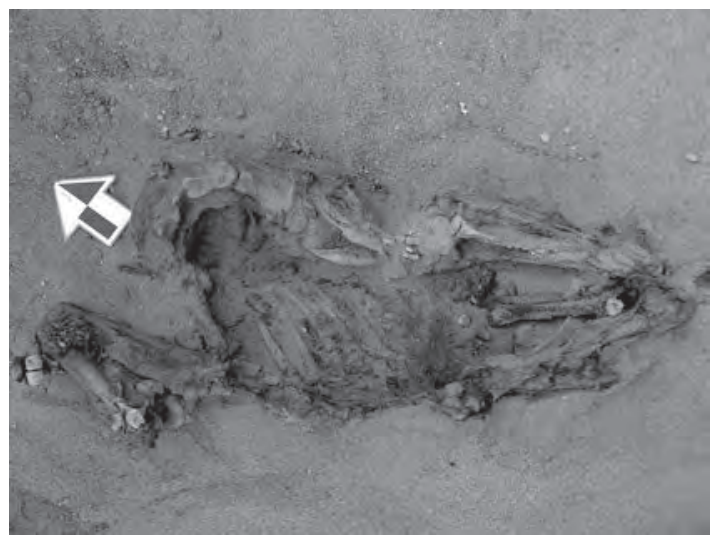

Figura 27. Llama CA-71 en posicion lateral con el cuello doblado en posicion opuesta.

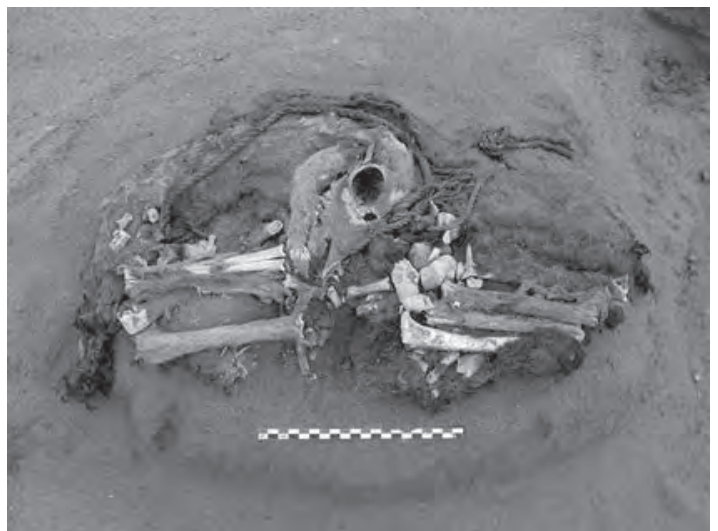

Figura 26. Llama CA-7 en posicion fetal.

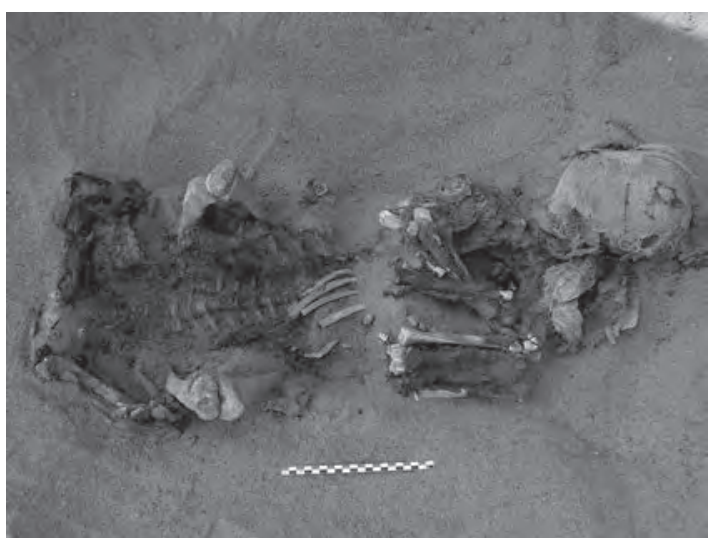

Figura 28. Llama CA-11 en posicion ventral sobre E-10. Notese que ambos estan en la misma posicion.

servación de la erupción dentaria y del desgaste (Wheeler 1982). En este contexto, todos los camélidos eran muy jóvenes, entre 0 y 1 año, lo que indica una selección muy fuerte de los individuos: 72.7\% del corpus tiene entre 0 y 9 meses (Fig. 29). Este dato sugiere también que los animales eran demasiado jóvenes para llegar de la sierra e indica probablemente una crianza local. ¿Venían de rebaños reservados a los rituales (como fue descrito por los cronistas para el imperio Inca)? ¿Estos rebaños fueron controlados por el estado Chimú?

Un elemento excepcional es la conservación de los restos. Casi todos los camélidos presentaban pelaje y pudimos observar, (y es muy raro poder llegar a este nivel de información), los tonos de colores de los animales seleccionados: beige, marrón claro, marrón oscuro y moteados como marrón con manchas beige. El color más frecuente es marrón (35\%) y moteados (38\%). El beige solo fue registrado en $13 \%$ de los camélidos depositados. Después de la corta edad de los especímenes, la preferencia por camélidos de color marrón fue otro criterio de selección en este contexto.

Durante las excavaciones, pudimos registrar la presencia de sogas colocadas alrededor del cuello de los camélidos y de sus extremidades. Fueron hechas con cabuya, una fibra vegetal, y no sirvieron para ahogar los animales, tampoco para transportarlos, sino para mantenerlos firmes probablemente al momento del sacrificio (Figs. 30 y 31). En este tema, no hay claras huellas que permiten determinar la técnica utilizada para matar los camélidos. Si bien se registró varias huellas de corte en los esternones y las costillas, no podemos aun asegurar que son causas de la muerte de los especímenes (Fig. 32). 


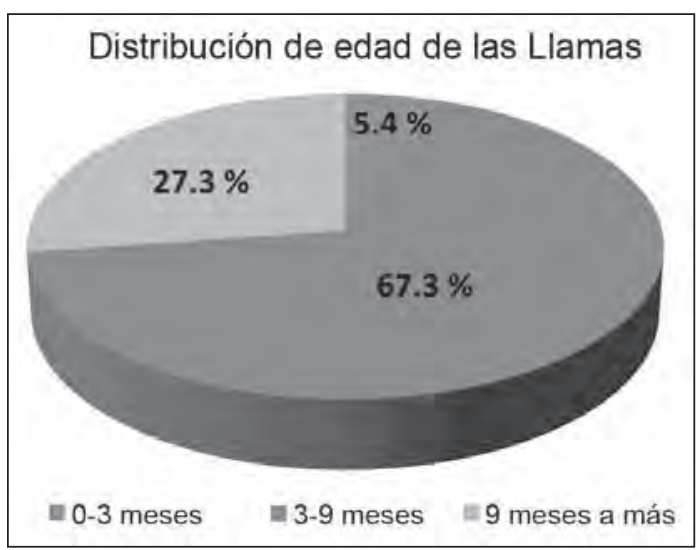

Figura 29. Distribucion de las edades de las llamas registradas en el contexto de sacrificio.

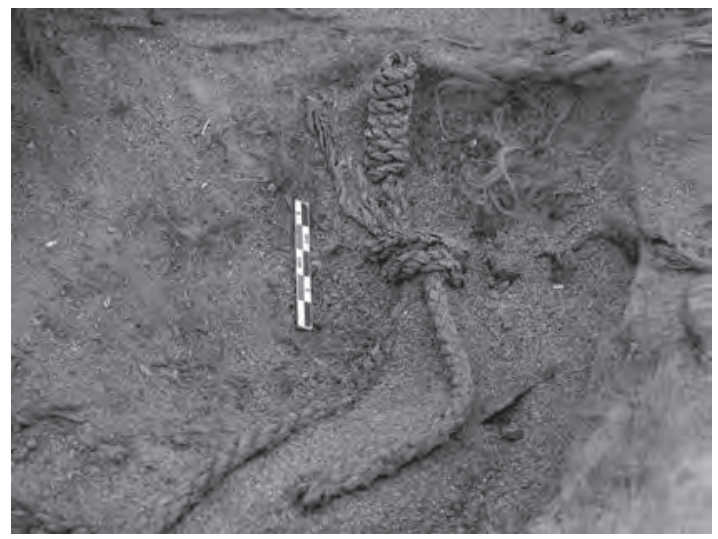

Figura 31. Amarre de soguilla de fibra vegetal del CA-7. Adviertase el detalle para jalar al animal

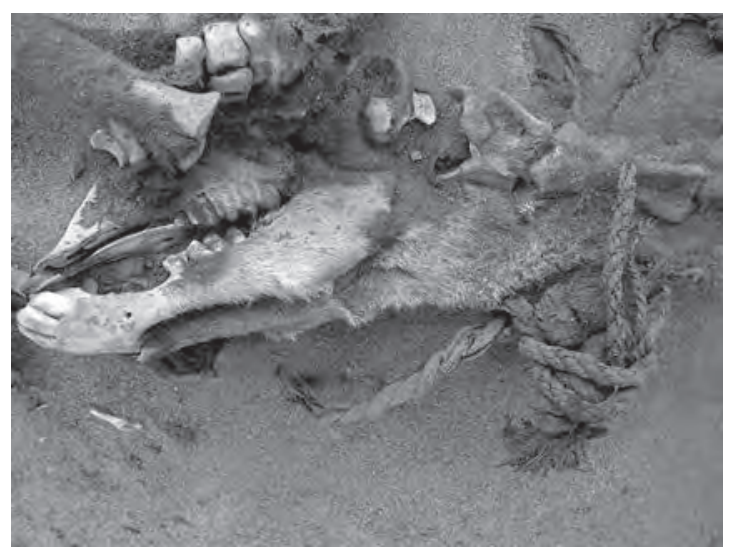

Figura 30. Detalle de CA 32 con soga alrededor del cuello

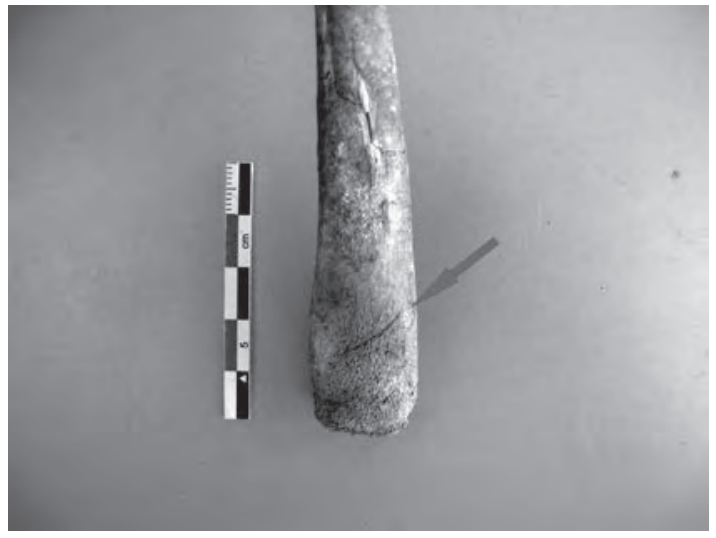

Figura 32. Huella de corte en costilla de llama CA-25. La flecha indica el corte.

Al principio, la presencia de estas huellas de corte en los huesos de los camelidos nos hicieron pensar en una ceremonia similar a la ch'illa (Miller 1977, 1979), es decir la técnica de sacrificio por extracción del corazón o cardiectomía. El oficiante hace una pequeña incisión $(5-10 \mathrm{~cm})$ en la panza del animal para poder pasar su brazo en la caja torácica del animal. Una vez adentro, corta la aorta con su uña y retira el corazón y los pulmones. Pero la ubicación de estas huellas de corte en las partes distales las primeras costillas no concuerde con esa práctica, por lo que aún tenemos que entender el significado de estas marcas. En el caso de las huellas en el esternón, podría ser más cercano y posible pero todas estas hipótesis quedan aún por confirmar.

El registro de micro-restos asociado a los camélidos proporciona otros tipo de datos. Pudimos observar restos vegetales en el pelaje de los camélidos, que corresponden al «cadillo» (Cenchrus echinatus) ${ }^{8}$, pequeña bolitas estrelladas que se pegan al cuerpo cuando se camina en los campos y praderas entre la zona del sacrificio y Chan Chan. Esto nos indica que los animales fueron probablemente criados en las cercanías, entre Chan Chan y Huanchaquito donde había tierras para pastar ganado y de allí mismo fueron traídos al emplazamiento del sacrificio. Por otro lado, la presencia de insectos, en particular pupas

8 Agradecemos las identificaciones botánicas al biólogo Giancarlo Ubillus quien está a cargo de la identificación de todos los restos macro-botánicos del sitio Pampas Gramalote. 
de moscas, indican que después de sacrificar estos individuos, los Chimú, dejaron sus cuerpos expuestos al aire libre antes enterrarlos. Al momento de excavar, recuperamos también gran cantidad de coprolitos y restos intestinales. Todos estos elementos quedan aún por analizar y los resultados proporcionaran datos sobre la dieta de los camélidos sacrificados poco tiempo antes de morir.

\section{¿UN SACRIFICIO ESTATAL «INCLUSIVO»?}

Varios autores han destacado la importancia a nivel geopolítico, económico y social que implicó la conquista de los territorios Chimu por parte de los Incas hacia 1470 d.C. (Rowe 1948; Moseley 1990; Donnan 1990). Del mismo modo se ha planteado la importancia política y económica que implicó para los Chimu conquistar a la sociedad Lambayeque (Heyerdahl et al. 1995). Esta sociedad tuvo un desarrollo político, social y económico sin precedentes y ligeramente anterior al desarrollo de Chimu en el valle de Moche (Shimada 1995). Lo «Lambayeque» (especialmente el Lambayeque Tardío) que fue cuando se construyeron y remodelaron centros como el de Pacatnamu, Túcume, Huaca Chotuna, Huaca Chornancap y tantos otros centros monumentales, son solo una muestra de la complejidad de esta sociedad. En el siglo XVII el agustino Antonio de la Calancha recopiló registros orales de las sucesivas luchas entre los Chimu y los Lambayeque en el valle de Jequetepeque por dominar el escenario político de la costa norte del Perú. Al vencer los Chimu ganaron muchas tierras, producción artesanal, sistemas hidráulicos y el acceso a las redes de distribución de las conchas de spondylus y sus productos derivados (Pillsbury 1996). Si bien es cierto la interacción entre Lambayeque y Chimu no ha sido del todo explorada por los expertos de estas sociedades, es muy posible que el sistema ideológico Lambayeque Tardío haya influenciado de cierta manera al Chimu. Como parte de esta influencia e intercambio de costumbres, tradiciones, sistemas ideológicos, entre otros, es muy posible que los Chimu hayan adoptado las prácticas sacrificiales Lambayeque.

En el caso específico del valle de Moche, el sacrificio masivo de niños y adolescentes con la técnica de abrir la caja torácica no había sido reportado para periodos previos. Sin embargo, en la región de Lambayeque el sacrificio masivo de niños con evidencia de abrir la caja torácica está bien documentada en un contexto Lambayeque Medio Tardío en Cerro Cerrillos (Klaus et al. 2010) y en el centro ceremonial Lambayeque de Chotuna (Carlos Wester, comunicación personal Agosto 2011). En base a esta evidencia y otros contextos más tardíos, se ha propuesto que abrir la caja torácica puede haber estado relacionada a la extracción del corazón (Toyne 2008: 353; Klaus et al. 2010: 1118; Toyne 2011: 515). Dado que en la región Lambayeque se tienen casos cronológicamente más tempranos que muestran este tipo de prácticas sacrificiales, sugerimos que esta práctica sacrificial se pudo originar en la región de Lambayeque durante el periodo Lambayeque Tardío o quizá antes.

En este contexto, tras la conquista Chimu sobre los Lambayeque, la práctica sacrificial de abrir las cajas torácicas pudo haber sido intencionalmente adoptada por el estado Chimu en un intento por incluir en sus actos religiosos-estatales solemnes, elementos de las sociedades que habían conquistado, en un afán por generar una sensación de inclusión y respeto por las tradiciones de los vencidos así como producir una sensación de pertenencia e identidad entre la facción Lambayeque que ahora era parte de «lo Chimu». El uso de prácticas sacrificiales Lambayeque en ceremonias estatales Chimu pudo tener el objeto de conciliar e incluir tradiciones de las regiones conquistadas pero bajo un esquema político y social netamente Chimu ejecutado por el estado que regía el gran centro urbano de Chan Chan.

Sin embargo, queda en discusión la forma en la que se ejecutó el posible corte mortal en los individuos de Huanchaquito-Las Llamas. Los datos de Cerro Cerrillos y de Túcume, indican que el corte se hizo verticalmente o paralelo al esternón, dejando un patrón de cortes verticales en el esternón y otros huesos (Klaus et al. 2010: 1107, Fig. 3). En el caso de Huanchaquito-Las Llamas, el corte es horizontal y oblicuo en el esternón, indicando por un lado que la práctica de abrir cajas torácicas fue adoptada, pero la técnica del corte para el sacrificio no fue o a) bien entendida por los Chimu o b) 
deliberadamente modificada. Alternativamente, podría tratarse simplemente de otra forma de abrir la caja torácica persiguiendo el mismo fin de posiblemente extraer el corazón.

\section{INTERPRETACIÓN: EL EFECTO INVERSO DEL SACRIFICIO: ¿EVITANDO UN DESASTRE CLIMÁTICO Y SOCIO-ECONÓMICO?}

Es posible que este sacrificio masivo haya sido una ofrenda estatal Chimu para apaciguar un posible ENSO ocurrido entre 1400 y 1450 d.C. Durante el registro arqueológico de los contextos de Huanchaquito-Las Llamas se advirtió que sobre la duna de arena había un sedimento grueso de arcilla que fue probablemente acarreado por una fuerte lluvia desde la falda del piedemonte donde se encuentra depositada o recostada la duna de arena. La forma de asociar el sedimento de arcilla al evento de enterrar a los humanos y camélidos está en que las fosas donde se depositaron fueron hechas cortando este sedimento. En las fosas rellenas de arena que cortan el sedimento de arcilla, se ha podido apreciar la intrusión de filtraciones de agua, materializadas por estratos muy finos de un barro arcilloso ubicados al interior de la fosa (Fig. 33). Esto indica que las fosas se hicieron poco después de la deposición de arcilla sobre la arena y más importante aún que durante el momento de entierro de los humanos y camélidos, hubo agua en los alrededores, probablemente una lluvia fuerte, lo que género que esos sedimentos finos de arcilla intruyan en las fosas que estaban en proceso de ser tapadas.

Algunos camélidos fueron depositados directamente sobre el barro húmedo, dejando su huella en él y dejando trazas de agua en los pelajes de las llamas. En varios camélidos, su pelaje estuvo pegado e impregnado de arena reseca, como si se hubiera mojado y luego secado con la arena circundante. También se apreció el contacto de agua con el pelo de los niños y adolescentes.

Entre 1000 y 1470 d.C., el estado Chimu en el valle de Moche experimentó varios eventos ENSO de diferente intensidad, los que aparentemente no alteraron la estabilidad política, económica y social del sistema (Billman y Huckleberry 2008: 109, Fig. 5). Sin embargo se sabe que estos fenómenos climáticos alteraron y destruyeron costosos sistemas de irrigación artificial en campos estatales Chimu

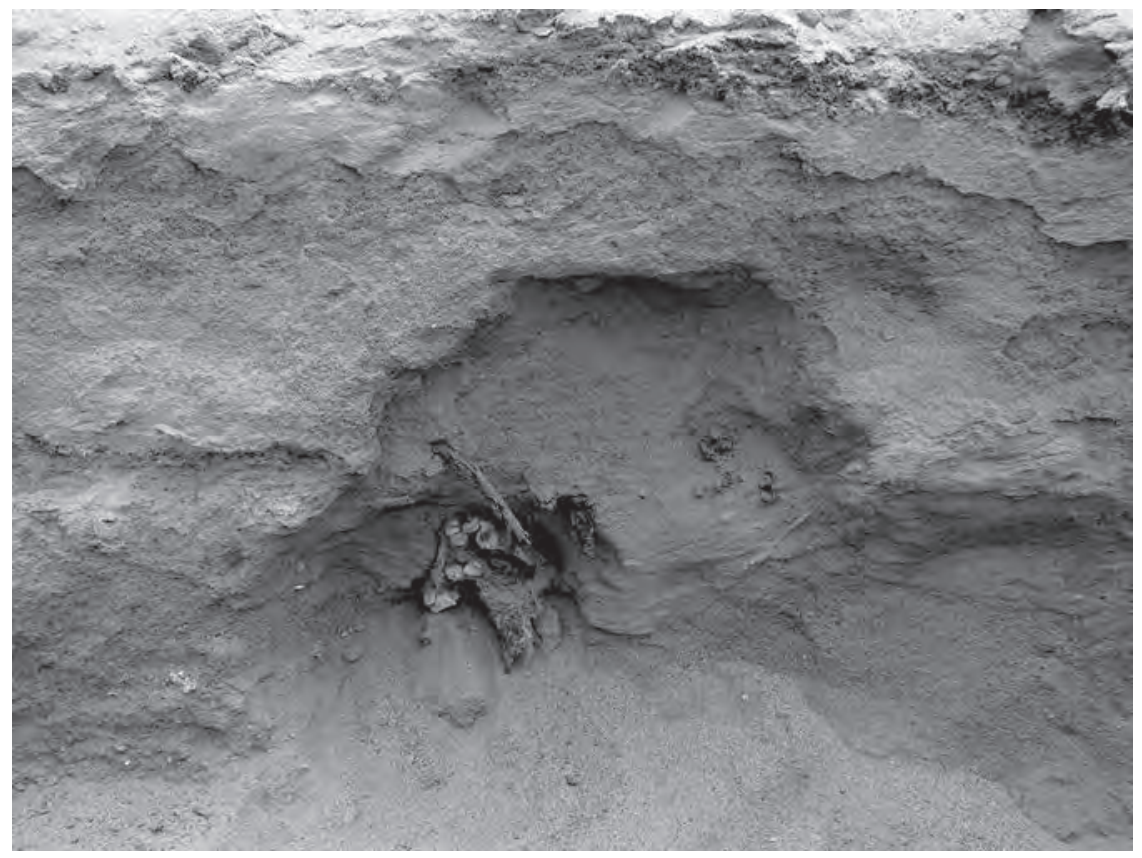

Figura 33. Vista del perfil norte en el que se ve el grueso sedimento cortado por una fosa con llama. 
entre el 1100 y el 1300 d.C. (Farrington y Park 1978). En muchos casos, los canales tuvieron que ser reconstruidos siguiendo diferentes trazos y en otros simplemente fueron abandonados (Kus 1972; Farrington and Park 1978; Ortloff et al. 1983). La gran cantidad de mano de obra invertida para la construcción de dichos canales y el acondicionamiento de los campos debió significar una inversión laboral muy costosa para el estado Chimu. Su perdida repentina durante eventos ENSO por lo tanto debió ser un golpe político y económico severo. Aunque Billman y Huckleberry han argumentado que con la gran cantidad de mano de obra disponible por el estado Chimu los canales y campos podían repararse completamente, la evidencia sugiere que mucha de esta infraestructura fue abandonada y nunca más utilizada, indicando que la capacidad de respuesta del estado Chimu no fue tan contundente como se ha pensado.

En este contexto, un evento ENSO si bien es cierto no conllevó durante el Intermedio Temprano al colapso de Moche (Uceda 2010) ni ciertamente al colapso posterior del estado Chimu, no deja de significar una grave preocupación para el estado que tenía que prever el mantenimiento de infraestructura hidráulica, campos, caminos y también estragos dentro del mismo Chan Chan. Bajo esta perspectiva, quisiéramos proponer que el sacrificio masivo de niños, adolescentes y camélidos jóvenes de Huanchaquito-Las Llamas fue uno de los mecanismos desarrollado por el estado Chimu para apaciguar y disminuir el efecto de un evento ENSO a nivel social e ideológico.

Al parecer, una de las preocupaciones de la elite del estado Chimu era garantizar su continuidad y su legitimidad frente al resto de la población. Al mismo tiempo, como correctamente ha propuesto Roscoe (2008), los eventos ENSO pudieron haber sido utilizados por las entidades políticas tardías del valle de Moche como mecanismos para afianzar su poder y legitimidad «evitando» el desencadenamiento de eventos catastróficos a través, por ejemplo, de eventos sacrificiales masivos como el que venimos describiendo.

En el contexto de la costa norte del Perú, los eventos de lluvias fuertes eran considerados castigos divinos enviados por la mala conducta de los señores y sacerdotes. Es decir, que se reconocía que estos eventos catastróficos eran producidos no por el pueblo, sino por el estado mismo ante su incapacidad de cumplir las normas y tradiciones. Esto se basa en la descripción hecha por Miguel Cabello de Valvoa quien registró en el siglo XVI que uno de los descendientes de Naymlap, al «acostarse» (casarse? establecer una alianza estratégica?) con una mujer de otro pueblo originó que esta mujer influya en modificar las prácticas religiosas tradicionales, introduciendo sus propias creencias y divinidades. En respuesta, se produjeron lluvias torrenciales que duraron muchos días, causando hambruna, destrucción y caos social (Cabello de Valvoa [1586] 1951). Por esta razón, según este cronista los pobladores tomaron acciones inmediatas y mataron al gobernante en falta, ahogándolo y hundiéndolo en el mar, restaurando el orden roto por el y su esposa hereje. Si esta narración se toma por el mensaje que quiere dar, indica que entre los pobladores comunes estaba muy claro que si los gobernantes no hacían su trabajo como era adecuado o alteraban las normas, siempre estaba presente la posibilidad de ser fácilmente depuestos por la masa social. Así, para las elites del estado Chimu puede haber sido muy claro que un evento climático como un ENSO podría ocasionar no solo pérdidas de infraestructura y de carácter económico, sino propiciar revueltas sociales que podrían derivar en una toma de poder, algo así como un golpe de estado. Considerando que los gobernantes y la elite Chimu debieron tener más de un enemigo, es posible entonces que estos hayan estado siempre prevenidos ante cualquier situación que comprometa su continuidad en el poder.

¿Qué interpretación podríamos darle a los elementos utilizados por el estado chimu en la ofrenda sacrificial de Huanchaquito-Las Llamas?

El hecho de sacrificar niños y adolescentes varones en gran número definitivamente es una inversión social alta, dado que estos junto con las niñas y jovencitas, son el futuro que garantiza la reproducción y continuidad social del grupo. Los datos disponibles actualmente para el valle de Moche sugieren la plena disposición de individuos jóvenes para actos sacrificiales. El impresionante número 
propuesto por Conrad (1980) y Pozorski (1980) de 300 mujeres jóvenes sacrificadas para una de las plataformas funerarias de un rey Chimu es muy gráfico. Ahora cabe preguntar, ¿fue esta inversión un costo social mínimo? ¿O es que realmente significó una inversión muy alta que impactó a la sociedad Chimu? Por el momento no podemos responder estas preguntas pero si podemos valorar el número de individuos sacrificados en un solo evento.

Considerando los cráneos alterados previamente a nuestras excavaciones es posible que haya habido un promedio de 60 a 70 individuos sacrificados en Huanchaquito-Las Llamas. El patrón de edad, preferentemente niños y en menor medida adolescentes, indica una alta selectividad y por lo tanto tiene un significado intrínseco casi imposible de descifrar. No obstante, se ha propuesto que el sacrificio de individuos tan jóvenes puede estar relacionado con simbolizar la «regeneración» del ciclo vital y por ende del orden instaurado (Toyne 2008; Klaus et al. 2010). Marla Toyne y Haagen Klaus han referido la cita del agustino Antonio de la Calancha quien indica que en la costa norte se ofrendaban niños a la luna. Si aceptamos que la luna fue una de las divinidades principales del panteón Chimu (Carrion Cachot 1939; Ravines 1980; Mackey 2001), concordamos con que el sacrificio de los niños de Huanchaquito-Las Llamas fue dedicado a la luna. Es muy posible que la luna, al ser la entidad divina más poderosa del cosmos Chimu, haya sido invocada para que controle las lluvias que pudieron haber estado asolando la región en ese momento en particular o para evitar desastres mayores. Por otro lado los adolescentes pudieron haber tenido también un fin específico y posiblemente estén asociados a otra divinidad del panteón Chimu. Con esto no queremos decir que los demás contextos de la costa norte del Intermedio Tardío en los que se han hallado niños sacrificados estén dedicados a la luna. Esta propuesta solo se hace para el caso particular de Huanchaquito-Las Llamas.

La ubicación en la que se hizo el sacrificio es frente al mar y de hecho la mayoría de los niños sacrificados están con los cuerpos orientados o mirando hacia el mar (Tabla 1). Cuando la luna es visible, siempre se oculta por el oeste, es decir por el mar. En este sentido, es posible que una de las razones para emplazar el sacrificio en ese lugar fue para que la luna pueda «apreciar» el evento sacrificial cuando se «ocultaba» por el mar. Esto es particularmente interesante porque sin la necesidad de la ciencia, los pescadores y pobladores tradicionales del valle de Moche saben que los fenómenos ENSO se ocasionan por un calentamiento de las aguas del mar. ¿Podría ser que la ubicación del sacrificio frente al mar sea para recordar a la luna en su diario ingreso/inmersión marina no se olvide de «enfriar» las aguas para reducir las lluvias y el caos climático? El factor de «enfriar» el ambiente también es consecuente con la muerte masiva de varias personas y el efecto que la muerte produce en los cuerpos inertes.

Muchos trabajos previos han enfatizado el uso de conchas de spondylus en ofrendas para «propiciar las lluvias» y garantizar la fertilidad de la tierra (Paulsen 1974). Las conchas de spondylus al provenir de aguas cálidas, trasladaban su temperatura a los dioses para propiciar el aumento de la temperatura en el mar y con ello propiciar las lluvias. Muchos contextos de ofrenda Chimu incluyen conchas de spondylus. Resulta interesante que en el contexto de Huanchaquito-Las Llamas no se ha registrado ni una valva de este apreciado molusco. Es decir, que este factor de ausencia en nuestro contexto reforzaría la propuesta que se trata de un sacrificio orientado a no propiciar las lluvias y posiblemente frenar dicho efecto.

Otro factor que apunta hacia la intención de «enfriar» el ambiente, pueden ser los camélidos. Si bien es cierto los camélidos en la costa norte han sido criados desde el Intermedio Temprano (Vasquez et al. 2003; Goepfert et al. 2013), siempre se les ha asociado a regiones frías y de altitud (Bonavia 1996). Por otro lado, tradicionalmente en la costa se les relaciona a la temporada de vegetación de lomas durante el invierno, en que dichos animales solían bajar de la sierra para pastar en los extensos pastizales estacionales producidos por las lomas (Miller 1977; Inamura 1981). Esta estación se caracteriza por ser relativamente fría, ventosa y con una constante neblina desde la línea de playa hasta las primeras estribaciones andinas. El sacrificio masivo de camélidos puede estar orientado entonces 
a que los espíritus de estos animales propicien un ambiente más frio que haga frenar las lluvias y sus efectos. Probablemente, la asociación de camélidos-frío-invierno puede reforzar la propuesta que este sacrificio fue dedicado a frenar las lluvias y el calentamiento del mar que las estaba generando.

Hay otros factores simbólicos que asocian a los camélidos con el mar. En las creencias andinas, las llamas se consideran hijas de las lagunas las que a su vez están conectadas al mar o mamacocha (Flores Ochoa et al. 1994; Duviols 1993). Las lagunas son lugares de creación, paqarinas, y están vinculadas a los rebaños de llamas y alpacas, y a su fertilidad. En el pasado y hoy en día, en las alturas de los andes, se sacrifican llamas adultas para propiciar las lluvias (Miller 1977). Bajo esta perspectiva, la presencia de llamas jóvenes sacrificadas en una duna de arena junto al mar puede haber simbolizado la intención mitigar las lluvias, en vez de propiciarlas.

Resulta también interesante mencionar que en las famosas narraciones de Huarochirí, se indica la relación de las llamas con diluvios. En un caso una llama le anunció a su pastor que iba a haber un gran diluvio y que por eso estaba triste y no comía. En otro caso, el cronista Cristóbal de Molina recogió un relato en que un hato de llamas dejando de comer y «mirando a las estrellas» interpretaron la proximidad de un diluvio lo que permitió a que la familia de pastores a cargo se protegiera en las cumbres más elevadas y después esta familia pudo repoblar la tierra (Millones y Mayer 2012: 58, 69). En este contexto resulta muy interesante relacionar a las llamas como elementos premonitorios de fuertes eventos de lluvia, con lo cual tendría sentido el sacrificarlas para evitar los efectos catastróficos de estas anomalías climáticas.

Los cronistas españoles Cobo y Molina nos indican que en la sociedad Inca existió un código de colores para la selección de los camélidos en los diferentes ritos religiosos. Así, cada divinidad poseía un color propio: las llamas marrones fueron sacrificados en honor de Viracocha, el dios creador (curiosamente asociado al mar) (Itier 2013), las llamas blancas para Inti, el Sol, y los moteados para Illapa, dios del relámpago. Otro cronista, Polo de Ondegardo señala también que las llamas de color marrón eran sacrificadas entre los meses de agosto y setiembre, al inicio de las siembras (en los Andes); las llamas blancas y negras eran sacrificadas al inicio de mes de octubre para llamar las lluvias, las blancas durante la cosecha en mayo. Así, existía a la vez que un código de color por divinidad también a nivel del calendario.

Otro aspecto a enfatizar es que en el contexto de la costa norte, las llamas son psicopompas, es decir que conducen las almas de los muertos al otro mundo. Bajo esta perspectiva, también estarían representando una función de transporte de los niños y adolescentes con los que fueron enterrados. Esto se relaciona al factor clave de la importancia económica de los camélidos en la sociedad Chimu. A nivel de dieta, los camélidos han cumplido un rol fundamental desde el Intermedio Temprano en el valle de Moche (Vásquez et al. 2003). Durante el Intermedio Tardío los camélidos siguieron siendo la fuente de proteínas más importante al menos en el sitio de Chan Chan (Pozorski 1982: 182). Por otro lado, su uso como medios de transporte y carga, fue fundamental para los intereses Chimu de producción, distribución y consumo de productos suntuarios a lo largo de su territorio. No debe olvidarse que en el contexto de las sociedades tradicionales andinas, la llama es un animal imprescindible en el ciclo vital del hombre y es vital para la construcción de sus rituales y universo mítico (Millones y Mayer 2012: 70). En este contexto, se podría concluir que fuera del aspecto simbólico, tanto niños, adolescentes y camélidos pudieron haber sido considerados los elementos más valiosos de la sociedad Chimu desde el punto de vista social y económico. En este contexto, su sacrificio debió realizarse por una razón muy importante.

\section{UN GRAN EVENTO SACRIFICIAL?}

Desde el inicio de este artículo hemos enfatizado la magnitud y escala de este evento sacrificial sin precedentes en la costa norte del Perú y el área andina en general. Hemos indicado que aparte de 
los 43 humanos y 74 camélidos, muchos otros fueron disturbados antes de nuestra intervención y afortunadamente aún quedan varios contextos con humanos y camélidos por excavar en el sitio de Huanchaquito-Las Llamas. Conservadoramente podemos estar refiriéndonos a un contexto que pudo contener originalmente unos 60 a 70 humanos y aproximadamente 100 camélidos sacrificados. En la costa norte existen contextos con mayor número de humanos sacrificados, como por ejemplo el caso de Cerro Cerrillos, Túcume y Punta Lobos (Klaus et al. 2010; Toyne 2011; Verano 2007). Sin embargo en los primeros dos casos se trata de una acumulación de sacrificios humanos y de camélidos a lo largo de 200 a 300 años. En el caso de Punta Lobos, es muy posible que haya sido un solo evento pero está enmarcado en un contexto de «ajusticiamiento» por parte del estado Chimu en contra de la población local. John Verano ha sugerido que estos individuos fueron sacrificados para «castigar» una rebelión local contra el estado Chimu en el valle de Huarmey (Verano 2007). Si esto es correcto, entonces el contexto de Punta Lobos no encajaría del todo en un contexto de sacrificio ritual-religioso?.

Por otro lado, en varias regiones del Perú se han hallado ofrendas masivas de camélidos. Por ejemplo en sitio de San José de Moro en el valle de Jequetepeque, se hallaron asociados a un contexto Mochica Tardío cráneos y extremidades de camélidos principalmente menores a 2 años llegándose a contabilizar en base a NMI 78 individuos (Goepfert 2011). Sin embargo estos no estuvieron completos y las huellas de cortes sugieren que fueron consumidos en banquetes rituales, siendo su presencia en contexto ocupacional de «descarte ritual» tras su consumo en un evento especial posiblemente asociado al culto a los ancestros. Otro caso es el de Cahuachi en Nazca donde se hallaron 64 camélidos en contexto de ofrenda (Orefici 1994). En el mismo Chan Chan, asociado a la plataforma funeraria del palacio Laberino (Las Avispas), se registró en uno de los patios (patio oeste) «abundantes» huesos de camélidos que parecen haber sido parte de ofrendas (Conrad 1980: 219; Pozorski 1980: 242). Recientemente en Huaca de la Luna se ha registrado un evento de ofrenda Chimu en la Plaza 1 donde se han hallado 48 camélidos en una posición y distribución muy similar a la de Huanchaquito-Las Llamas (Tufinio 2006; Meneses et al. 2010). Sin embargo, ninguno de los contextos descritos, coincide con la escala y configuración al de Huanchaquito-Las Llamas reafirmando que se trata de una nueva modalidad identificada de sacrificio masivo durante el Intermedio Tardío en el contexto de la costa norte del Perú.

Quisiéramos sugerir, que este contexto sacrificial pudo ser mucho mayor (en escala) a lo que hemos propuesto. Esto se basa en que los tres contextos que describiremos a continuación comparten los siguientes elementos: a) se trata de niños y adolescentes; b) tienen asociados llamas jóvenes de menos de un año de edad y ningún otro tipo de ofrendas; c) generalmente están dispuestos en un contexto horizontal a la misma profundidad abarcando un área moderadamente amplia, con un patrón de ordenamiento y a escasa profundidad; d) no están asociados directamente a estructuras arquitectónicas tipo huacas y e) están muy cerca del mar, por lo general en zonas arenosas.

En 1968 Christopher Donnan excavó al sur de la iglesia colonial de Huanchaco (y a escasos 3 km. del sitio de Las Llamas) un contexto sacrificial muy similar, conformado por 17 humanos entre los $6 \mathrm{y}$ 12 años de edad y 20 camélidos menores a un año de edad. El contexto no se terminó de excavar y muchos huesos ya habían sido alterados por huaqueros antes de su excavación científica. Los patrones de enterramiento son casi idénticos así como el perfil de las víctimas. Más interesante aún resulta que el fechado proporcionado data de 1405 d.C. (UCLA-1879, sin calibrar) (Donnan y Foote 1978: 399, 403). Cuando se le enseño el material fotográfico de Huanchaquito-Las Llamas al Dr. Donnan, este indicó que eran idénticos a lo que el excavó en 1968, sugiriendo que podría tratarse del mismo evento histórico dada su contemporaneidad, cercanía y similitud (Christopher Donnan, comunicación personal agosto del 2011). Coincidentemente, durante recientes trabajos de excavación arqueológica en el sitio de Pampa La Cruz-La Poza ubicado inmediatamente al sur donde Donnan y Foote hallaron su contexto, se registraron en una de las áreas excavadas 5 camélidos entre 0 y 9 meses de edad asociados

9 Sin embargo, John Verano (2007) cita a Héctor Walde quien cree que pudo tratarse de una ofrenda Chimu al mar. 
a un niño (Fig. 34). Muy cerca de ellos se halló un paquete envuelto en una tela llana de algodón conteniendo hasta tres juegos de vestuarios de niños varones conformados por un tocado, camiseta y taparrabo (Prieto y Campaña 2013). La naturaleza restringida de las excavaciones no permitió extender el área, pero en los perfiles se advirtieron más restos de camélidos y humanos. Este hallazgo se encuentra a su vez a $2.5 \mathrm{~km}$. al norte del sitio de Huanchaquito-Las Llamas, entre este punto y el hallazgo de Donnan y Foote (Fig. 35). Aun no contamos con un fechado absoluto de los camélidos registrados en Pampa La Cruz - La Poza, pero el contexto ocupacional era claramente Chimu. ¿Son estos tres con-

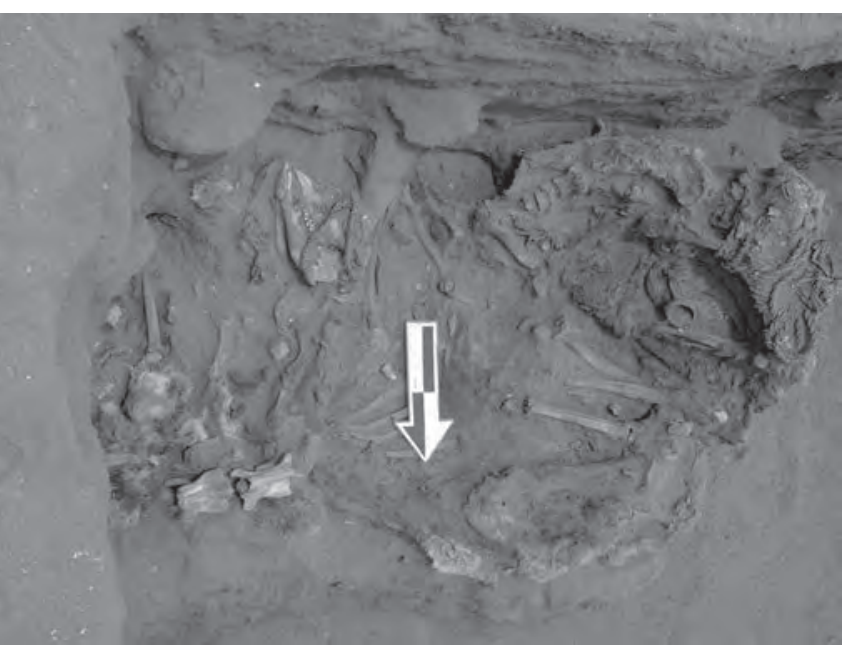

Figura 34. Conjunto de 5 camelidos hallados en el sitio de Pampa La Cruz - La Poza en Huanchaco. textos en los que se han hallado humanos y camélidos con similares perfiles de edad y forma de muerte parte de un mega-contexto sacrificial emprendido por el estado Chimu ante un evento de crisis? ¿O es que son acaso el resultado de una ceremonia institucionalizada llevada a cabo periódicamente por los Chimu? ¿Se trata de eventos realizados en un lapso de tiempo corto -50 años quizá- para propiciar la estabilidad climática y social en el valle?

Estas preguntas y las otras interrogantes previamente planteadas en este artículo direccionarán nuestras investigaciones en los próximos años para aproximarnos más a la naturaleza de estos contextos. Del mismo modo, dado que tenemos la oportunidad de trabajar con contextos contemporá-

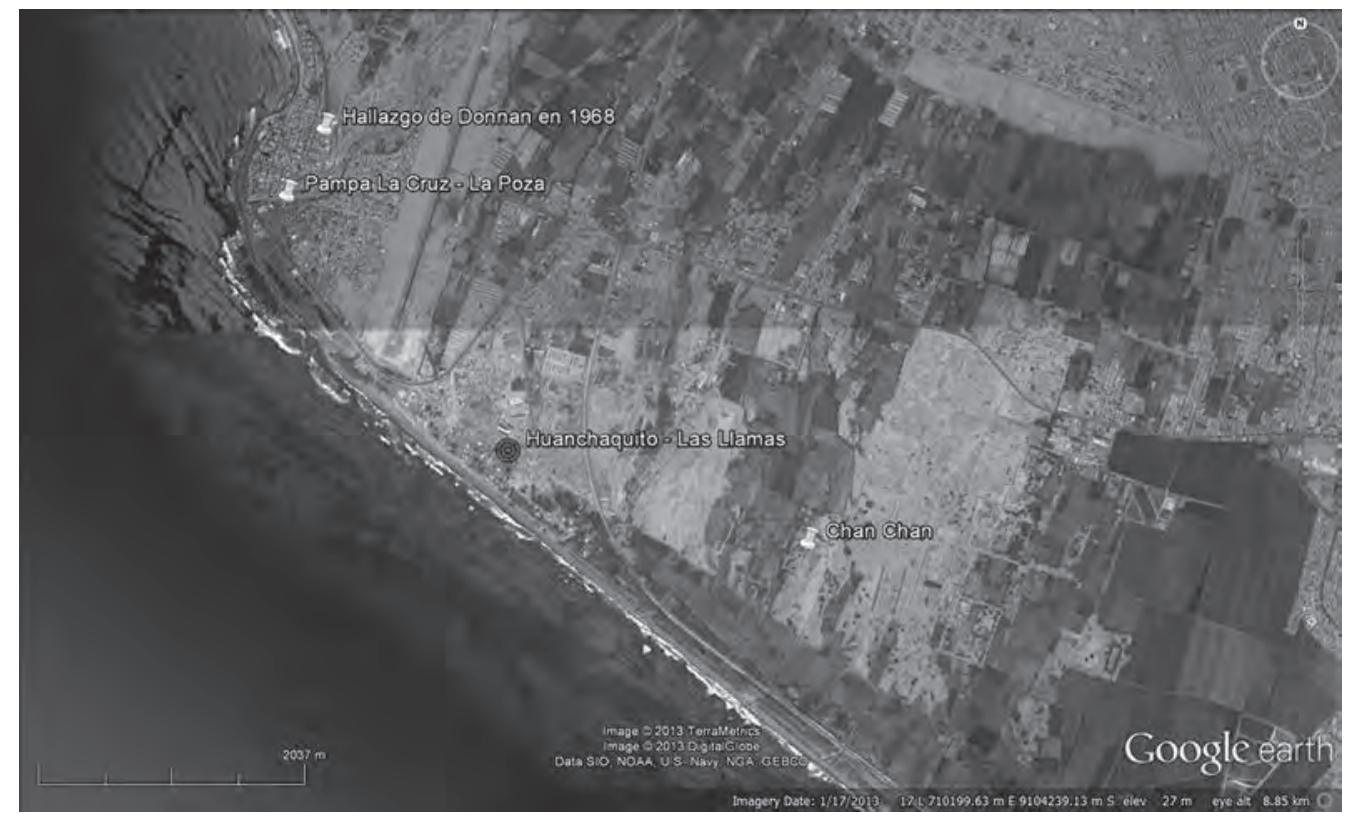

Figura 35. Vista satelital de los tres sitios en los que se hallan contextos sacrificiales similares. 
neos y similares de sitios distintos en un área restringida, podremos expandir nuestro conocimiento en torno a estas prácticas, hasta el momento desconocidas para la sociedad Chimu del valle de Moche. Quizá toda el área que rodea a Chan Chan, es decir los extramuros de la ciudad, fue articulada como un espacio sagrado previamente planificado y donde se realizaron ceremonias y festines que recién estamos empezando a descubrir, mientras que muy posiblemente otros se hayan perdido bajo los campos de cultivo modernos y la expansión urbana de Trujillo y Huanchaco.

Nuestra propuesta de ser este evento sacrificial el resultado de una respuesta inmediata del estado a una crisis originada por una alteración climática así como un mecanismo de coerción y legitimación debe considerarse dado que al no realizarse dentro de las grandes plazas de Chan Chan, sino en las afueras de la ciudad, tuvo quizá la intención que todos los pobladores observen dichos eventos en los que numerosas personas y animales perdían la vida a favor de garantizar la estabilidad social, política y económica del valle.

\section{Agradecimientos}

Los autores de este artículo están particularmente agradecidos al poblador de Huanchaquito quien tuvo la insistencia de hacernos visitar el área en que se halló este fabuloso contexto y a su esposa quien durante los tres meses de trabajo proporcionó alimentos y refrescos a los arqueólogos, estudiantes de arqueología y trabajadores que participaron en las excavaciones. Un agradecimiento especial al Dr. John Verano y al Dr. Andrew Nelson quienes leyeron versiones previas de este manuscrito y aportaron con importantes comentarios y sugerencias. También estamos muy agradecidos al Sr. Enrique Sánchez-Maura, ex director de la Dirección Regional de Cultura de La Libertad, quien personalmente llevó a cabo los trámites en la sede de Lima del Ministerio de Cultura para que sea aprobado el proyecto de emergencia y de esta manera poder trabajar de acuerdo a ley tan importante sitio. Del mismo modo al arqueólogo asignado por su despacho, Lic. Juan Vilela (co-autor en este artículo) quien asumió la responsabilidad de firmar el proyecto de emergencia. Del mismo modo, estamos muy agradecidos a María del Carmen Vega y Mellisa Lund quienes nos brindaron su apoyo para realizar los primeros trabajos de excavación y análisis de antropología física. Los autores quieren agradecer a Sheba Schilk, responsable de las excavaciones y laboratorio de este proyecto y a todos los estudiantes de arqueología de la Universidad Nacional de Trujillo quienes trabajaron arduamente en el sitio de principio a fin. Finalmente queremos expresar un agradecimiento muy especial al Ing. Fernando Bazán Pinillos, alcalde del Distrito de Huanchaco quien nos dio apoyo logístico (seguridad, transporte) y recursos económicos para realizar la excavación y los primeros trabajos de laboratorio, así como el pago de los trabajos de levantamiento topográfico del sitio. El trabajo conjunto de rescate que se hizo en Huanchaquito-Las Llamas entre investigadores, Ministerio de Cultura y la Municipalidad Distrital de Huanchaco muestran que podemos - juntos- rescatar nuestro patrimonio del abandono y olvido en que gran parte de él se encuentra. Finalmente, queremos agradecer a todos los investigadores asociados a este proyecto que vienen trabajando con los materiales excavados y quienes en el mediano plazo, estarán dándonos más luces sobre este fascinante descubrimiento. 


\section{BiBLIOGRAFíA}

ALVA, Walter

1999 Sipán. Descubrimiento e Investigaciones. Edición del autor, versión resumida de la edición de Backus y Johnston S.A.A. de 1994. Lima Perú.

ANHUAMÁN, Pedro

2008 Cultura Viva Muchik-Chimor de la Costa Norte del Perú. Historia, Tradiciones, Leyendas y Personajes. Una visión endógena. Trujillo.

BAWDEN, Garth

1996 The Moche. Cambridge: Blackwell.

BILLMAN, Brian

1996 The Evolution of Prehistoric Political Organizations in the Moche Valley, Peru. Unpublished Doctoral Dissertation submitted to the Department of Anthropology, University of Santa Barbara.

BILLMAN, Brian y Gary HUCKLEBERRY

2008 «El Niño events on the north coast of Peru». En: D. Sandweiss y J. Quilter (eds.) El Niño, catastrophism and culture change in ancient America. Pp. 101-128. Washington D.C.: Dumbarton Oaks.

BONAVIA, Duccio

1996 Los Camélidos sudamericanos. Una introducción a su estudio, Travaux de l'Institut Français d'Études Andines (IFEA), tome 93, Lima: IFEA-UPCH-Conservación International.

BOURGET, Steve

2001 «Children and Ancestor: Ritual Practices at the Moche site of Huaca de la Luna, North Coast of Peru». En: E. Benson y A. Cook (eds.) Ritual Sacrifice in Ancient Peru. Pp. 93-119. Austin: University of Texas Press.

1997a «Las Excavaciones en la plaza 3A». En: S. Uceda, E. Mujica y R. Morales (eds.) Investigaciones en Huaca de la Luna 1995. Pp. 51-59. Facultad de Ciencias Sociales, Universidad Nacional de Trujillo.

1997b «Excavaciones en el Cerro Blanco». En: S. Uceda, E. Mujica y R. Morales (eds.) Investigaciones en Huaca de la Luna 1995. Pp. 108-123. Facultad de Ciencias Sociales, Universidad Nacional de Trujillo.

CABELLO DE VALBOA, Miguel

1951 [1586] Miscelánea Antártica. Una Historia del Perú Antiguo. Universidad Nacional Mayor de San Marcos. Facultad de Letras. Instituto de Etnología. Lima, Perú.

CAMPANA, Cristóbal

2008 «La Vida en Chan Chan: Representación y comunicación». Revista del Museo de Arqueología, Antropología e Historia de la Universidad Nacional de Trujillo 8: 11-22. Facultad de Ciencias Sociales, Trujillo.

2006 Chan Chan del Chimo: estudio de la ciudad de adobe más grande de América antigua. Editorial Orus.

CARRION-CACHOT, Rebeca

1939 «La Luna y su personificación ornitomorfa en el arte Chimu». Actas y Trabajos del XXVII Congreso Internacional de Americanistas, Tomo II. Pp. 571-587. Lima, Perú.

CONKLIN, William

1990 «Architecture of the Chimu: Memory, Function and Image». En: M. Moseley y A. Cordy-Collins (eds.) The Northern Dynasties: Kingship and Statecraft in Chimor, pp. 43-74. Washington D.C.: Dumbarton Oaks.

CONRAD, Geoffrey

1980 «Plataformas funerarias». En: R. Ravines (ed.) Chan Chan, Metropoli Chimu. Pp. 217-230. Instituto de Estudios Peruanos (IEP). Lima, Perú.

CORDY-COLLINS, Alana

2001 «Decapitation in Cupisnique and Early Moche Societies». En: A. Cook y E. Benson (eds.) Ritual Sacrifice in Ancient Peru. Pp. 21-33. Austin: University of Texas Press.

1992 «Archaism or Tradition?: The Decapitation Theme in Cupisnique and Moche Iconography». Latin American Antiquity 3(3): 206-220. 
CUTRIGHT, Robyn

2011 «Food for the Dead, Cuisine for the Living: Mortuary Food Offerings from the Jequetepeque Valley, Peru». En: C.M. Zori e I. Johnson (eds.) From State to Empire in the Prehistoric Jequetepeque Valley, Peru. Pp. 83-92. British Archaeological Reports (BAR) International Series 2310, Oxford.

2010 «Food, Family and Empire: Relating Political and Economic Domestic Change in the Jequetepeque Hinterland». En: R.E. Cutright, E. Lopez-Hurtado y A.J. Martin (eds.) Comparative Perspectives on the Archaeology of Coastal South America. Pp. 27-44. Center for Comparative Archaeology. Department of Anthropology, University of Pittsburgh.

DELIBES, Rocío

2012 Desenterrando tesoros en el siglo XVI: Compañías de Huaca y participación indígena en Trujillo del Perú. Secretariado de Publicaciones de la Universidad de Sevilla; Madrid, Consejo Superior de Investigaciones Científicas.

DONNAN, Christopher

1990 «An Assessment of the validity of the Naymlap Dynasty». En: M. Moseley y A. Cordy-Collins (eds.) The Northern Dynasties: Kingship and Statecraft in Chimor. Pp.243-274. Washington D.C.: Dumbarton Oaks.

DONNAN, Chritopher and Leonard FOOTE

1978 «Child and Llama Burials from Huanchaco». En: C. Donnan y C.J. Mackey (eds.) Ancient Burial Patterns of the Moche valley. Pp. 399-408. Austin: University of Texas Press.

DONNAN, Christopher B. y Carol J. MACKEY

1978 Ancient Burial Patterns of the Moche Valley, Peru. Austin: University of Texas Press.

DONNAN, Christopher y Donnan MCCLELLAND

1999 Moche fineline painting: its evolution and its artist. UCLA Fowler Musem of Cultural History.

DUVIOLS, Pierre

1993 Religions des Andes et langues indigee: Equateur, Perou, Bolivie, avant et après la conquete espagnole: actes du colloque III d'etudes andines. Universite de Provence.

FARRINGTON, Ian y C.C. PARK

1978 «Hydraulic Engineering and Irrigation Agriculture in the Moche Valley, Perú: c. A.D. 1250-1532». Journal of Archaeological Science 5: 255-268.

FLORES OCHOA, Jorge A., Kim MacQUARRIE y Javier PORTUS

1994 Oro de los Andes. Las Llamas, Alpacas, Vicuñas y Guanacos de Sudamérica, , Jordi Blassi, 2 volumen,. Barcelona.

GLENDON, Weir y Herbert ELING

1989 «Pollen evidence for economic plant utilization in prehistoric agricultural fields of Jequetepeque valley». En: R. Matos, S.A. Turpin y H. Eling (eds.) Andean Archaeology. Papers in memory of Clifford Evans. Monograph XXVII. Pp. 150-162. Institute of Archaeology. L.A.: University of California.

GOEPFERT Nicolas

2012 «New zooarqueological and funerary perspectives on Mochica Culture (100-800 A.D.), Peru». Journal of Field Archaeology, n³7(2): 104-120.

2011 Frayer la route d'un monde inversé. Sacrifice et offrandes animales dans la culture Mochica (100-800 apr. J.-C.), côte nord du Pérou, Paris Monographs in American Archaeology 28, B.A.R. (British Archaeological Reports) International Series 2278.0xford.

2010 «Llama and deer : food and symbolical dualism in the Central Andes area». Anthropozoologica, $\mathrm{n}^{\circ} 45$ (1): 25-41.

2008 «Ofrendas y sacrificio de animales en la cultura mochica: el ejemplo de la Plataforma Uhle, Complejo Arqueológico Huacas del Sol y de la Luna». En: L.J. Castillo, H. Bernier, G. Lockard y J. Rucabado (eds.) Arqueología Mochica. Nuevos Enfoques. Actas del Primer Congreso Internacional de Jóvenes Investigadores de la Cultura Mochica, Lima, 4-5 de agosto de 2004. Lima: IFEA-PUCP. Pp. 231244. 
GOEPFERT, Nicolas y Gabriel PRIETO

2012 «Offering Lamas to the Sea: The Economic and Ideological Importance of Camelids in Chimu Society, North Coast of Peru». Paper presented to the 111st Annual Meeting of the American Anthropological Association (AAA). Symposim «Recent Anthropological Perspectives on Past and Present Andean Pastoralism». Del 14 al 18 de noviembre del 2012. San Francisco, USA.

GOEPFERT Nicolas, Elise DUFOUR Belkys GUTIÉRREZ y Claude CHAUCHAT

2013 «Origen geográfico de camélidos en la época mochica (100-800 AD) y análisis isotópico secuencial del esmalte dentario: enfoque metodológico y aportes preliminares». Bulletin de l'Institut Français d'Etudes Andines 42(1).

HEYERDAHL, Thor, Daniel SANDWEISS y Alfredo NARVAEZ

1995 Pyramids of Túcume. The quest for Peru's forgotten city. N.Y.: Thames and Hudson.

HORKHEIMER, Hans

1944 Vistas Arqueológicas del Noroeste del Perú. Instituto Arqueológico de la Universidad Nacional de Trujillo.

INAMURA, Tetsuya

1981 «Adaptacion Ambiental de los pastores altoandinos en el sur del Peru. Simbiosis economico-social con los agricultores». En: S. Masuda (ed.) Estudios Etnograficos del Peru Meridional. Pp. 65-84. Universidad de Tokio.

ITIER, Cesar

2013 Viracocha o El Oceano. Lima. IFEA - IEP.

KEATINGE, Richard

1975 «Urban settlement systems and rural sustaining communities: an example from Chan Chan's hinterland». Journal of Field Archaeology 2: 215-227

KLAUS, Haagen, Jorge CENTURION y Manuel CURO

2010 «Bioarchaeology of human sacrifice: violence, identity and the evolution of ritual killing at Cerro Cerrillos, Peru». Antiquity 84: 1102-1122.

KLYMYSHYNG, Ulana

1982 «Elite Compounds in Chan Chan». En: M.E. Moseley y K. Day (eds.) Chan Chan Andean Desert City. pp. 119-143. A School of American Research Book. Albuquerque: University of New Mexico Press.

KOLATA, Alan

1990 «The Urban Concept of Chan Chan». En: M. Moseley y A. Cordy-Collins (eds.) The Northern Dynasties: Kingship and Statecraft in Chimor. Pp. 107-144. Washington D.C.: Dumbarton Oaks.

1978 Chan Chan: The Form of the City in Time. Unpublished dissertation presented to the Department of Anthropology, Harvard University.

KUS, James

1980 «La agricultura estatal en la costa norte del Perú». América Indígena 40: 713-729.

1972 Selected Aspects of Irrigated Agricultura in the Chimu Heartland, Peru. Unpublished Ph.D. dissertation, University of California, Los Angeles.

MACKEY, Carol

2005 «La Transformación socioeconómica de Farfán bajo el gobierno Inka». Boletín de Arqueología PUCP Nro. 7, P. Kaulicke y T. Dillehay (eds.). Pp. 321-353. Lima: PUCP.

2004 «La Ocupación de dos Centros Administrativos en el Valle de Jequetepeque: El Algarrobal de Moro y Farfán». En: L. Valle Álverez (ed.) Desarrollo Arqueológico de la Costa Norte, Tomo II . Pp. 75-88. Trujillo: Editorial SIAN.

2001 «Los Dioses que Perdieron los Colmillos». En: K. Makowski (ed.) Los Dioses del Antiguo Peru, Vol II: 111-157. Lima.

1987 «Chimu administration in the provinces». En: J. Haas, S. Pozorski y T. Pozorski (eds.) The Origins and development of the Andean state. Pp. 121-129. Cambridge University Press. 
MACKEY, Carol y Ulana KLYMYSHING

1990 «The southern frontier of the Chimú Empire». En: M. Moseley y A. Cordy-Collins (eds.) The Northern Dynasties: Kingship and Statecraft in Chimor. Pp.195-226. Washington D.C.: Dumbarton Oaks.

MENESES, Jorge, Sofía LINARES, José GOMEZ y Margarita PEÑARANDA

2010 «Excavaciones en el Frontis Norte y en la Plaza 1 de la Huaca de la Luna». En: S. Uceda y R. Morales (eds.) Proyecto Arqueológico Huaca de la Luna. Informe Técnico 2009. Pp. 51-96. Facultad de Ciencias Sociales, Universidad Nacional de Trujillo.

MILLER, George R.

1979 An Introduction to the Ethnoarchaeology of the Andean Camelids, Berkeley, University of California, $\mathrm{PhD}$ en Antropología.

1977 «Sacrificio y beneficio de camélidos en el sur del Perú». En: J. Flores Ochoa (ed.) Pastores de puna. Uywamichiq punarunakuna. Pp. 193-210. Lima: IEP.

MILLONES, Luis y Renata MAYER

2012 La Fauna Sagrada de Huarochirí. Lima: IFEA - IEP.

MONTOYA, María

2004 «Complejo de ofrendas rituales y su asociación a sacrificios humanos de niños en la época Chimu en el valle de Moche». En: L. Valle Álvarez (ed.) Desarrollo Arqueológico. Costa Norte del Perú, Tomo II. Pp. 27-48. Trujillo: Ediciones SIAN.

MOORE, Jerry

2008 «El Periodo Intermedio Tardío en el Departamento de Tumbes». Revista del Museo de Arqueologia, Antropología e Historia 10: 155-174. Universidad Nacional de Trujillo, Facultad de Ciencias Sociales.

1992 «Patterns and Meaning in Prehistoric Peruvian Architecture: The Architecture of Social Control in the Chimu State». Latin American Antiquity 3(2): 95-113.

MOORE, Jerry y Carol MACKEY

2008 «The Chimu Empire». En: H. Silverman y W. Isbell (eds.) The Handbook of South American Archaeology. Pp. 783-806. NY: Springer.

MOSELEY, Michael

2001 The Incas and their Ancestors. Thames and Hudson press.

1990 «Structure and History in the Dynastic Lore of Chimor». En: M. Moseley y A. Cordy-Collins (eds.) The Northern Dynasties: Kingship and Statecraft in Chimor. Pp.1-41. Washington DC: Dumbarton Oaks.

1975 The maritime foundations of Andean civilization. Cummings Archaeology Series. Menlo Park, California.

MOSELEY, Michael y Kent C. DAY

1982 Chan Chan Andean Desert City. Michael E. Moseley y Kent Day, editors. A School of American Research Book. Albuquerque: University of New Mexico Press.

MOSELEY, Michael y Carol J. MACKEY

1973 «Chan Chan, Peru's Ancient City of Kings». National Geographic 143(3), 318-345.

ORBEGOSO, Milagros, Liz RAMIREZ y Lucy CHUMBE

2012 «Excavaciones en el Frontis Norte y en la Plaza 1 de Huaca de la Luna». En: S. Uceda y R. Morales (eds.) Proyecto Arqueológico Huaca de la Luna. Informe Técnico 2011. Pp. 129-214. Facultad de Ciencias Sociales, Universidad Nacional de Trujillo.

OREFICI, Giuseppe

1994 «El recinto de los Camélidos». Documentos de trabajo. Memorias del VI Congreso de la FIEALL (Varsovia 23 mai-2 juin 1993), CESLA-Universidad de Varsovia, pp. 49-53.

ORTLOFF, Charles

1981 «La Ingeniería Hidraúlica Chimú (parte I): el sistema de canales La Cumbre». En: H. Lechtman y A.M. Soldi (eds.) La Tecnología en el mundo andino. Pp. 91-111. México DF: Universidad Autónoma de México.

ORTLOFF, Charles, Michael MOSELEY y Robert FELDMAN

1983 «The Chicama-Moche Intervalley Canal: Social Explanations and Physical Paradigms». American Antiquity 48(2): 375-389. 
PAULSEN, Allison

1974 «The Thorny Oyster and the Voice of God: Spondylus and Strombus in Andean Prehistory». American Antiquity 39(4): 597-607

PILLSBURY, Joan

1996 «The Thorny Oyster and the Origins of Empire: Implications of Recently Uncovered Spondylus Imagery from Chan Chan, Peru». Latin American Antiquity 7(4): 313: 340.

PILLSBURY, Joanne y Banks L. LEONARD

2004 «Identifying Chimu Palaces: Elite Residential Architecture in the Late Intermediate Period». En: S.T. Evans y J. Pillsbury (eds.) Palaces of the Ancient New World. Pp. 247-298. Washington, DC: Dumbarton Oaks Research Library and Collection.

PIMINCHUMO, Victor y Cesar GALVEZ

2003 «La Muralla de la Cumbre. Morfología y Función de una estructura monumental Chimu en el valle de Moche». Revista SIAN 14: 18-25.

POZORSKI, Shelia

1982 «Subsistence Systems in the Chimu State». En: M. Moseley y K.C. Day (eds.) Chan Chan, Andean Desert City. Pp. 177-196. A School of American Research Book. Albuquerque: University of New Mexico Press.

POZORSKI, Thomas

1980 «Las Avispas: Plataforma Funeraria». En: R. Ravines (ed.) Chan Chan, Metropoli Chimu. Pp. 231-242. Lima: IEP.

PRIETO, Gabriel

2011 «Chicha Production during the Chimu Period at San Jose de Moro, Jequetepeque valley, North Coast of Peru». En: C.M. Zori e I. Johnson (eds.) From State to Empire in the Prehistoric Jequetepeque Valley, Peru. Pp. 105-128. British Archaeological Reports (BAR) International Series 2310, Oxford.

2010a «Characterizing ritual activities in an early fishing village of the Peruvian North Coast». Paper presented to the 29th Northeast Conference on Andean Archaeology and Ethnohistory. Drew University, Madison, NJ. Saturday, October 23th, 2010.

2010 b «proximaciones a la configuración política Lambayeque: una perspectiva desde el sitio de San José de Moro, valle de Jequetepeque». En: R.E. Cutright, E. López-Hurtado y A. J. Martin (eds.) Perspectivas Comparativas sobre la Arqueología de la Costa Sudamericana/Comparative Perspectivas on the Archaeology of Coastal South America. Pp. 232-246. University of Pittsburgh Press, Pontificia Universidad Católica del Perú y Ministerio de Cultura del Ecuador.

2008 «Cerámica Utilitaria Chimu de San José de Moro: Tipología de Formas y Modelos Interpretativos». Revista del Museo de Arqueología, Antropología e Historia 10: 111-154. Universidad Nacional de Trujillo, Facultad de Ciencias Sociales.

PRIETO, Gabriel y Víctor CAMPAÑA

2013 Proyecto de Evaluación Arqueológico con Excavaciones «Las Lomas de Huanchaco». Informe de Excavaciones. Informe Técnico presentado al Ministerio de Cultura del Perú. Huanchaco, Trujillo, Perú.

PRIETO, Gabriel, Nicolás GOEPFERT Y Katya VALLADARES

2012 «Rituales y Sacrificios al Mar en la Cultura Chimu». Ponencia presentada en la Primera Conferencia Intercontinental de la Society for American Archaeology SAA. Del 13 al 15 de Enero 2012, Ciudad de Panamá, Panama.

RAVINES, Rogger

1980 Chan Chan, Metropoli Chimu. Lima: IEP.

ROSCOE, Paul

2008 «Catastrophe and the Emergence of Political Complexity: A Social Anthropological Model». En: D. Sandweiss y J. Quilter (eds.) El Niño, catastrophism and culture change in ancient America. Pp. 77-100. Washington, DC: Dumbarton Oaks. 
1946 «Inca Culture at the Time of Spanish Conquest». En: J. Steward (ed.) Handbook of South American Indians, Vol II. Pp. 183-330. Bulletin 143, U.S. Washington, DC: Government Printing Office.

SAKAI, Masato

1998 Reyes, estrellas y cerros en Chimor: El proceso de cambio de la organización espacial y temporal en Chan Chan. Lima: Editorial Horizonte.

SHIMADA, Izumi

1995 Cultura Sican. Dios, riqueza y poder en la costa norte del Peru. Lima: Fundacion del Banco Continental para el foment de la educacion y la cultura (EDUBANCO).

SHIMADA, Izumi, Ken-ichi SHINODA, Julie FARNUM, Robert Corruccini y Hirokatsu WATANABE

2004 «An Integrated Analysis of Pre-Hispanic Mortuary Practices. A Middle Sican Case Study». Current Anthropology 45(3): 369-402.

STRONG, Duncan y Clifford EVANS

1956 Cultural Stratigraphy in the Viru Valley, Northern Peru. The Formative and Florescent Epochs. New York: Columbia University Press.

SUTTER, Richard y Rosa J. CORTEZ

2005 «The Nature of Moche Human Sacrifice. A Bio-Archaeological Perspective». Current Anthropology 46(4): 521-549.

SUTTER, Richard y John VERANO

2007 «Biodistance analysis of the Moche sacrificial victims from Huaca de la Luna plaza 3C: Matrix method test of their origins». American Journal of Ph ysical Anthropology 132(2): 193-206.

SWENSON, Edward

2011 «Architectural Renovation as Ritual Process in Late Intermediate Period Jequetepeque». En: C.M. Zori e I. Johnson (eds.) From State to Empire in the Prehistoric Jequetepeque Valley, Peru. Pp. 127-146. British Archaeological Reports (BAR) International Series 2310, Oxford.

2004 Ritual and Power in the Hinterland: Religious Pluralism and Political Descentralization in Late Moche Jequetepeque, Peru. Unpublished Doctoral Dissertation, Division of Social Sciences, University of Chicago, Chicago.

TOPIC, John

1990 «Craft Production in the Kingdom of Chimor». En: M. Moseley y A. Cordy-Collins (eds.) The Northern Dynasties: Kingship and Statecraft in Chimor. Pp.145-176. Washington DC: Dumbarton Oaks.

1982 «Lower-Class Social and Economic Organization at Chan Chan». En: E. Moseley y K. Day (eds.) Chan Chan Andean Desert City. Michael. Pp. 145-175. A School of American Research Book. Albuquerque: University of New Mexico Press.

TOPIC, Theresa y John TOPIC

1980 «Agricultura en Chan Chan». En: R. Ravines (ed.) Chan Chan, Metropoli Chimu. Pp. 194-208. Lima: IEP.

TOYNE, Marla

2011 «Interpretations of Pre-Hispanic Ritual Violence at Tucume, Peru, from Cut Mark Analysis». Latin American Antiquity 22(4): 505-523.

2008 Offering their hearts and their heads: a bioarchaeological analysis of ancient human sacrifice on the northern coast of Peru. Unpublished dissertation submitted to the Department of Anthropology, Tulane University.

TUFINIO, Moisés

2008 «Frontis Norte, Huaca de la Luna: ofrenda Chimu». En: S. Uceda y R. Morales (eds.) Proyecto Arqueológico Huaca de la Luna. Informe Técnico 2007. Pp. 13-19. Facultad de Ciencias Sociales, Universidad Nacional de Trujillo.

2006 «Excavaciones en el Frontis Norte y Plaza 1 de Huaca de la Luna». En: S. Uceda y R. Morales (eds.) Proyecto Arqueológico Huaca de la Luna. Informe Técnico 2005. Pp. 41-77. Facultad de Ciencias Sociales, Universidad Nacional de Trujillo. 
TUFINIO, Moisés, Carol ROJAS, Ronny VEGA y Liz RAMIREZ

2011 «Excavaciones en la Plataforma III de Huaca de la Luna». En: S. Uceda y R. Morales (eds.) Proyecto Arqueologico Huaca de la Luna. Informe Técnico 2010. Pp. 163-175. Facultad de Ciencias Sociales, Universidad Nacional de Trujillo.

UCEDA, Santiago

2010 «Relationships between the temple and urban nucleus and political change at the Huacas de Moche». En: J. Quilter y L.J. Castillo (eds.) New Perspectives on Moche Political Organization. Pp. 132-158. Washington DC: Dumbarton Oaks.

1997 Esculturas en Miniatura y una maqueta de madera. En: S. Uceda, E. Mujica y R. Morales (eds.) Investigaciones en la Huaca de la Luna 1995. Pp. 151-176. Facultad de Ciencias Sociales de la Universidad Nacional de Arqueología. Trujillo.

UCEDA CASTILLO, Santiago y Moisés TUFINIO

2003 «El Complejo arquitectónico religioso Moche de Huaca de la Luna: una aproximación a su dinámica ocupacional». En: S. Uceda y E. Mujica (eds.) Moche: hacia el final del Milenio. Actas del Segundo Coloquio Sobre la Cultura Moche (Trujillo 1 al 7 de agosto de 1999). T.II. Pp. 179-228. Lima, Universidad Nacional de Trujillo y PUCP.

VERANO, John W.

2008 «Trophy Head-Taking and Human Sacrifice in Andean South America». En: H. Silverman y W. Isbell. Handbook of South American Archaeology. Pp. 1045-1058. Springer.

2007 «Conflict and Conquest in Pre-Hispanic Andean South America. Archaeological Evidence form Northern Coastal Peru». En: R.J. Chacon y R.G. Mendoza (eds.) Latin American Indigenous Warfare and Ritual Violence. Pp. 105-115. The University of Tucson Arizona Press.

2001 «War and Death in the Moche World: Osteological Evidence and Visual Discourse». En: J. Pillsbury (ed.) Moche Art and Archaeology in Ancient Peru. . Pp. 111-125. Studies in the History of Art 63. Center for Advanced Studies in the Visual Arts, Symposium Papers XL. National Gallery of Art, Washington, D.C.

1986 «A mass burial of mutilated individuals at Pacatnamu». En: C. Donnan y G. Cock (eds.) The Pacatnamu Papers, Volumen I. Pp. 117-138. Los Angeles: UCLA, Fowler Museum of Cultural History.

VERANO, John W. and J. Marla Toyne

2011 «Estudio bioantropológico de los restos humanos del Sector II, Punta Lobos, valle de Huarmey». Arqueología de la Costa de Ancash. ANDES 8: Boletín del Centro de Estudios Precolombinos de la Universidad de Varsovia, edited by M. Giersz, pp. 421-446. l'Institut français d'études andines, Varsovia, Poland; Lima Peru.

VOGEL, Melissa

2012 Frontier Life in Ancient Peru. The Archaeology of Cerro La Cruz. University Press of Florida.

2011 «Style and interregional interaction: ceramics from the Casma capital of El Purgatorio». Nawpa Pacha 31 (2): 201-224

WESTER, Carlos

2010 Chotuna-Chornancap. «Templos, Rituales y Ancestros Lambayeque». Lima: Editorial Super Grafica E.I.R.L.

WHEELER, Jane

1982 «Aging Llamas and Alpacas by their Teeth». En: Llama World 1(2): 12-17.

WILSON, David

1988 Prehispanic Settlement Patterns in the Lower Santa Valley, Peru. A regional perspective on the origins and development of complex north coast of society. Smithsonian Institution Press. Washington, D.C., London.

ZORI, Collen e Ilana JOHNSON

2011 From State to Empire in the Prehistoric Jequetepeque Valley, Peru. British Archaeological Reports (BAR) International Series 2310, Oxford. 